\title{
Exploring the fear-avoidance model after brain injury
}

Citation for published version (APA):

Wijenberg, M. L. M. (2021). Exploring the fear-avoidance model after brain injury. [Doctoral Thesis, Maastricht University]. Ridderprint. https://doi.org/10.26481/dis.20210705mw

Document status and date:

Published: 01/01/2021

DOI:

10.26481/dis.20210705mw

Document Version:

Publisher's PDF, also known as Version of record

\section{Please check the document version of this publication:}

- A submitted manuscript is the version of the article upon submission and before peer-review. There can be important differences between the submitted version and the official published version of record.

People interested in the research are advised to contact the author for the final version of the publication, or visit the DOI to the publisher's website.

- The final author version and the galley proof are versions of the publication after peer review.

- The final published version features the final layout of the paper including the volume, issue and page numbers.

Link to publication

\footnotetext{
General rights rights.

- You may freely distribute the URL identifying the publication in the public portal. please follow below link for the End User Agreement:

www.umlib.nl/taverne-license

Take down policy

If you believe that this document breaches copyright please contact us at:

repository@maastrichtuniversity.nl

providing details and we will investigate your claim.
}

Copyright and moral rights for the publications made accessible in the public portal are retained by the authors and/or other copyright owners and it is a condition of accessing publications that users recognise and abide by the legal requirements associated with these

- Users may download and print one copy of any publication from the public portal for the purpose of private study or research.

- You may not further distribute the material or use it for any profit-making activity or commercial gain

If the publication is distributed under the terms of Article $25 \mathrm{fa}$ of the Dutch Copyright Act, indicated by the "Taverne" license above, 


\section{Exploring the fear-avoidance model after brain injury}

Melloney Leonarda Maria Wijenberg 
Cover Inspired by a participant with mild traumatic brain injury

Original picture retrieved from: pixabay.com, no. 2696947

Printing Ridderprint | www.ridderprint.nl

This thesis is printed on recycled paper

ISBN

$978-94-6423-316-2$

(C) 2021 Melloney L.M. Wijenberg, Maastricht

All rights reserved. No part of this publication may be reproduced or transmitted in any form or by any means, without written permission from the author or, when applicable, by the publisher from the published articles. The copyright of the published articles has been transferred to the respective journals.

Printing of this thesis was kindly supported by Maastricht University. 


\title{
Exploring the fear-avoidance model after brain injury
}

\author{
PROEFSCHRIFT \\ ter verkrijging van de graad van doctor aan de Universiteit Maastricht, \\ op gezag van de Rector Magnificus, Prof.dr. Rianne M. Letschert, \\ volgens het besluit van het College van Decanen, \\ in het openbaar te verdedigen \\ op maandag 5 juli 2021 om 13.00 uur \\ door \\ Melloney Leonarda Maria Wijenberg \\ Geboren op 25 augustus 1992 te Maastricht
}




\section{Promotores}

Prof. dr. C.M. van Heugten

Prof. dr. J.A. Verbunt

\section{Copromotor}

Dr. S.Z. Stapert

\section{Beoordelingscommissie}

Prof. dr. M. Peeters (voorzitter)

Prof. dr. C. van Bennekom (Heliomare; Amsterdam Universitair Medische Centra)

Prof. dr. M. Rijkeboer

Prof. dr. J. Spikman (Universitair Medisch Centrum Groningen)

The research described in this thesis was performed at the department of Neuropsychology and Psychopharmacology, Faculty of Psychology and Neuroscience, Maastricht University and as part of the Limburg Brain Injury Center (Expertisecentrum Hersenletsel Limburg). 


\section{Table of contents}

Chapter 1 General Introduction 7

Chapter 2 Explaining fatigue in multiple sclerosis: cross- 23

validation of a biopsychosocial model

Published in Journal of Behavioral Medicine

Chapter 3 Psychological factors after stroke: Are they stable

over time?

Published in Journal of Rehabilitation Medicine

Chapter 4 Does the fear-avoidance model explain persistent

61 symptoms after traumatic brain injury?

Published in Brain Injury

Chapter 5 Psychometric properties of the Post-Concussion

Catastrophizing Scale (PCS-CS) and the Fear of

Mental Activity Scale (FMA)

Submitted

Chapter 6 Do fear and catastrophizing about mental activities relate to fear-avoidance behavior in a community sample? An experimental study.

Published in Journal of Clinical and Experimental

Neuropsychology

Chapter 7 Relevance of the fear-avoidance model for chronic

disability after traumatic brain injury.

Published in Journal of Neurotrauma

Chapter 8 General Discussion

Chapter 9 Scientific and Societal Impact

Addendum Summary

Samenvatting

Vragenlijsten PCS-CS en FMA

Curriculum Vitae

List of publications

Dankwoord 



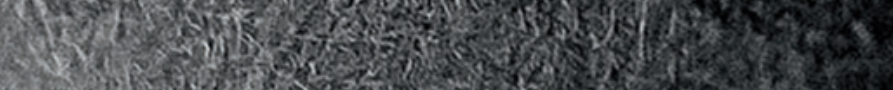

8. Chapter 1

General Introduction

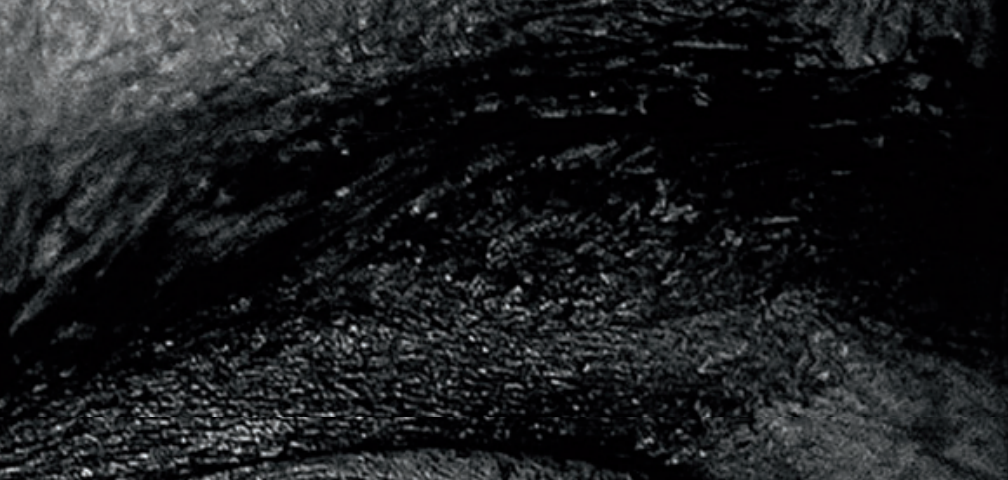

(25)

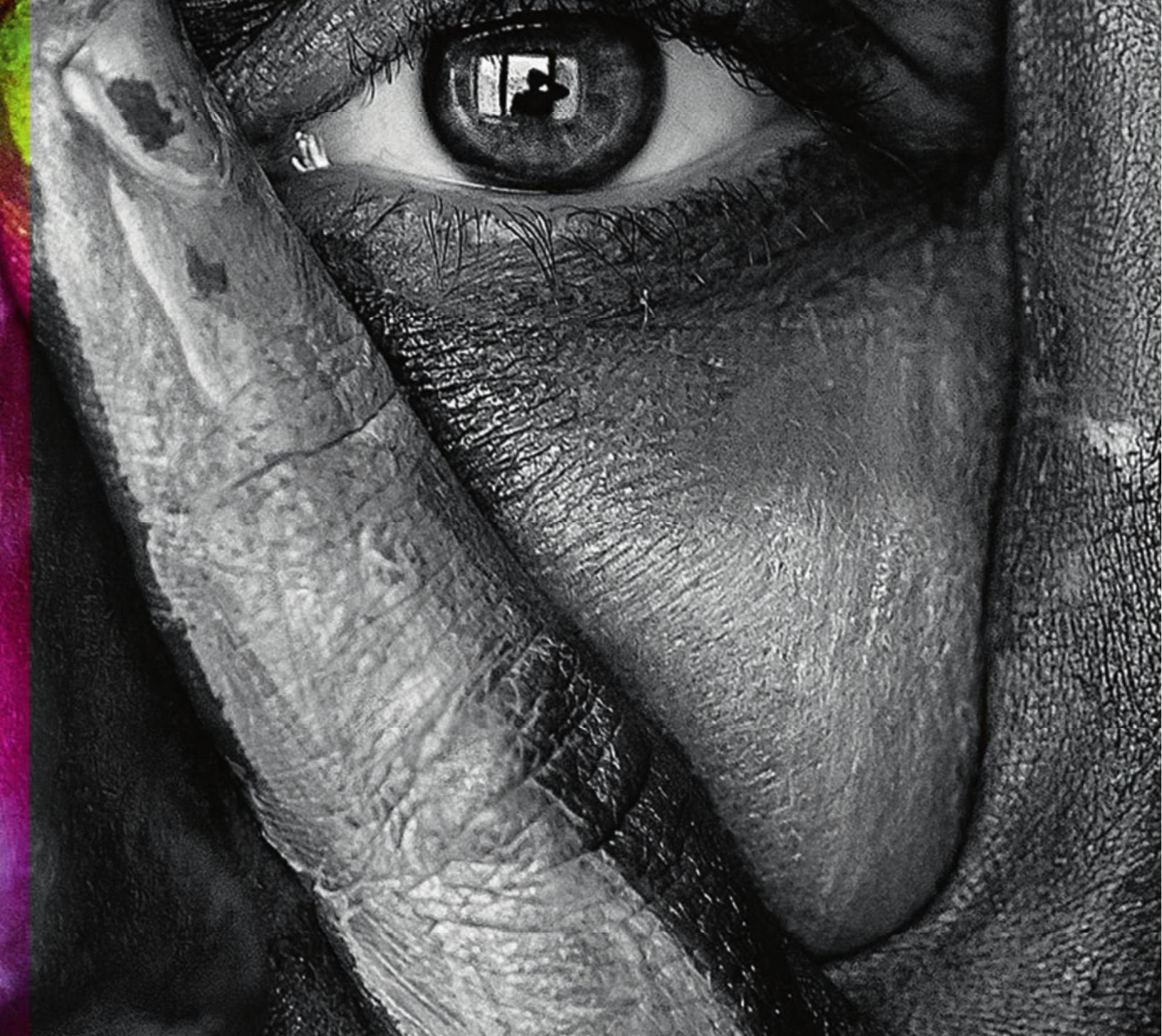




\section{Case}

A 35-year-old male, John, works as an accountant for an international firm and cycles to work every day. Six months ago, he fell on his way to work due to a slippery road. He hit his head on the curve, resulting in loss of consciousness for 10 minutes. Afterwards, he felt dizzy, had a headache and threw up. The emergency physician diagnosed a mild traumatic brain injury (Glasgow Coma Scale of 14, loss of consciousness 10 minutes, no CT abnormalities and post-traumatic amnesia (PTA) of 1 hour). Within a few hours, he was discharged from the hospital with an information pamphlet on 'concussion'. The physician stated that he should take it easy and mentioned that full recovery usually takes place within weeks. From the start, John was eager to recover as fast as possible and rested when experiencing symptoms, convinced that these symptoms were the result of his damaged brain and he would relieve his brain by resting. He gradually resumed work after one month and noticed it was difficult to help his wife with their two young children of three and five years old after a working day. He tried to cope by minimizing social activities and focusing on work and their family, but he kept experiencing the differences of his abilities compared with before the injury. Nowadays, John still experiences symptoms such as concentration problems, fatigue, headaches, and increased sensitivity for noise. He works half of his contract hours and uses the remaining time to recover and attend to his wife and children to the best of his abilities. John feels helpless: worried that he will never recover from his damaged brain and regain his pre-injury abilities. His general practitioner referred him to the neurologist for advice.

\section{Persistent symptoms after mild traumatic brain injury}

Traumatic brain injury (TBI) poses a major global health issue with a high prevalence, annual worldwide incidence of 295 per 100,000 and subsequent high societal costs. ${ }^{1}$ TBI severity (varying between mild, moderate, and severe) depends on the duration of post-traumatic amnesia (PTA), loss of consciousness, or Glasgow Coma Scale (GCS) score. ${ }^{2,3}$ The majority of TBI cases, approximately $80 \%$, is considered to be mild (mTBI), similar to John (see section 'Case'). ${ }^{4} \mathrm{mTBI}$ is defined as a TBI with GCS score 13-15, loss of consciousness of 30 minutes or less, post-traumatic amnesia of 24 hours or less, and/or other transient neurological signs. ${ }^{5,6}$ The vast majority of patients with mTBI show rapid recovery within days to months. ${ }^{3}$ Although full recovery is expected, some patients show a suboptimal recovery pattern and report persistent symptoms (e.g., physical, cognitive, 
emotional, and/or behavioral symptoms such as fatigue, headaches, and memory problems).

In the last three decades, various developments gave rise to an increase in well-designed studies regarding the recovery pattern after mTBI. These developments include, but are not limited to, development of in vivo imaging techniques ${ }^{7,8}$, advanced monitoring techniques for pathophysiological changes ${ }^{9}$, and increased awareness and research funding for persistent symptoms after $\mathrm{mTBI}^{10}$. Given the high impact for the individual and their surroundings, the high prevalence within chronic care settings and societal costs associated with suboptimal recovery, persistent symptoms after mTBI in civilian populations is the focus of many researchers.

Based on group studies in civilian populations, recovery after mTBI is typically characterized by absence of consequences or disabling symptoms at three months post-injury. ${ }^{2}$ However, a minority of the patients, approximately $20 \%$, report persistent symptoms beyond three months post-injury. The exact size of this minority remains inconclusive as various percentages across several studies are reported due to methodological differences and inconsistencies regarding its definition, study design, and/or timing of measurement. ${ }^{11-13}$ Nevertheless, because of the high incidence of TBI, the number of patients with persisting disabling symptoms is high. As presented in the case of John, these patients experience long-term consequences of their mTBI that interfere with their daily functioning, also known as persistent post-concussion symptoms (PCS). This patient group has been long known to physicians, with varying references to their symptom complex (e.g., 'traumatic neurosis', '(persistent) postconcussive syndrome', 'postconcussion syndrome' or 'postconcussional disorder'), going back at least to $1889 .{ }^{14,15}$ Nowadays, PCS is included in the DSM-V ${ }^{16}$, the International Classification of Diseases (ICD)-10 17 , and ICD-11 ${ }^{18}$. Unfortunately, studies searching for the explanation for PCS remain inconclusive. ${ }^{19,20}$

\section{The search for an explanation of persistent post-concussion symptoms (PCS)}

Quite clearly, despite a first understanding of mTBI as benign and transient in nature ${ }^{21}, \mathrm{mTBl}$ is not always a mild experience on an individual level. Despite the large efforts and advancing techniques to date, neuroimaging methods still lack 
the individual patient-level sensitivity and specificity to serve as a diagnostic tool for outcome after $\mathrm{mTBI}^{7}$, and - possibly unintentionally - stimulate the search for a biomedical cause by each introduction of a new neuroimaging tool. Furthermore, neuropsychological measures do not correlate well with subjective symptom experience (e.g., memory or concentration problems) and based on several metaanalyses, cognitive performance is normalized at three months post-injury on a group level. ${ }^{14,22}$ Already in 1995, Alexander ${ }^{23}$ concluded that biomedical measures fail to predict suboptimal recovery and introduced psychological factors as important additional predictors.

Since then, diathesis-stressor models are proposed to combine both 'physiogenic' and 'psychogenic' factors for the development of PCS. ${ }^{3}$ They typically centralize the idea proposed by Lishman ${ }^{24}$ that early physiogenic (i.e., biomedical) mechanisms (such as neurological symptoms or neurocognitive functions) may be responsible for early PCS symptoms, but vicious cycles of nonorganic, psychological mechanisms may be responsible for persistence over time. ${ }^{3}$ For example, King ${ }^{14}$ proposed psychological processes within the patient such as 'early worries about symptom longevity' and 'experienced dissonance between mild injury severity and severity of symptoms'.

Silverberg and Iverson ${ }^{25}$ updated this diathesis-stressor approach in the light of the accumulating evidence that psychological factors play an important etiological role from the onset, not only in the chronic phase. Psychological factors, such as mental health status or anxiety, present before the injury, are found to be among the strongest predictors of the severity and course of PCS. ${ }^{21,26}$ More recently, Silverberg et al. ${ }^{20}$ conclude that a biopsychosocial model shows the best fit with the data and improve explanation of the development and maintenance of PCS. That is, the combination of biomedical and psychosocial factors, possibly with individual differences in their relative contributions ${ }^{27}$, can contribute to PCS throughout its course.

Especially the role of anxiety and maladaptive thoughts about these symptoms seem important psychological predictors for PCS. ${ }^{3}$ 20, 26 Many inconsistencies regarding predictors can be found in the literature, but Silverberg and Iverson ${ }^{25}$ highlighted a potential confounder in group studies. They stated that group studies aggregated data from patients with two drastically different 
recovery curves; (1) a small subgroup with increasing anxiety and persistent symptoms; and (2) a larger subgroup with decreasing anxiety and timely recovery. This would centralize the role of anxiety in understanding recovery. Furthermore, Whittaker et al. ${ }^{28}$ showed in a longitudinal study that individuals, who initially viewed their injury as 'having serious and persisting negative consequences' soon after injury, have more symptoms at three months, potentially resulting in 'selfsustaining dysfunctional loops'27. In these loops, maladaptive thoughts about symptoms lead to symptoms resulting in more maladaptive thoughts and further maintaining or intensifying symptom experience. A biopsychosocial model centralizing the role of anxiety and explaining PCS as a self-sustaining dysfunctional loop is the fear-avoidance (FA) model.

\section{A potential new explanation: introducing the FA model into neuropsychology}

The FA model is originally developed in 1995 to explain chronic musculoskeletal pain. In the last decades, it has been useful in patients who experience longstanding symptoms and it explains disability in chronic pain, tinnitus, chronic fatigue, whiplash syndrome, cancer survivors and fibromyalgia. ${ }^{29-34}$ The generic nonspecific biopsychosocial FA model suggests that it is not only the severity of the injury itself, but a combination with a psychosocial disease process over time. This process consists of extended catastrophical thinking about the initial symptoms and fear-avoidance behavior, initiated by a biomedical injury, which will explain the level of disability and persistence of symptoms.

Applying this model to PCS in mTBI, specifically to John (see section 'Case'), would indicate that he erroneously interpreted his symptoms as a sign of brain pathology over which one has little or no control (e.g., "convinced that these symptoms were the result of his damaged brain"). Such catastrophizing thoughts could extend to fear of mental activities, introduced as 'cogniphobia'23,24 (similar to 'kinesiophobia' or fear of physical activity in chronic pain), and subsequently decrease activity levels and may result in progressive disuse, symptoms of depression, and disability. In the case of John, his maladaptive thoughts resulted in resting when experiencing symptoms, not returning to work the entire first month and his thoughts were reinforced by symptom exaggeration when resuming work activities. Furthermore, minimizing social activities and feelings of 
failing to resume to pre-injury roles as employee and husband resulted in symptoms of depression (e.g. 'feeling hopeless') and disability (e.g. 'working half his contract hours, no social activities'). This could then increase the amount and magnitude of PCS concluding its cyclic pattern. ${ }^{35,36}$ This PCS-related FA model is depicted in Figure 1. Although a biopsychosocial approach is suggested by various studies $^{20,37-39}$, including a systematic review ${ }^{20}$, the applicability of the FA model in mTBI has not been studied before. Besides enriching our current understanding of recovery after mTBI, a first exploration of the FA model in mTBI will potentially clarify a disease process over time and potentially reveal treatment targets for delayed recovery after mTBI.

Figure 1. The FA model applied to mTBl.

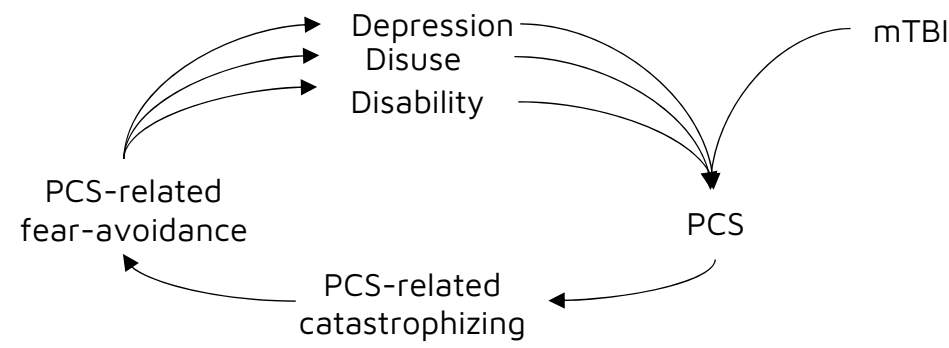

Notes. $\mathrm{mTBI}=$ Mild Traumatic Brain Injury, PCS = persistent post-concussion symptoms.

\section{Exploring the FA model in neuropsychology}

One of the first explorations of the FA model in a neurological disease was performed by Bol et al. ${ }^{40}$. To apply the FA model to neurological conditions, adaptations to the original pain-related FA model were needed. Firstly, to explain symptoms experienced by patients with brain injury, such as fatigue, headaches or cognitive symptoms, the symptom 'chronic pain' should be changed to these neuropsychological symptoms. Bol et al. ${ }^{40}$ proposed the fatigue equivalent of the original FA model to understand the multifactorial pathogenesis of fatigue in 262 patients with multiple sclerosis (MS). Although the results were promising, crossvalidation in another dataset remained necessary to proof the model by 
replication and make a valid generalization and application to everyday clinical practice possible.

Before exploring the potential of a biopsychosocial model to explain the disease process over time in $\mathrm{mTBI}$, it is important to attend to the role of psychosocial variables specifically. Previous studies revealed that psychosocial variables (e.g., coping and personality characteristics) are relevant to understand persistent symptoms after TBI. ${ }^{38,41}$ Investigating their temporal stability (i.e., if psychosocial variables remain stable during a disease process with a biomedical onset) would be an important next step. Results from such studies can be used to gain knowledge about whether these factors should be taken into account when trying to explain PCS and if they can be influenced in such way that outcome can be altered. Similar to mTBI, previous studies reveal the importance of incorporating psychosocial variables when explaining neuropsychological disabling symptoms in stroke. ${ }^{42-44}$ Although large longitudinal studies examining various psychological characteristics over time in neurological conditions are scarce, a large longitudinal cohort study, known as the Restore4Stroke Cohort study ${ }^{45}$, has been conducted in patients with stroke. This study enables exploration of the temporal stability of psychological characteristics in the first two years poststroke.

Next to temporal stability of psychological characteristics, development and validation of proper measures to assess PCS-related catastrophizing and fearavoidance thoughts are needed to explore the FA model in mTBI. This was also one of the first steps in the development of the FA model in chronic pain. ${ }^{46}$ Besides the adaptation to measure PCS instead of chronic pain, another adaptation is needed. Instead of explaining symptoms by a mechanism fueled by fear of movement, also known as kinesiophobia ${ }^{29}$, symptoms may be explained by cogniphobia ${ }^{23,24}$. Due to these two major adaptations, valid and reliable diagnostic instruments need to be constructed to measure PCS-related catastrophizing and fear-avoidance thoughts.

\section{Measures of the PCS-related FA model}

These newly-developed questionnaires can be derived from widely used and validated questionnaires assessing these psychological aspects regarding chronic 
pain ${ }^{47}$. To assess PCS-related catastrophizing and fear-avoidance thoughts, an adaptation of the Pain Catastrophizing Scale ${ }^{48}$ and the Tampa Scale of Kinesiophobia ${ }^{46}$ is needed. Validation and reference data of these two new questionnaires are not yet available. Moreover, based on the original experimental paradigm in chronic pain of Vlaeyen et al. ${ }^{31}$, to establish further validity of the PCS-related fear-avoidance measures, it would be interesting to see if high levels of PCS-related catastrophizing and fear-avoidance thoughts would lead to behavioral avoidance of mental activities.

Important to note is that it is well established in the literature that PCS, similar to pain, are nonspecific ${ }^{25,49}$; they can arise from other conditions, separately or in combination, such as chronic headaches, chronic pain, depression, or post-traumatic stress disorder. ${ }^{25}$ The nature and extent of symptoms reported by individuals with mTBI can be influenced by psychological distress, psychosocial factors (e.g., misattributions such as the good-old-day bias), and personality characteristics (e.g., pre-injury personality traits). ${ }^{20,37-39,50-56}$ Moreover, these symptoms are also common in the general population and in people with medical problems. ${ }^{57-59}$ Similar to studies assessing the original FA model (assessing pain) ${ }^{48}$ 60, 61, validation and experimental studies performed in healthy adults can provide relevant insights into the adapted FA model.

These studies would reveal potential thoughts, attitudes and associated behavior regarding symptoms occurring in everyday situations (e.g., headache, fatigue, or feelings of anxiety) and enable differentiating and quantifying these constructs in patient populations. Furthermore, studies based on experimental psychopathology contribute to the formation of theories explaining disease processes, in this instance the FA model, by introducing a manipulating variable (e.g., cognitively challenging tasks) in order to evoke features of psychopathology (e.g., fear-avoidance behavior) in healthy subjects. ${ }^{62,63}$

\section{The FA model in mTBI}

After the development of reliable and valid measures, the potential of the PCSrelated FA model in mTBI can be explored. As this model is not studied in mild TBI before, patient studies are warranted. To establish its value in explaining a disease process over time, especially persistence of symptoms, studies in the chronic 
phase after mTBI (i.e., at least three months post-injury) are necessary. To reveal if the PCS-related FA model can be applied to all severities (mild, moderate, severe), studies including patients with mTBI and moderate to severe TBI are required.

\section{Aims and outline of this thesis}

The main aim of this thesis is to provide novel insights on persistent symptoms after brain injury by exploring the PCS-related fear-avoidance (FA) model. To achieve this, this thesis addresses the following research questions:

1. Does a biopsychosocial model, the FA model, explain persistent symptoms after MS?

2. Are psychological characteristics after stroke stable over time?

3. Can newly developed measures reliably and validly assess PCS-related catastrophizing and fear-avoidance thoughts?

4. Does the PCS-related FA model explain outcome after mild and moderate to severe $\mathrm{TBI}$ ?

\section{Outline}

- In chapter 2, we investigated the first research question exploring the FA model in patients with MS.

- In chapter 3, we examined the second research question if psychological characteristics remain stable in the first two years post-stroke.

- In chapter 4, relating to our fourth research question, our pilot study of exploring the PCS-related FA model in a cross-sectional sample of patients with TBI is presented.

- In chapter 5, results regarding our third research question are reported, describing psychometric properties of two newly developed questionnaires assessing PCS-related catastrophizing and fear-avoidance thoughts.

- In chapter 6, an experimental study is presented showing the applicability of the PCS-related FA model in a community sample and continues the exploration of our third research question regarding the validity of the newly developed measures. 
- In chapter 7, extending our answer on our fourth research question, a large Australian cohort study is presented revealing the additive value of the PCS-related FA model in understanding outcome after TBI of all severities.

- In chapter 8, a general discussion is provided reviewing the main findings, methodological considerations, and implications for researchers and clinicians. 


\section{References}

1. Nguyen, R., Fiest, K.M., McChesney, J., Kwon, C.-S., Jette, N., Frolkis, A.D., Atta, C., Mah, S., Dhaliwal, H. and Reid, A. (2016). The international incidence of traumatic brain injury: a systematic review and meta-analysis. Canadian journal of neurological sciences. 43, 774-785.

2. Levin, H.S. and Diaz-Arrastia, R.R. (2015). Diagnosis, prognosis, and clinical management of mild traumatic brain injury. The Lancet Neurology. 14, 506-517.

3. Williams, W.H., Potter, S. and Ryland, H. (2010). Mild traumatic brain injury and postconcussion syndrome: a neuropsychological perspective. Journal of Neurology, Neurosurgery \& Psychiatry. 81, 1116-1122.

4. Faul, M., Xu, L., Wald, M., Coronado, V. and Dellinger, A.M. (2010). Traumatic brain injury in the United States: national estimates of prevalence and incidence, 2002-2006. Injury Prevention. 16, A268-A268.

5. Cassidy, J., Carroll, L., Peloso, P., Borg, J., von Holst, H., Holm, L., Kraus, J. and Coronado, V. (2004). WHO Collaborating Centre Task Force on Mild Traumatic Brain, Injury, Incidence, risk factors and prevention of mild traumatic brain injury: results of the WHO Collaborating Centre Task Force on Mild Traumatic Brain Injury. J Rehabil Med. 43, 28-60.

6. Vos, P., Alekseenko, Y., Battistin, L., Ehler, E., Gerstenbrand, F., Muresanu, D., Potapov, A., Stepan, C., Traubner, P. and Vecsei, L. (2012). Mild traumatic brain injury. European journal of neurology. 19, 191-198.

7. Eierud, C., Craddock, R.C., Fletcher, S., Aulakh, M., King-Casas, B., Kuehl, D. and LaConte, S.M. (2014). Neuroimaging after mild traumatic brain injury: review and meta-analysis. Neurolmage: Clinical. 4, 283-294.

8. Niogi, S.N. and Mukherjee, P. (2010). Diffusion tensor imaging of mild traumatic brain injury. The Journal of head trauma rehabilitation. 25, 241-255.

9. Madikians, A. and Giza, C.C. (2006). A clinician's guide to the pathophysiology of traumatic brain injury. Indian Journal of Neurotrauma. 3, 9-17.

10. Parbhoo, P. (2020). Biopsychosocial outcome indicators in traumatic brain injuries.

NeuroRehabilitation, 1-10.

11. Broomhall, L.G., Clark, C.R., McFarlane, A.C., O'Donnell, M., Bryant, R., Creamer, M. and Silove,

D. (2009). Early stage assessment and course of acute stress disorder after mild traumatic brain injury. J Nerv Ment Dis. 197, 178-181.

12. Meares, S., Shores, E.A., Taylor, A.J., Batchelor, J., Bryant, R.A., Baguley, I.J., Chapman, J., Gurka, J. and Marosszeky, J.E. (2011). The prospective course of postconcussion syndrome: the role of mild traumatic brain injury. Neuropsychology. 25, 454.

13. Wood, R.L. (2007). Post concussional syndrome: all in the minds eye! J Neurol Neurosurg Psychiatry. 78, 552.

14. King, N.S. (2003). Post-concussion syndrome: clarity amid the controversy? The British Journal of Psychiatry. 183, 276-278. 
15. Brown, S.J., Fann, J.R. and Grant, I. (1994). Postconcussional disorder: time to acknowledge a common source of neurobehavioral morbidity. Journal of Neuropsychiatry and Clinical Neurosciences. 6, 15-15.

16. American Psychiatric Association (2013). Diagnostic and statistical manual of mental disorders (DSM-5®). American Psychiatric Pub.

17. World Health Organization (1993). The ICD-10 classification of mental and behavioral disorders: diagnostic criteria for research. Vol 2. World Health Organization.

18. World Health Organization (2018). International classification of diseases for mortality and morbidity statistics (11th Revision): retrieved from https://icd.who.int/en/.

19. Ruff, R.M. (2005). Two decades of advances in understanding of mild traumatic brain injury. The Journal of head trauma rehabilitation. 20, 5-18.

20. Silverberg, N.D., Gardner, A.J., Brubacher, J.R., Panenka, W.J., Li, J.J. and Iverson, G.L. (2015). Systematic review of multivariable prognostic models for mild traumatic brain injury. Journal of neurotrauma. 32, 517-526.

21. McCrory, P.R. and Berkovic, S.F. (2001). Concussion: the history of clinical and pathophysiological concepts and misconceptions. Neurology. 57, 2283-2289.

22. Rohling, M.L., Larrabee, G.J. and Millis, S.R. (2012). The "Miserable Minority" following mild traumatic brain injury: Who are they and do meta-analyses hide them? The Clinical Neuropsychologist. 26, 197-213.

23. Alexander, M.P. (1995). Mild traumatic brain injury: pathophysiology, natural history, and clinical management. Neurology.

24. Lishman, W. (1988). Physiogenesis and psychogenesis in the 'post-concussional syndrome'. The British Journal of Psychiatry. 153, 460-469.

25. Silverberg, N.D. and Iverson, G.L. (2011). Etiology of the post-concussion syndrome: physiogenesis and psychogenesis revisited. NeuroRehabilitation. 29, 317-329.

26. Cassidy, J.D., Cancelliere, C., Carroll, L.J., Côté, P., Hincapié, C.A., Holm, L.W., Hartvigsen, J., Donovan, J., Nygren-de Boussard, C. and Kristman, V.L. (2014). Systematic review of self-reported prognosis in adults after mild traumatic brain injury: results of the International Collaboration on Mild Traumatic Brain Injury Prognosis. Archives of Physical Medicine and Rehabilitation. 95, S132S151.

27. Ruff, R.M. (2011). Mild traumatic brain injury and neural recovery: rethinking the debate. NeuroRehabilitation. 28, 167-180.

28. Whittaker, R., Kemp, S. and House, A. (2007). Illness perceptions and outcome in mild head injury: a longitudinal study. Journal of Neurology, Neurosurgery \& Psychiatry. 78, 644-646.

29. Vlaeyen, J.W. and Linton, S.J. (2012). Fear-avoidance model of chronic musculoskeletal pain: 12 years on. Pain. 153, 1144-1147.

30. Cima, R.F., Crombez, G. and Vlaeyen, J.W. (2011). Catastrophizing and fear of tinnitus predict quality of life in patients with chronic tinnitus. Ear and hearing. 32, 634-641.

31. Vlaeyen, J.W., Kole-Snijders, A.M., Boeren, R.G. and Van Eek, H. (1995). Fear of movement/(re) injury in chronic low back pain and its relation to behavioral performance. Pain. 62, 363-372. 
32. Nijs, J., Roussel, N., Van Oosterwijck, J., De Kooning, M., Ickmans, K., Struyf, F., Meeus, M. and Lundberg, M. (2013). Fear of movement and avoidance behavior toward physical activity in chronic-fatigue syndrome and fibromyalgia: state of the art and implications for clinical practice. Clinical Rheumatology. 32, 1121-1129.

33. Nieto, R., Miró, J. and Huguet, A. (2009). The fear-avoidance model in whiplash injuries. European Journal of Pain. 13, 518-523.

34. Velthuis, M.J., Peeters, P.H., Gijsen, B.C., van den Berg, J.-P., Koppejan-Rensenbrink, R.A., Vlaeyen, J.W. and May, A.M. (2012). Role of Fear of Movement in Cancer Survivors Participating in a Rehabilitation Program: A Longitudinal Cohort Study. Archives of Physical Medicine and Rehabilitation. 93, 332-338.

35. Todd, D., Martelli, M. and Grayson, R. (1998). The Cogniphobia Scale (C-Scale): A measure of headache impact. Test in the public domain.

36. Martelli, M., MacMillan, P. and Grayson, R. (1999). Kinesiophobia and cogniphobia: Avoidanceconditioned pain-related disability (ACPRD). Archives of Clinical Neuropsychology. 14, 804-804. 37. Theadom, A., Parag, V., Dowell, T., McPherson, K., Starkey, N., Barker-Collo, S., Jones, K., Ameratunga, S. and Feigin, V.L. (2016). Persistent problems 1 year after mild traumatic brain injury: a longitudinal population study in New Zealand. British Journal of General Practice. 66, e16. 38. Scheenen, M.E., Spikman, J.M., de Koning, M.E., van der Horn, H.J., Roks, G., Hageman, G. and van der Naalt, J. (2017). Patients "at risk" of suffering from persistent complaints after mild traumatic brain injury: The role of coping, mood disorders, and post-traumatic stress. Journal of neurotrauma. 34, 31-37.

39. Wäljas, M., Iverson, G.L., Lange, R.T., Hakulinen, U., Dastidar, P., Huhtala, H., Liimatainen, S., Hartikainen, K. and Öhman, J. (2015). A prospective biopsychosocial study of the persistent postconcussion symptoms following mild traumatic brain injury. Journal of neurotrauma. 32, 534-547. 40. Bol, Y., Duits, A.A., Lousberg, R., Hupperts, R.M., Lacroix, M.H., Verhey, F.R. and Vlaeyen, J.W. (2010). Fatigue and physical disability in patients with multiple sclerosis: a structural equation modeling approach. Journal of behavioral medicine. 33, 355-363.

41. Ponsford, J., Willmott, C., Rothwell, A., Cameron, P., Kelly, A.-M., Nelms, R., Curran, C. and Ng, K. (2000). Factors influencing outcome following mild traumatic brain injury in adults. Journal of the International Neuropsychological Society. 6, 568-579.

42. Darlington, A.-S.E., Dippel, D.W., Ribbers, G.M., van Balen, R., Passchier, J. and Busschbach, J.J. (2007). Coping strategies as determinants of quality of life in stroke patients: a longitudinal study. Cerebrovascular Diseases. 23, 401-407.

43. van Mierlo, M., van Heugten, C., Post, M.W., Hoekstra, T. and Visser-Meily, A. (2018). Trajectories of health-related quality of life after stroke: results from a one-year prospective cohort study. Disability and rehabilitation. 40, 997-1006.

44. van Mierlo, M.L., Schröder, C., van Heugten, C.M., Post, M.W., de Kort, P.L. and Visser-Meily, J.M. (2014). The influence of psychological factors on Health-Related Quality of Life after stroke: a systematic review. International journal of stroke. 9, 341-348. 
45. van Mierlo, M.L., van Heugten, C.M., Post, M.W., Lindeman, E., de Kort, P.L. and Visser-Meily, J.M. (2014). A longitudinal cohort study on quality of life in stroke patients and their partners: Restore4Stroke Cohort. International journal of stroke. 9, 148-154.

46. Kori, S., Miller, R. and Todd, D. (1990). Kinisophobia: a new view of chronic pain behavior. Pain Management, 35-43.

47. Vlaeyen, J.W., Crombez, G. and Linton, S.J. (2016). The fear-avoidance model of pain. Pain. $157,1588-1589$.

48. Sullivan, M.J., Bishop, S.R. and Pivik, J. (1995). The pain catastrophizing scale: development and validation. Psychological assessment. 7, 524.

49. Dean, P.J., O’Neill, D. and Sterr, A. (2012). Post-concussion syndrome: prevalence after mild traumatic brain injury in comparison with a sample without head injury. Brain injury. 26, 14-26. 50. Ponsford, J. (2017). Anxiety and depression following TBI. In: Neurobehavioural disability and social handicap following traumatic brain injury. McMillan, T.M., Wood, R.L. (eds). Routledge: Milton Park, Abingdon, Oxon; New York, NY, pps. 167-177.

51. Ponsford, J., Wong, D., McKay, A., Alway, Y., Haines, K., Lee, N.K., Downing, M. and O'Donnell, M.L. (2016). Depression and anxiety following traumatic brain injury: Can these high prevalence disorders be effectively treated using adapted cognitive behavioral therapy? Innovations and Future Directions in the Behavioural and Cognitive Therapies, 182.

52. Wardlaw, C., Hicks, A.J., Sherer, M. and Ponsford, J.L. (2018). Psychological resilience is associated with participation outcomes following mild to severe traumatic brain injury. Frontiers in neurology. 9.

53. Belanger, H.G., Kretzmer, T., Vanderploeg, R.D. and French, L.M. (2010). Symptom complaints following combat-related traumatic brain injury: relationship to traumatic brain injury severity and posttraumatic stress disorder. Journal of the International Neuropsychological Society. 16, 194-199. 54. Dikmen, S., Machamer, J., Fann, J.R. and Temkin, N.R. (2010). Rates of symptom reporting following traumatic brain injury. Journal of the International Neuropsychological Society. 16, 401411.

55. Ponsford, J., Draper, K. and Schönberger, M. (2008). Functional outcome 10 years after traumatic brain injury: its relationship with demographic, injury severity, and cognitive and emotional status. Journal of the International Neuropsychological Society. 14, 233-242.

56. van der Horn, H.J., Spikman, J.M., Jacobs, B. and van der Naalt, J. (2013). Postconcussive complaints, anxiety, and depression related to vocational outcome in minor to severe traumatic brain injury. Archives of Physical Medicine and Rehabilitation. 94, 867-874.

57. Lee, A.R., Son, S.-M. and Kim, K.K. (2016). Information and communication technology overload and social networking service fatigue: A stress perspective. Computers in Human Behavior. 55, 5161.

58. Aaronson, L.S., Pallikkathayil, L. and Crighton, F. (2003). A qualitative investigation of fatigue among healthy working adults. Western journal of nursing research. 25, 419-433.

59. Wong, J.L., Regennitter, R.P. and Barrios, F. (1994). Base rate and simulated symptoms of mild head injury among normals. Archives of Clinical Neuropsychology. 9, 411-425. 
60. Houben, R.M., Leeuw, M., Vlaeyen, J.W., Goubert, L. and Picavet, H.S.J. (2005). Fear of movement/injury in the general population: factor structure and psychometric properties of an adapted version of the Tampa Scale for Kinesiophobia. Journal of behavioral medicine. 28, 415424.

61. Trost, Z., France, C.R. and Thomas, J.S. (2011). Pain-related fear and avoidance of physical exertion following delayed-onset muscle soreness. Pain. 152, 1540-1547.

62. Jansen, A., Hout, M.v.d. and Merckelbach, H. (2010). Gek : experimentele psychopathologie : over angst, verslaving, depressie en andere ellende. Bohn Stafleu van Loghum: Houten.

63. Forsyth, J.P. and Zvolensky, M.J. (2001). Experimental psychopathology, clinical science, and practice: An irrelevant or indispensable alliance? Applied and Preventive Psychology. 10, 243-264. 



\section{Chapter 2}

\section{Explaining fatigue in multiple sclerosis:}

\section{cross-validation of a biopsychosocial model}

Wijenberg, M.L.M., Stapert, S.Z., Köhler, S., \& Bol, Y. (2016) Journal of Behavioral Medieine, $39(5), 815-822$. doi: $10.1007 /$ s $10865-016-9749-3$.

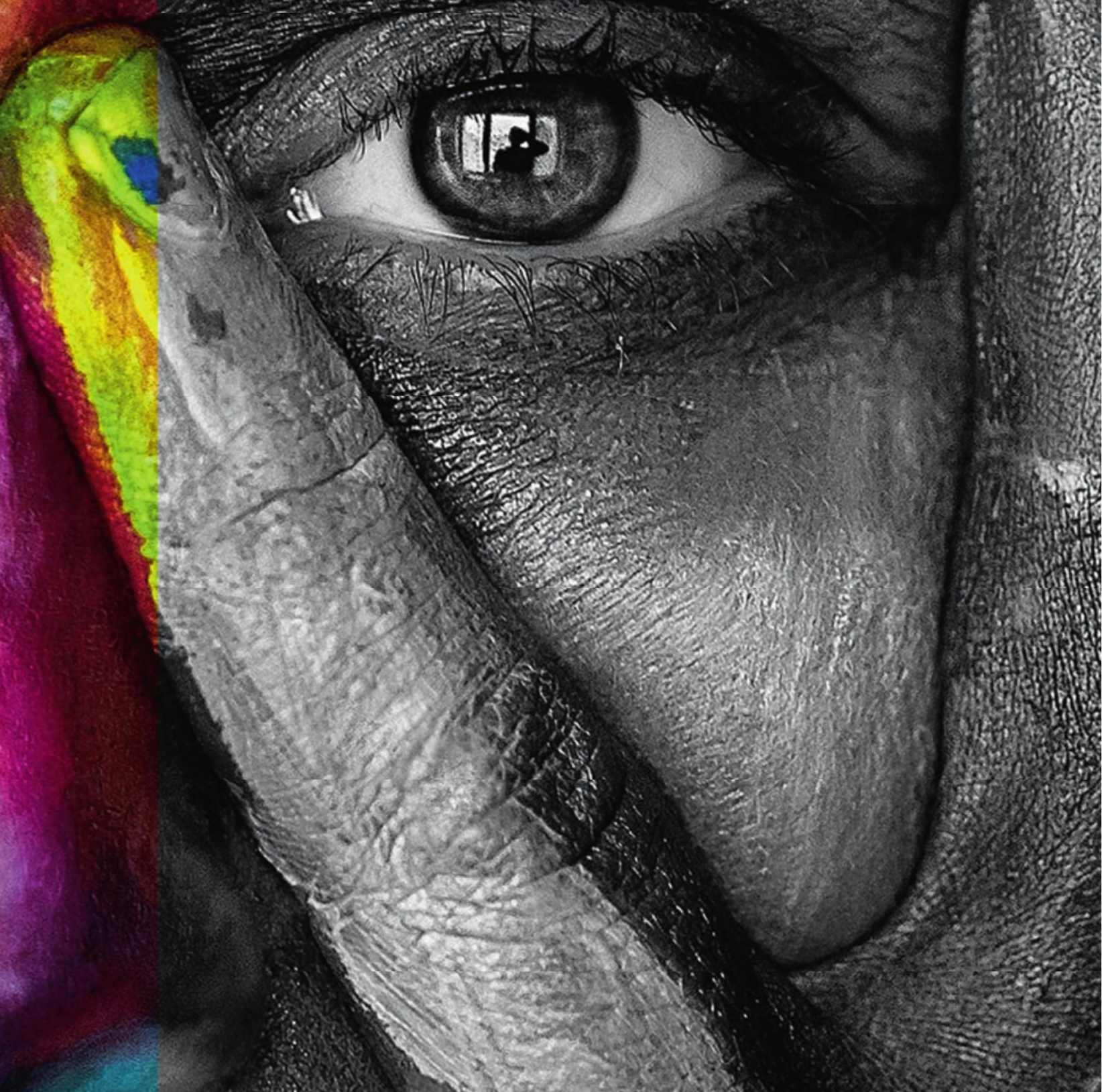




\begin{abstract}
Fatigue is a common and disabling symptom in patients with multiple sclerosis (MS), but its pathogenesis is still poorly understood and consequently evidencebased treatment options are limited. Bol et al. ${ }^{1}$ suggested a new model, which explains fatigue in MS from a biopsychosocial perspective, including cognitivebehavioral factors. For purposes of generalization to clinical practice, crossvalidation of this model in another sample of 218 patients with MS was performed using structural equation modeling. Path analysis indicated a close and adequate global fit (RMSEA = 0.053 and CFI = 0.992). The cross-validated model indicates a significant role for disease severity, depression and a fear-avoidance cycle in explaining MS-related fatigue. Modifiable factors, such as depression and catastrophizing thoughts, propose targets for treatment options. Our findings are in line with recent evidence for the effectiveness of a new generation of cognitive behavioral therapy, including acceptance and mindfulness-based interventions, and provide a theoretical framework for treating fatigue in MS.
\end{abstract}

Keywords: multiple sclerosis, fatigue, catastrophizing, physical disability, structural equation modelling, biopsychosocial model 


\section{Introduction}

Multiple sclerosis (MS) is characterized by a chronic inflammation of the central nervous system, which results in demyelination and atrophy, but has an unknown pathogenesis and an unpredictable course. It is one of the most common neurological disorder in young adults ${ }^{2}$ with a prevalence of 0.9 per $1000^{3}$. Patients with MS report a variety of physical and neuropsychiatric symptoms, with fatigue being the most frequent and disabling symptom reported: $80 \%-92 \%$ of patients with MS report fatigue, and 40\%-69\% rate fatigue as their most disabling symptom. ${ }^{4-6}$ Fatigue is a major reason for decreased societal participation and is also related to disability and poor quality of life.

Unfortunately, the multifactorial pathogenesis of fatigue in MS is not completely understood, and evidence-based treatment options remain scarce. ${ }^{7-10}$ Bol et al. ${ }^{1}$ examined its multifactorial pathogenesis by fitting a biomedical and a cognitive behavioral model in a sample of 262 patients with MS using structural equation modelling (SEM). Results showed that both models poorly explained fatigue in MS, and based on previous research and the results of their SEM analyses, they formulated a new model. This final model was an integration of the first two models, including both biomedical and cognitive-behavioral factors, and can be considered as the fatigue equivalent of the fear-avoidance model of chronic musculoskeletal pain. ${ }^{11,12}$ In this integrated model, catastrophizing about fatigue has a central role: being fueled by depression, it mediated the relationship between fatigue and fatigue related fear and avoidance behavior.'

Catastrophizing about fatigue is defined as a fearful interpretation of the meaning of fatigue by exaggerated negative thinking, magnification of symptoms, and helplessness (e.g. 'fatigue is terrible and I think it can never improve' or 'when I feel tired, there is nothing I can do to decrease its intensity'). ${ }^{13}$ If fatigue is erroneously interpreted as a sign of pathology over which one has little or no control, this could gradually extend to a fear and avoidance of physical activities and subsequently decreased physical abilities. According to the fear-avoidance model, this would then lead to an increase in fatigue concluding its cyclic pattern. Lukkahatai and Saligan ${ }^{13}$ showed in their systematic review a consistent strong positive correlation between catastrophizing and fatigue severity in several clinical 
conditions that share fatigue as one of their core symptoms, such as multiple sclerosis, chronic fatigue syndrome, fibromyalgia and cancer.

Besides the role of catastrophizing and fear-avoidance behavior, previous research has shown a significant association between depression and fatigue in patients with MS, independent of physical disability. ${ }^{14}$ With regard to the direction of influence, a longitudinal study of Patrick et al. ${ }^{15}$, including 2768 patients with MS, showed that depression was one of the most important predictors of fatigue at 1-year follow-up. With regard to disease severity, Hadjimichael et al. ${ }^{16}$ showed a significant positive correlation between disease severity and fatigue in patients with MS, explaining that more physical disability and neurological impairment are associated with higher levels of fatigue.

This biopsychosocial model of Bol et al. ${ }^{1}$ integrates these individual observations in a single model of fatigue in MS, however cross-validation is necessary to make a valid generalization and application to everyday clinical practice possible. In the present study, we hypothesize that the associations between fatigue, depression, catastrophizing and disease severity described by the biopsychosocial model will explain fatigue in another large group of MS patients. This cross-validation is important for the understanding of the origin and perpetuating of fatigue in patients with MS and will provide a theoretical framework for treating fatigue in patients with MS.

\section{Methods}

\section{Participants}

Participants were recruited from hospital databases of the department of Neurology of the Zuyderland Medical Center in Sittard-Geleen, the Netherlands. A total of 621 Dutch-speaking patients with clinically definite MS according to McDonald criteria ${ }^{17}$, aged between 18 and 65 years, were eligible for inclusion. Their treating neurologist sent the initial letters to secure confidentiality. A total of 403 patients were interested in participating and responded (65\% response rate). These patients were sent an information letter, an informed consent and questionnaires. A total of 312 participants returned the forms (77\% response rate). Questionnaires were filled in between May 2011 and September 2011. Participants who previously participated in the study of Bol et al. ${ }^{1}(\mathrm{~N}=86)$ were excluded. 
Informed consent was obtained from all participants included in the study. Patients did not receive any financial compensation for their participation.

\section{Measures}

Basic demographic information. Age, gender, level of education, employment status, marital status and use of psychopharmacological drugs were obtained by a demographic inventory filled in by the patients. The level of education was based on the highest completed level of education and divided into three categories: primary school (low level of education); junior vocational training (middle level of education); senior vocational training or academic training (high level of education). Medical data, such as disease duration, disease course, MS subtype and disease severity were collected from the hospital databases.

Disease severity. Disease severity was assessed with the Expanded Disability Status Scale (EDSS). ${ }^{18}$ This scale comprises the evaluation of 8 functioning systems (pyramidal, cerebellar, brainstem, mental, bowel and bladder, visual-optic, sensory and other). The EDSS score, based on the evaluation of an experienced neurologist, ranges from 0 to 10 , where 0 indicates a normal neurological examination and 10 indicates death due to MS. Recent EDSS scores (<3 months) were extracted from the hospital database.

Physical disability. Physical disability was assessed with the physical dimension of the SF-36, a Dutch translation of the Short Form Health Survey developed and validated by Aaronson et al. ${ }^{19}$. Bol et al. ${ }^{1}$ showed a high reliability of this measure in patients with MS. It consists out of four subscales; physical functioning, role limitations due to physical health problems, bodily pain, and general health. Each standardized subscore of the physical dimension ranges from 0 to 100 , where a total score of 400 resembles optimal physical health and no physical disability.

Fear-avoidance. Fear-avoidance was assessed with the fatigue version of the Tampa Scale for Kinesiophobia $(T S K-F)^{20}$, which is an adjusted version of the TSK for chronic pain. ${ }^{12,21}$ Silver et al. ${ }^{20}$ replaced in all 17 items the word 'pain' by the word 'fatigue' to make the questionnaire suitable for investigation of fatiguerelated fear and avoidance behavior. The score ranges from 17 to 68, where a 
higher score indicates a higher level of fear-avoidance behavior. This instrument is found to be valid ${ }^{20}$ and reliable in patients with MS. ${ }^{1,20}$

Catastrophizing. Catastrophizing about fatigue was assessed with the Fatigue Catastrophizing Scale (FCS), which is an adapted version of the Pain Catastrophizing Scale (PCS). ${ }^{22}$ Psychometric properties of the PCS are adequate. ${ }^{23}$ The PCS consists out of 13 items measuring the self-reported frequency of catastrophizing thoughts about experienced pain. As with the TSK adaptation, Bol et al.' adapted all the PCS items by replacing the word 'pain' by the word 'fatigue'. Scoring alternatives ranged from 'strongly disagree' to 'strongly agree'. As in the study of Bol et al.', three MS-related items were added ('When I am tired, this is a signal there is something wrong in my brain', 'When I am tired, this is a warning for physical decline', 'When I am tired, this is a sign that my MS is getting worse'). In total 16 items were administered and the score ranges from 0 to 64 with higher scores indicating higher intensity of catastrophizing. Bol et al. ${ }^{1}$ showed a high reliability of this measure in patients with MS. In the current sample the reliability was excellent $(\alpha=0.94)$.

Fatigue. Fatigue was assessed with the Abbreviated Fatigue Questionnaire (AFQ), a valid and reliable instrument. ${ }^{24}$ Administration to patients with MS also revealed its reliability. ${ }^{1}$ This questionnaire is a selection of four items of the Checklist Individual Strength (CIS-20) developed by Vercoulen et al. ${ }^{25}$. Items are rated on a 7-point Likert scale with scoring alternatives ranging from 'Yes, that is true' to 'No, that is not true'. The final score ranges from 4 till 28 , with higher scores indicating a higher severity of physical fatigue.

Depression. Depression was assessed with the subscale depression of the Hospital Anxiety and Depression Scale (HADS) ${ }^{26}$, a valid and reliable screening instrument for patients with MS. ${ }^{27}$ The total score ranges from 0 to 21 with a higher score indicating a higher intensity of depression. Honarmand and Feinstein ${ }^{27}$ showed that patients with MS with a score of 8 or higher are likely depressed.

\section{Statistical analyses}

Data analyses were performed using SPSS 22.0.0.0 for Windows (SPSS Inc., Chicago, IL). If less than $25 \%$ of the items of questionnaires, or more than $50 \%$ if a 
questionnaire consisted of four items, were missing, missing values were imputed by the mean of the remaining non-missing items of the scale (27 values across 24 participants). Descriptive statistics were used to describe the sample. No variable was significantly skewed (skewness $<-1$ or $>1$ ) nor were there any significant outliers (all cases were within 1.5 interquartile ranges from the upper or lower quartile). Cronbach's alpha was used to test reliability of all questionnaires. Relations between all variables were analyzed by Pearson-correlations. An alpha level of .05 was used for all statistical tests.

Cross-validation was analyzed with structural equation modeling in Mplus 7. ${ }^{28}$ The biopsychosocial model of Bol et al. ${ }^{1}$ was specified in a path analysis using manifest variables only (no measurement model). Error terms were assumed to be uncorrelated and left free. The Root Mean Square Error of Approximation (RMSEA) was used as a global fit index, because parsimony and sample size are taken into account. RMSEA represents the lack of fit in comparison with a perfect fit and should therefore be low. RMSEA values up to 0.05 indicate a close fit, values between 0.05 and 0.08 indicate an acceptable fit, values between 0.08 and 0.10 indicate a mediocre fit, and those greater than 0.10 indicate a poor fit. Furthermore, the comparative fit index (CFI) was used, because it represents the relative improvement of the model in comparison with a baseline model, usually a model in which all observed variables are uncorrelated. Values larger than 0.95 indicate a good fit and values between 0.90 and 0.95 indicate an acceptable fit. Furthermore, the Chi square test of model fit, Standardized Root Mean Square Residual (SRMR) and Tucker-Lewis Index (TLI) were also reviewed as fit indexes. A non-significant Chi square test of model fit indicates a good fit. SRMR values smaller than 08 indicate an acceptable fit, whereas values smaller than 0.05 indicate a good fit. TLI values higher than .90 are acceptable and values higher than 95 represent a good fit. To control for possible normality assumption violation, a robust maximum likelihood estimator for standard errors, also known as the 'Huber Sandwich Estimator', was used. ${ }^{29}$ Modification indices were inspected to consider further fine-tuning of the model to the data-at-hand in an exploratory fashion. Finally, direct and total effects of the significant variables were calculated. 


\section{Results}

\section{Patient sample}

A total of two participants were excluded due to too many missing values ( $>25 \%$ of items of questionnaires missing). Finally, six participants were excluded due to a missing value in the single exogenous variable, EDSS, which was necessary for proper structural equation modeling (SEM) analysis. This resulted in a final sample of 218 outpatients (53 men, 165 women) with an average age of 48.0 years (SD = 10.5 , range $19-65$ ). Most of them had a relapsing remitting disease course ( $n=$ 153), while 43 patients had a secondary progressive disease course and 21 patients had a primary progressive disease course (1 missing value). The mean disease duration was 8.8 years ( $S D=7.5$, range $0-30$ years) with an average EDSS score of 3.6 ( $S D=1.9$, range 0.5 - 8.0), which resembles a moderate disease severity. Around $24 \%$ of the sample showed high levels of catastrophizing, using the cutoff score of 30 as suggested by Sullivan et al. ${ }^{22}$ for patients with pain. Around $34 \%$ of the sample showed high levels of fear-avoidance, using the cutoff score of 37 as suggested by Vlaeyen et al. ${ }^{12}$ for patients with pain. See Table 1 for a summary of all patient characteristics.

Table 1. Patient characteristics $(n=218)$

\begin{tabular}{lll}
\hline Variable & Value & \\
\hline Gender \% female ( $($ ) & $76(165)$ & \\
Age in years [mean, (SD)] & $48.0(10.5)$ & Range 19.6-65.6 \\
Disease duration in years (mean, (SD)) & $8.8(7.5)$ & Range 0.1-30.2 \\
Disease course & & \\
$\quad$ Relapsing Remitting (\%) & 71 & \\
$\quad$ Secondary Progressive (\%) & 20 & \\
$\quad$ Primary Progressive (\%) & 9 & \\
Use of disease modifying drugs (\% yes, \% no) & $61 / 39$ \\
Use of psychopharmaca (\% yes, \% no) & $25 / 75$ \\
Level of education (\% low, \% middle, \% high) & $24 / 37 / 39$ \\
Marital status (\% partner, \% no partner) & $82 / 28$ \\
Employment status (\% working, \% not working) & $32 / 68$ & \\
\hline
\end{tabular}

\section{Reliability and correlations}

Table 2 resembles means, standard deviations, ranges, reliability indexes (Cronbach's alphas) for all measures and their intercorrelations (Pearson). All questionnaires had a satisfactory internal consistency (range 0.69 - 0.94). All intercorrelations were statistically significant $(\rho<0.01)$ with the strongest correlation between depression and physical disability. Higher levels of depression 
were associated with lower levels of physical ability $(r=-0.58, p<0.001)$. The weakest correlation was found between disease severity and catastrophizing about fatigue $(r=0.21, \rho<0.01)$.

Table 2. Means, standard deviations (SD), ranges, Cronbach's alphas ( $\alpha$ ) and Pearsoncorrelations of all measures

\begin{tabular}{|c|c|c|c|c|c|c|c|c|c|}
\hline & & Mean (SD) & Range & $\alpha$ & 2 & 3 & 4 & 5 & 6 \\
\hline 1. & $\begin{array}{l}\text { Disease severity } \\
\text { (EDSS) }\end{array}$ & $3.6(1.9)$ & $0.5-8$ & - & $.23^{* *}$ & $.21^{*}$ & $.22^{* *}$ & $.29 * *$ & $-.48^{* *}$ \\
\hline 2. & $\begin{array}{l}\text { Fatigue } \\
\text { (AFQ) }\end{array}$ & $19.7(6.8)$ & $4-28$ & 0.90 & - & $.55^{* *}$ & $.34^{* *}$ & $.54^{* *}$ & $-.63^{* *}$ \\
\hline 3. & $\begin{array}{l}\text { Catastrophizing } \\
\text { about fatigue (FCS) }\end{array}$ & $19.9(14.1)$ & $0-56$ & 0.94 & - & - & $.58^{* *}$ & $.57^{* *}$ & $-.55^{* *}$ \\
\hline 4. & $\begin{array}{l}\text { Fatigue-related } \\
\text { fear and avoidance } \\
\text { (TSK-F) }\end{array}$ & $34.3(8.3)$ & $20-68$ & 0.73 & - & - & - & $.41^{* *}$ & $-.42^{* *}$ \\
\hline 5. & $\begin{array}{l}\text { Depression } \\
\text { (HADS-D) }\end{array}$ & $6.0(4.0)$ & $0-17$ & 0.82 & - & - & - & - & $-.58^{* *}$ \\
\hline 6. & $\begin{array}{l}\text { Physical disability } \\
\text { (SF-physical) }\end{array}$ & $208.5(92.1)$ & $25-400$ & 0.69 & - & - & - & - & - \\
\hline
\end{tabular}

Notes. EDSS Expanded Disability Status Scale, AFQ Abbreviated Fatigue Questionnaire, FCS Fatigue Catastrophizing Scale, TSK-F Fatigue Version of the Tampa Scale for Kinesiophobia, HADS-D depression subscale of the Hospital Anxiety and Depression Scale, SF-physica/Physical scale of the Short Form Health Survey. ${ }^{*} p<0.01 ;{ }^{* *} p<0.001$

\section{Structural equation modeling analyses}

Figure 1 shows the results of the path analysis of the new model proposed by Bol et al.'. The RMSEA value was $0.053(90 \% \mathrm{Cl}: 0.000-0.112)$, which indicates an acceptable fit. The SRMR, CFI and TLI value were respectively $0.023,0.992$ and 0.979 , indicating a good fit. The Chi-square test of model fit was non-significant ( $\rho=0.138$ ) also indicating a good fit. Furthermore, all hypothesized relationships were statistically significant. The total explained variance of fatigue measured with the AFQ was $44 \%$. All variables provided a significant contribution to this explained variance. Both depression $(\beta=.27)$ and physical disability $(\beta=-.45)$ were directly associated with fatigue. There were no modification indexes given, suggesting that no alternative specification of relationships between the variables were identified which could improve the model. We added a relationship from disease severity to depression, due to its significance in the second model postulated by Bol et al. ${ }^{1}$, but this worsened the global fit of our model and was subsequently removed. Moreover, we ran an additional post hoc analysis to study the variance in fatigue explained by the fear-avoidance cycle. For this, we omitted the paths to and from depression and disease severity (see Fig. 1) from the model. 
This showed that physical disability, fear-avoidance, catastrophizing and their underlying associations explain $39 \%$ of the variance in fatigue, compared with $44 \%$ of the total model. See Table 3 for an overview of the standardized direct, indirect and total effects on fatigue.

Figure 1. Path analysis of the biopsychosocial model of fatigue in multiple sclerosis $(n=218$ )

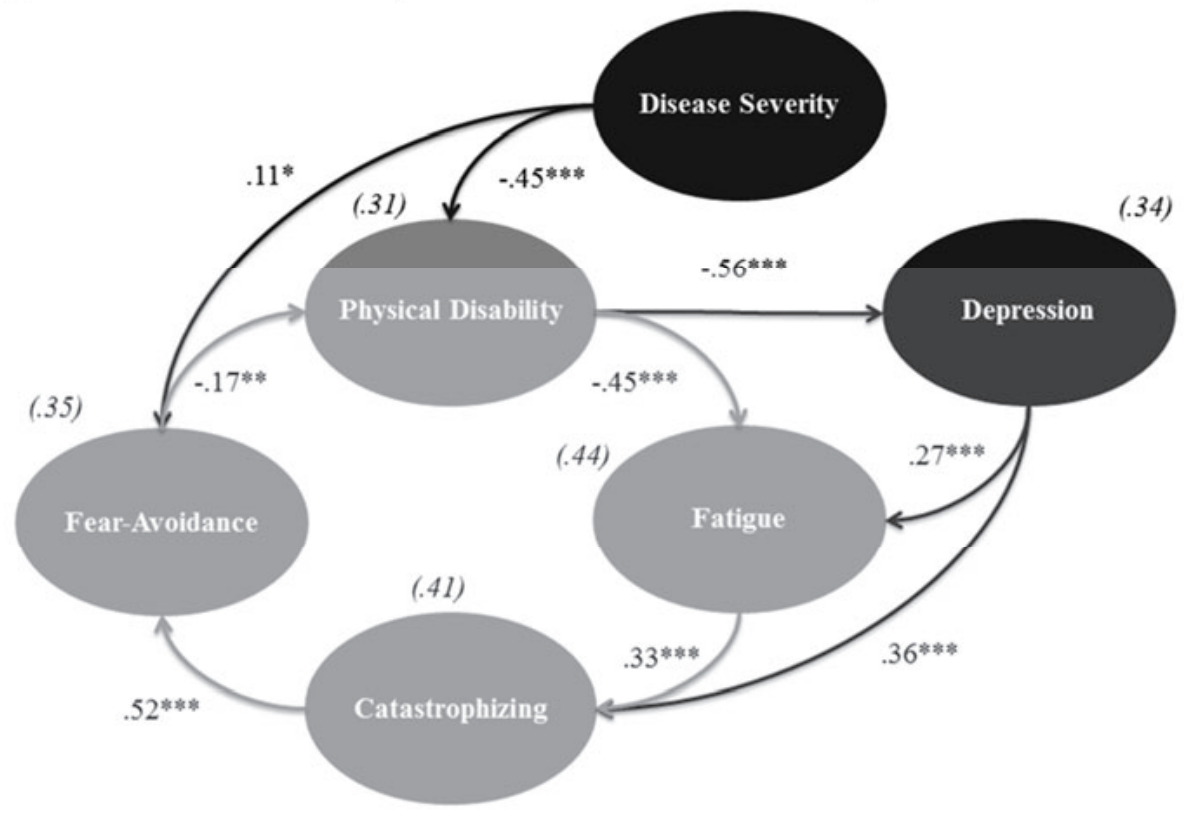

Notes. Values shown are standardized regression coefficients and based on cross-sectional data. Light grey variables and their relationships represent the fear-avoidance cycle within the model. Explained variances are provided in parentheses. Please note that the scale of physical disability is inverted. ${ }^{*} p<0.05 ;{ }^{* *} p<0.01 ;{ }^{* * *} p<0.001$

Table 3. Standardized direct, indirect and total effects on fatigue

\begin{tabular}{llll}
\hline Variable & Direct & Indirect & Total \\
\hline Fear-Avoidance (TSK-F) & 0.000 & $0.103^{* *}$ & $0.103^{* *}$ \\
Physical disability (SF-physical) & $-0.447^{* * *}$ & $-0.173^{* * *}$ & $-0.620^{* * *}$ \\
Depression (HADS-D) & $0.274^{* * *}$ & $0.024^{*}$ & $0.298^{* * *}$ \\
Disease severity (EDSS) & 0.000 & $0.288^{* * *}$ & $0.288^{* * *}$ \\
Catastrophizing (FCS) & 0.000 & $0.054^{*}$ & $0.054^{*}$ \\
\hline
\end{tabular}

Notes. TSK-FFatigue Version of the Tampa Scale for Kinesiophobia, SF-physicalPhysical scale of the Short Form Health Survey, HADS-D depression subscale of the Hospital Anxiety and Depression Scale, EDSS Expanded Disability Status Scale, FCS Fatigue Catastrophizing Scale ${ }^{*} p<0.05 ;{ }^{* *} p<0.01 ;{ }^{* * *} p<0.001$ 


\section{Discussion}

Due to the high prevalence of fatigue in patients with MS and its disabling impact on everyday activities and quality of life, understanding its pathogenesis and identifying its modifiable contributing factors are crucial. Bol et al. ${ }^{1}$ showed that neither a biomedical nor a cognitive-behavioral model explained fatigue in 262 patients with MS, but suggested a new biopsychosocial model integrating elements of the previously tested models, i.e. disease severity, depression and fear-avoidance cycle. To generalize and apply this model to everyday clinical practice, cross-validation of this integrated model in another sample was needed. We hypothesized that the biopsychosocial model of Bol et al. ${ }^{1}$ can explain fatigue in MS in another large sample.

The SEM analyses presented in this study, explaining fatigue in a new sample of 218 patients with MS, showed good support of the biopsychosocial model of Bol et al. ${ }^{1}$. Catastrophizing, depression, physical disability, disease severity and fear-avoidance all contribute significantly to fatigue, either directly or indirectly. Comparing the results to that of the original publication, the global fit indices RMSEA and CFI even slightly improved respectively from 0.085 towards 0.053 and from 0.983 towards 0.992. This implies an increase in fit from mediocre to acceptable (RMSEA) or even good (CFI).

The biopsychosocial model indicates a significant role for disease severity, depression and an adapted fear-avoidance model in explaining MS-related fatigue. This integrated model partly overlaps with a recently formulated model by Wu et al. ${ }^{30}$ explaining post-stroke fatigue. They suggest also an integration of biological and psychological variables, including depressive symptoms, coping and behavioral factors. Also in stroke patients, an intervention including CBT elements showed a long term reduction in fatigue. ${ }^{31}$ Moreover, Zedlitz et al. ${ }^{31}$ stated that the addition of graded activity to the cognitive elements, which focuses on improvement of physical disability, resulted in a longer endurance of the fatigue reducing effects.

Translating the biopsychosocial model of Bol et al. ${ }^{1}$ to clinical practice in MS, the model indicates several modifiable factors, such as the fatigue-enhancing cycle of fear-avoidance and depression, which form important targets for interventions. Diagnosing and treating depression could be a first step to treat MS 
related fatigue. Depression is with a life-time prevalence of approximately $50 \%$ very prevalent in MS and probably underdiagnosed and untreated. ${ }^{32}$, 33 When depression is treated, for instance with cognitive behavioral therapy (CBT) ${ }^{34}$, it is likely that fatigue is also reduced. Next, CBT focusing on changing catastrophizing thoughts about fatigue could help fatigued MS patients. ${ }^{35-37}$ Knoop et al. ${ }^{35}$ concluded that changes in thoughts about fatigue play a crucial role in CBT for fatigue in MS. Hoogerwerf et al. ${ }^{38}$ showed that also the third generation CBT, Mindfulness Based Cognitive Therapy (MBCT) is an effective intervention for severely fatigued MS patients. Patients were not only less fatigued after MBCT, but also less depressed and less catastrophizing about fatigue. This suggests that catastrophizing can be reduced not only by altering the content of thoughts such as in regular CBT, but even by disengaging from the maladaptive thoughts about fatigue.

There are several limitations to this study, which should be taken into account when interpreting the results and could be addressed in future studies. First of all, the design is cross-sectional making it impossible to draw firm conclusions about causality and temporal relations in the disease process. More prospective and longitudinal studies are needed to confirm the proposed causal relationships. Secondly, postal questionnaires were used which made us unable to compare responders with non-responders. The response rate was favorable (77\%), but lower in comparison with Bol et al. ' (93\% response rate). A possible explanation could be related to the fact that more questionnaires were included which demanded more time and energy of the participants. As a result, we cannot exclude the possibility of a selection bias. Thirdly, all data were self-reported and are therefore sensitive to retrospective bias and response styles. Fourthly, our main outcome measure, the $A F Q$, is a questionnaire consisting out of four items. Despite its sufficient validity and reliability, Horemans et al. ${ }^{39}$ argued that the AFQ lacks precision at the individual patient level. Future studies should include fatigue questionnaires which are validated in MS patients, such as the Fatigue Severity Scale or the Modified Fatigue Impact Scale. ${ }^{40}$ Finally, other factors, some even modifiable, such as sleep disorders, cognitive impairments and maladaptive coping styles, were not assessed and therefore lacking in the biopsychosocial model. Their inclusion could increase the explained variance of the model due to 
their previously established influences on fatigue in MS. ${ }^{41-43}$ Furthermore, the overall anxiety level and other distorted cognitive thinking habits besides catastrophizing, in which elements of rumination, magnification and helplessness are embedded 22 , could possibly be another useful addition for future studies due its modifiable character and insight in effective therapeutic elements.

Despite these limitations, this cross-validation of the biopsychosocial model of Bol et al. ${ }^{1}$ forms an important next step in explaining MS-related fatigue and highlights a promising role for CBT. The integrated model supports the clinical practice guidelines that both biological and psychological factors should be taken into account during the clinical assessment and treatment of fatigue in MS. ${ }^{44,45}$ It is expected that development and evaluation of targeted psychological interventions will help improving the biopsychosocial model of MS related fatigue.

\section{Acknowledgements}

We would like to thank all the patients who took part in this study; the therapists, psychological assistants and MS nurses of Zuyderland Medical Center; Drs. Myreen Moors for her effort in gathering and monitoring the data acquisition; Prof. Dr. Raymond Hupperts for his kind cooperation and time investment.

\section{Compliance with ethical standards}

The authors declare that they do not have any conflict of interest. All procedures were approved by and in accordance with the ethical standard of the medical ethics committee of Zuyderland Medical Center and with the 1964 Helsinki declaration and its later amendments. Informed consent was obtained from all patients for being included in the study. 


\section{References}

1. Bol, Y., Duits, A.A., Lousberg, R., Hupperts, R.M., Lacroix, M.H., Verhey, F.R. and Vlaeyen, J.W. (2010). Fatigue and physical disability in patients with multiple sclerosis: a structural equation modeling approach. Journal of behavioral medicine. 33, 355-363.

2. Compston, A. and Coles, A. (2008). Multiple sclerosis. The Lancet. 372, 1502-1517.

3. Hirtz, D., Thurman, D., Gwinn-Hardy, K., Mohamed, M., Chaudhuri, A. and Zalutsky, R. (2007). How common are the "common" neurologic disorders? Neurology. 68, 326-337.

4. Brañas, P., Jordan, R., Fry-Smith, A., Burls, A. and Hyde, C. (2000). Treatments for fatigue in multiple sclerosis: a rapid and systematic review. Health technology assessment (Winchester, England). 4, 1.

5. Giovannoni, G. (2006). Multiple sclerosis related fatigue. Journal of Neurology, Neurosurgery \& Psychiatry. 77, 2-3.

6. Minden, S.L., Frankel, D., Hadden, L., Perloff, J., Srinath, K.P. and Hoaglin, D.C. (2006). The Sonya Slifka Longitudinal Multiple Sclerosis Study: methods and sample characteristics. Multiple Sclerosis. 12, 24-38.

7. Asano, M., Berg, E., Johnson, K., Turpin, M. and Finlayson, M.L. (2014). A scoping review of rehabilitation interventions that reduce fatigue among adults with multiple sclerosis. Disability \& Rehabilitation, 1-10.

8. Bol, Y., Duits, A.A., Hupperts, R.M., Vlaeyen, J.W. and Verhey, F.R. (2009). The psychology of fatigue in patients with multiple sclerosis: a review. Journal of psychosomatic research. 66, 3-11. 9. Kos, D., Kerckhofs, E., Nagels, G. and D’Hooghe, M. (2008). Origin of fatigue in multiple sclerosis: review of the literature. Neurorehabilitation and Neural Repair. 22, 91-100.

10. Pucci, E., Branas, P., D’Amico, R., Giuliani, G., Solari, A. and Taus, C. (2007). Amantadine for fatigue in multiple sclerosis. Cochrane Database Syst Rev. 1.

11. Crombez, G., Eccleston, C., Van Damme, S., Vlaeyen, J.W. and Karoly, P. (2012). Fearavoidance model of chronic pain: the next generation. The Clinical Journal of Pain. 28, 475-483. 12. Vlaeyen, J.W., Kole-Snijders, A.M., Rotteveel, A.M., Ruesink, R. and Heuts, P.H. (1995). The role of fear of movement/(re) injury in pain disability. Journal of occupational rehabilitation. 5, 235252.

13. Lukkahatai, N. and Saligan, L.N. (2013). Association of catastrophizing and fatigue: A systematic review. Journal of psychosomatic research. 74, 100-109.

14. Bakshi, R., Shaikh, Z., Miletich, R., Czarnecki, D., Dmochowski, J., Henschel, K., Janardhan, V., Dubey, N. and Kinkel, P. (2000). Fatigue in multiple sclerosis and its relationship to depression and neurologic disability. Multiple Sclerosis. 6, 181-185.

15. Patrick, E., Christodoulou, C. and Krupp, L. (2009). Longitudinal correlates of fatigue in multiple sclerosis. Multiple Sclerosis. 15, 258-261.

16. Hadjimichael, O., Vollmer, T. and Oleen-Burkey, M. (2008). Fatigue characteristics in multiple sclerosis: the North American Research Committee on Multiple Sclerosis (NARCOMS) survey. Health Qual Life Outcomes. 6, 100. 
17. Polman, C.H., Reingold, S.C., Edan, G., Filippi, M., Hartung, H.P., Kappos, L., Lublin, F.D., Metz, L.M., McFarland, H.F. and O'Connor, P.W. (2005). Diagnostic criteria for multiple sclerosis: 2005 revisions to the "McDonald Criteria". Annals of neurology. 58, 840-846.

18. Kurtzke, J.F. (1983). Rating neurologic impairment in multiple sclerosis an expanded disability status scale (EDSS). Neurology. 33, 1444-1444.

19. Aaronson, N.K., Muller, M., Cohen, P.D., Essink-Bot, M.-L., Fekkes, M., Sanderman, R., Sprangers, M.A., te Velde, A. and Verrips, E. (1998). Translation, validation, and norming of the Dutch language version of the SF-36 Health Survey in community and chronic disease populations. Journal of clinical epidemiology. 51, 1055-1068.

20. Silver, A., Haeney, M., Vijayadurai, P., Wilks, D., Pattrick, M. and Main, C. (2002). The role of fear of physical movement and activity in chronic fatigue syndrome. Journal of psychosomatic research. 52, 485-493.

21. Miller, R., Kori, S., Todd, D., Vertaling, G.N., Vlaejen, J., Kole-Snijders, A., Crombez, G., Boeren, R. and Rotteveel, A. (1991). Tampaschaal voor Kinesiofobie (TSK).

22. Sullivan, M.J., Bishop, S.R. and Pivik, J. (1995). The pain catastrophizing scale: development and validation. Psychological assessment. 7, 524.

23. Osman, A., Barrios, F.X., Gutierrez, P.M., Kopper, B.A., Merrifield, T. and Grittmann, L. (2000). The Pain Catastrophizing Scale: further psychometric evaluation with adult samples. Journal of behavioral medicine. 23, 351-365.

24. Alberts, M., Smets, E., Vercoulen, J., Garssen, B. and Bleijenberg, G. (1997). 'Verkorte vermoeidheidsvragenlijst': een practisch hulpmiddel bij het scoren van vermoeidheid. Nederlands tijdschrift voor geneeskunde. 141, 1526-1530.

25. Vercoulen, J., Alberts, M. and Bleijenberg, G. (1999). De checklist individuele spankracht (CIS). Gedragstherapie. 32, 131-136.

26. Zigmond, A.S. and Snaith, R.P. (1983). The hospital anxiety and depression scale. Acta psychiatrica scandinavica. 67, 361-370.

27. Honarmand, K. and Feinstein, A. (2009). Validation of the Hospital Anxiety and Depression Scale for use with multiple sclerosis patients. Multiple Sclerosis.

28. Muthén, L.K. and Muthén, B.O. (1998). Mplus. Statistical analyses with latent variables. User's guide. 3.

29. Huber, P.J. (1967). The behavior of maximum likelihood estimates under nonstandard conditions. In: Proceedings of the fifth Berkeley symposium on mathematical statistics and probability, pps. 221-233.

30. Wu, S., Mead, G., Macleod, M. and Chalder, T. (2015). Model of Understanding Fatigue After Stroke. Stroke. 46, 893-898.

31. Zedlitz, A.M., Rietveld, T.C., Geurts, A.C. and Fasotti, L. (2012). Cognitive and Graded Activity Training Can Alleviate Persistent Fatigue After Stroke A Randomized, Controlled Trial. Stroke. 43, 1046-1051.

32. Feinstein, A. (2011). Multiple sclerosis and depression. Multiple Sclerosis Journal. 17, 1276-1281. 
33. Maier, S., Balasa, R., Buruian, M., Maier, A. and Bajko, Z. (2015). Depression in multiple sclerosis - review. Romanian jounal of neurology. 14, 22.

34. Hind, D., Cotter, J., Thake, A., Bradburn, M., Cooper, C., Isaac, C. and House, A. (2014). Cognitive behavioral therapy for the treatment of depression in people with multiple sclerosis: a systematic review and meta-analysis. BMC psychiatry. 14, 5.

35. Knoop, H., Van Kessel, K. and Moss-Morris, R. (2011). Which cognitions and behaviours mediate the positive effect of cognitive behavioral therapy on fatigue in patients with multiple sclerosis? Psychological medicine. 42, 205-213.

36. Moss-Morris, R., Dennison, L., Landau, S., Yardley, L., Silber, E. and Chalder, T. (2012). A randomized controlled trial of cognitive behavioral therapy (CBT) for adjusting to multiple sclerosis (the saMS trial): Does CBT work and for whom does it work? Journal of Consulting and Clinical Psychology. 81, 251-262.

37. van Kessel, K., Moss-Morris, R., Willoughby, E., Chalder, T., Johnson, M.H. and Robinson, E. (2008). A randomized controlled trial of cognitive behavior therapy for multiple sclerosis fatigue. Psychosomatic Medicine. 70, 205-213.

38. Hoogerwerf, A.E., Bol, Y., Lobbestael, J., Hupperts, R.M. and van Heugten, C.M. (2015). Mindfulness Based Cognitive Therapy is feasible and effective in severely fatigued patients with Multiple Sclerosis: a waiting list controlled study. Submitted.

39. Horemans, H.L., Nollet, F., Beelen, A. and Lankhorst, G.J. (2004). A comparison of 4 questionnaires to measure fatigue in postpoliomyelitis syndrome. Archives of Physical Medicine and Rehabilitation. 85, 392-398.

40. Rietberg, M., Van Wegen, E. and Kwakkel, G. (2010). Measuring fatigue in patients with multiple sclerosis: reproducibility, responsiveness and concurrent validity of three Dutch selfreport questionnaires. Disability and rehabilitation. 32, 1870-1876.

41. Rabinowitz, A.R. and Arnett, P.A. (2009). A longitudinal analysis of cognitive dysfunction, coping, and depression in multiple sclerosis. Neuropsychology. 23, 581.

42. Strober, L.B. and Arnett, P.A. (2005). An examination of four models predicting fatigue in multiple sclerosis. Archives of Clinical Neuropsychology. 20, 631-646.

43. Ukueberuwa, D.M. and Arnett, P.A. (2014). Evaluating the role of coping style as a moderator of fatigue and risk for future cognitive impairment in multiple sclerosis. Journal of the International Neuropsychological Society. 20, 751-755.

44. Kwaliteitsinstituut voor de Gezondheidszorg CBO, N.V.v.N. (2012). Richtlijn Multiple Sclerose. 45. Van Kessel, K. and Moss-Morris, R. (2006). Understanding multiple sclerosis fatigue: a synthesis of biological and psychological factors. Journal of psychosomatic research. 61, 583-585. 
2 



\section{Chapter 3}

\section{Psychological factors after stroke: Are they}

stable over time?

Wijenberg, M. L. M., van Heugten, C. M., Van Mierlo, M. L., VisserMeily, J. M. A., \& Post, M. W. M. (2019). Journal of Rehabilitation Medicine, 51(1); 18-25. doi: $10.2340 / 16501977-2688$.

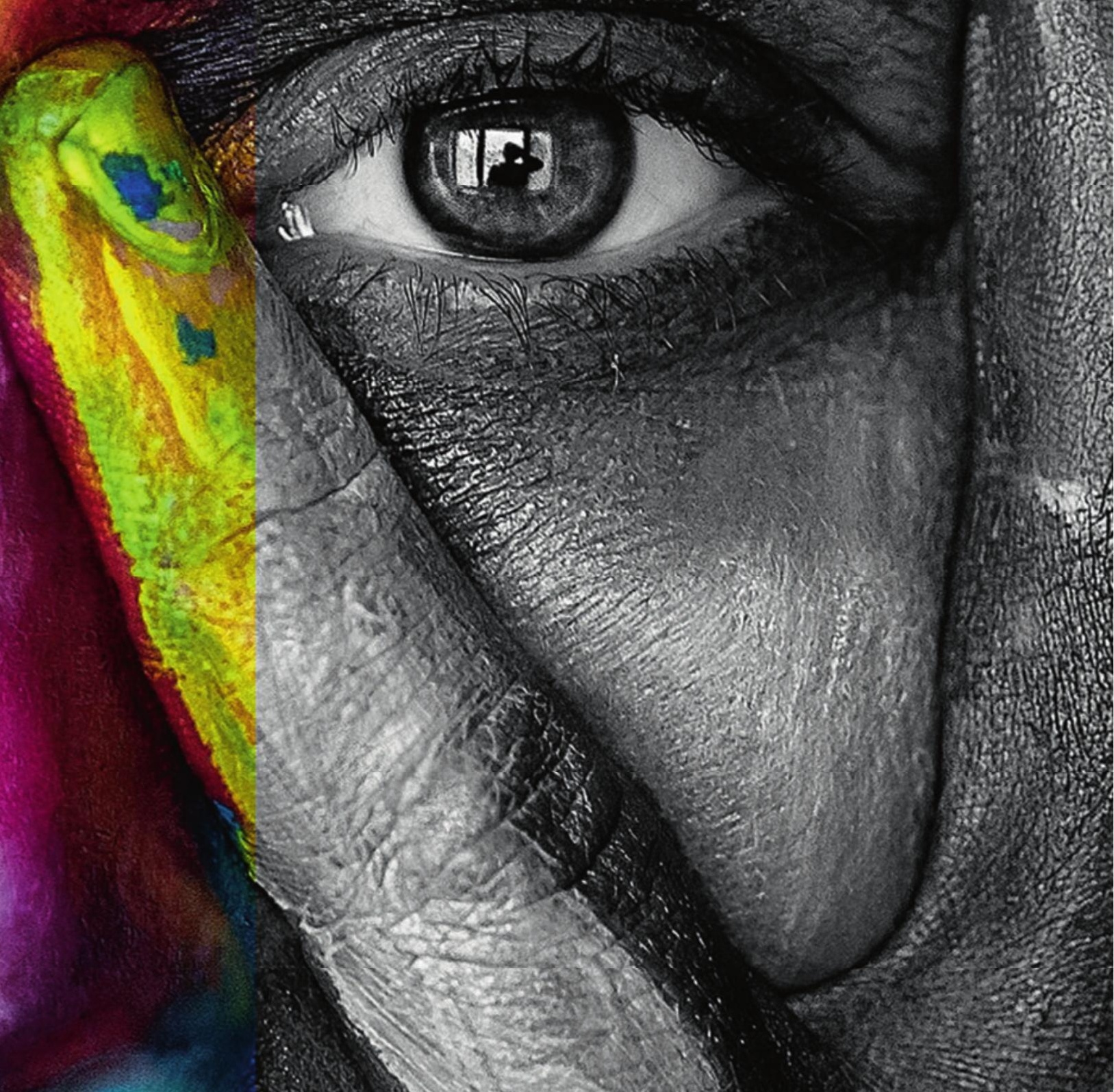




\begin{abstract}
Objective. Psychological factors influence stroke outcomes such as participation and quality of life. Although important for clinical practice, not much is known about the temporal stability of these factors. This study explored whether psychological factors are stable post-stroke.

Methods. Prospective longitudinal cohort study. The following psychological factors were assessed using self-report questionnaires at 2 months and at 2 years post-stroke: proactive coping, self-efficacy, extraversion, optimism, passive coping, neuroticism and pessimism. Changes over time, associations and dimensions among psychological factors were considered.
\end{abstract}

Results. Data for 324 participants were available. Only passive coping scores showed no change between 2 months and 2 years post-stroke. Participants showed less proactive coping, lower self-efficacy, less extraversion, less optimism, more neuroticism and more pessimism over time. All but one intercorrelations of psychological factors, $r=[-0.14-0.71]$, and all correlations over time, $r=[0.42-0.64]$, were significant. At both time points, the psychological factors clustered into an "adaptive psychological factor" (proactive coping, selfefficacy, extraversion) and a "maladaptive psychological factor" (passive coping, neuroticism).

Conclusion. Across all psychological factors, changes toward less favourable scores were found. Clinicians should pay attention to adaptive and maladaptive psychological factors among stroke patients during long-term care.

Keywords: stroke, psychological factors, rehabilitation, longitudinal studies

\title{
Lay abstract
}

Every person has a distinct personality. Personality traits may influence how people recover from stroke. This study followed 324 patients in the first 2 years after stroke and examined whether these personality traits are stable over time. We found changes to less favourable outcomes, such as less extraversion, less optimism and more neuroticism. Clinicians should be aware of these changes and stimulate the use of more adaptive psychological factors, such as proactive coping and optimism. 


\section{Introduction}

Stroke is a major health problem due to its high prevalence, disabling consequences and risk of recurrence. ${ }^{1}$ According to the International Classification of Disability, Functioning and Health (ICF), functioning and health are influenced by personal factors, including psychological factors. ${ }^{2}$ Examples of psychological factors are proactive coping, self-efficacy, extraversion, optimism, passive coping, neuroticism and pessimism.

In stroke, specifically, previous research has revealed associations between psychological factors and participation or quality of life..$^{3-5}$ Research has shown that proactive coping, self-efficacy, extraversion and optimism are related to better outcomes, whereas passive coping, neuroticism and pessimism are related to worse outcomes. ${ }^{3-7}$ These strong associations with outcome highlight the importance of gaining knowledge about the properties of these psychological factors, such as their stability after stroke. Knowledge about temporal stability can be used to optimize the timing of psychological assessments and to gain knowledge about whether these factors can be influenced in such a way that outcome can be optimized.

In healthy people psychological factors, especially personality traits, are generally regarded as stable. ${ }^{8}$ Most studies confirm the temporal stability among psychological factors in healthy adults ${ }^{9-13}$, but a few studies have reported changes over time in e.9., optimism ${ }^{14}$ and neuroticism ${ }^{10}{ }^{12}$. Studies in patients with stroke and similar neurological conditions, such as traumatic brain injury (TBI), have shown mixed findings. Regards personality traits, inconsistent results across and within factors have been found and specific evidence remains scarce for patients with stroke. 11, 12, 15-17 These inconsistencies are also found with regard to coping $^{3,17,18}$, possibly also because terminology for subtypes of coping styles differs widely ${ }^{19}$.

These inconsistencies and limited findings in patients with stroke show the need for further exploration of the temporal stability of psychological factors. Therefore, the main aim of the current study was to explore whether psychological factors, namely proactive coping, self-efficacy, extraversion, optimism, passive coping, neuroticism and pessimism, are stable over the first 2 
years post-stroke. Furthermore, we explored possible clustering of these psychological factors.

\section{Methods}

\section{Design and procedure}

The current study was part of the Restore4Stroke cohort study, a multicentre prospective longitudinal cohort study in which patients with stroke were recruited on admission to the acute stroke unit at 1 of 6 general hospitals in the Netherlands and were followed up for 2 years after their stroke. Details of the study procedures are given elsewhere. ${ }^{20}$ The medical ethics committees of all participating hospitals provided approval. Participants were recruited between March 2011 and March 2013 and all provided written informed consent.

After obtaining participants' informed consent, information on strokerelated factors (e.g. type of stroke, lateralization, stroke severity, activities of daily living ( $A D L$ ) dependency) was extracted from the hospital database. Information on demographic factors was obtained from the patient or family members (within the first week post-stroke). At two months post-stroke, participants completed self-report questionnaires regarding psychological factors and underwent cognitive screening with a trained research assistant. At 2 years post-stroke, participants completed the same self-report questionnaires regarding psychological factors. The questionnaires were administered on computer or paper and were guided by a research assistant if necessary.

\section{Participants}

Inclusion criteria of the Restore4Stroke cohort study were: $\geq 18$ years old, having a diagnosis of stroke (ischaemic or intracerebral haemorrhagic lesion) clinically confirmed by the treating neurologist and stroke onset within the last 7 days.

Exclusion criteria were: (1) having a serious other condition that could be expected to influence the study outcomes (e.g. cancer or dementia); (2) having already been dependent regarding activities of daily living (ADL) before the stroke, as defined by a Barthel Index (BI) score $\leq 17$; (3) having insufficient command of the Dutch language to understand and complete the questionnaires, based on clinical judgment and (4) experiencing cognitive decline before the stroke, as defined by a score $\geq 1$ on the Heteroanamnesis List Cognition (HLC). The HLC is a 
5-item questionnaire, completed by the patient's spouse, assessing premorbid cognitive dysfunctioning on 5 cognitive domains. Participants who completed the questionnaires for psychological factors at 2 years post-stroke were selected for the current study.

\section{Measures}

Details and references for all measures are described elsewhere. ${ }^{20}$

Demographic and stroke-related factors. Data regarding age, sex, education and marital status (single or in a relationship) were collected. The highest completed level of education was recorded according to the 7-point Verhage system, classifying the Dutch education system into 7 categories ranging from no primary school completed ("1") to completion of a higher educational level (such as college ("6") and university ("7")). Stroke-related factors, such as type (ischaemic, haemorrhagic or unknown/other), lateralization (left, right, cerebellar, brainstem or unknown/other), severity (assessed by the National Institutes of Health Stroke Scale (NIHSS)) and discharge destination (home, or (geriatric) rehabilitation) were collected. ADL was measured with the Barthel Index at day 4 post-stroke and cognitive functioning was measured with the Montreal Cognitive Assessment (MoCA) at 2 months post-stroke.

Psychological factors. All questionnaires to assess psychological factors are reliable and valid in patients with stroke. ${ }^{20}$ Proactive coping competencies were assessed with the Utrecht Proactive Coping Competence scale (UPCC). The 1month test-retest reliability is $0.72 .{ }^{21}$ The questionnaire consists of 21 items scored on 4-point scale ranging from "not very competent" to "competent". A mean score is calculated, ranging from 1 to 4 , with a higher score indicating a higher level of proactive coping competencies.

Self-efficacy was assessed with the General Self-Efficacy Scale (GSES). The 7 -week test-retest reliability is $0.72 .^{22}$ The scale consists of 10 items scored on a 4-point scale ranging from 'not at all true' to 'exactly true'. A sum score is calculated, ranging from 10 to 40 , with a higher score indicating a higher level of self-efficacy.

Extraversion and neuroticism were assessed with 2 subscales of the Eysenck Personality Questionnaire Revised Short Scale (EPQ-SS). Both scales 
consist of 12 items with a dichotomous (yes/no) response option. The 6-month test-retest reliability is 0.85 for optimism and 0.70 for neuroticism. ${ }^{23} \mathrm{~A}$ sum score is calculated, ranging from 0 to 12 , with a higher score indicating a higher level of extraversion or neuroticism, respectively.

Optimism and pessimism were assessed with the Life Orientation Test Revised (LOT-R). The 4-month test-retest reliability is $0.68 .{ }^{24}$ It consists of 10 items, with 3 items measuring optimism, 3 items measuring pessimism and 4 filler items. The items are scored on a 5-point scale ranging from "strongly disagree" to "strongly agree". A score is calculated per subscale, ranging from 0 to 12 , with a higher score indicating a higher level of optimism or pessimism, respectively.

Passive coping was assessed with the passive reaction pattern subscale of the Utrecht Coping List (UCL). The 6-week test-retest reliability is 0.84 for the passive reaction pattern subscale. ${ }^{25}$ The questionnaire consists of 7 items scored on a 4-point scale ranging from "seldom" to "very often". A sum score is calculated, ranging from 7 to 28 , with a higher score indicating a higher level of passive coping.

\section{Statistical analyses}

Preparatory analyses. All data analyses were performed using SPSS Statistics 24.0 for Windows (IBM Corp., Armonk, NY, USA). Missing data were inspected and imputed with the average value within the corresponding subscale if at least $80 \%$ of the participant's data of the specific questionnaire was available. For the GSES, the criterion suggested by the manual of at least $70 \%$ non-missing data was used. Data were inspected for normality and outliers. In case of nonnormality (skewness or kurtosis value $<-1$ or $>+1$ ), data were transformed. Skewness to the right was resolved with a logarithmic transformation. A quadratic transformation was executed to resolve skewness to the left. All analyses were performed using an alpha level of 0.05

Baseline differences. Group differences on baseline characteristics between the included and excluded participants were analysed using Pearson $\chi^{2}$ tests for nominal variables including all available levels, independent t-tests ( $T$ ) for normally distributed continuous variables, and non-parametric tests (MannWhitney $U$ test) for continuous variables in case of non-normality. 
Changes over time. To reveal changes over time, paired samples t-tests were performed. For further inspection, changes over time were categorized into 3 categories: "worse", "equal" and "better". Hereby, we used a change of 0.5 SD as pragmatic indicator of change of the psychological variable score over time as suggested by Norman et al. ${ }^{26}$. For the variables proactive coping, self-efficacy, extraversion and optimism, an increase of more than 0.5 SD over time was considered an adaptive change ("better") (see Introduction). For the variables passive coping, neuroticism and pessimism an increase of more than $0.5 \mathrm{SD}$ over time was considered a maladaptive change ("worse") (see Introduction). A change of less than 0.5 SD over time was considered as no change over time ("equal"). Effect sizes were calculated using Glass's delta. ${ }^{27}$

Correlation and factor analyses. To explore associations among the psychological variables, Pearson correlations were calculated and interpreted as suggested by Evans ${ }^{28}$ ( $\leq 0.19$ very weak; 0.20-0.39 weak; 0.40-0.59 moderate; 0.60-0.79 strong; $\geq 0.80$ very strong). To explore dimensions among the psychological variables, exploratory factor analysis (EFA) (including the extraction methods principal axis factoring and maximum likelihood estimation) was performed using data from participants who completed all questionnaires at both time points $(n=282)$. Factor extraction was based on multiple criteria as suggested by Osborne and Costello ${ }^{29}$. The K1 criterion (eigenvalve $\geq 1.0$ ), the Scree plot, small residual correlations ([-0.1; 0.1]) and a non-significant goodness-of-fit test (based on maximum likelihood estimation) were used as 4 indicators for extraction. If the criteria suggested multiple solutions for factor extraction, e.g. a 1-factor structure on the basis of the Scree plot and a 2-factor structure on the basis of the K1 criterion, all suggestions of factor extraction were executed and the best solution, indicated by smaller residual correlations and a non-significant goodness-of-fit test, was chosen. Only factor loadings greater than 0.30 were displayed. Because we expected the factors to be correlated, Oblimin rotation was preferred over Varimax rotation. 


\section{Results}

\section{Sample}

Of the 395 participants in the Restore4Stroke cohort, 324 (82.0\%) provided data on psychological factors at 2 years post-stroke and were included in the current study. Furthermore, depending on the psychological factor, imputation was performed for 0.0-9.6\% of participants. Baseline characteristics of both the included group ( $N=324)$ and excluded group $(n=71)$ and significant differences between them are shown in Table 1. The participants in the included group were significantly younger, less often highly educated and more often involved in a relationship in comparison with the excluded group. Regarding stroke-related factors, the included group had a significantly higher level of cognitive functioning 2 months post-stroke and a significantly higher level of independence in ADL 4 days post-stroke in comparison with the excluded group. 
Table 1. Patients' characteristics at baseline

\begin{tabular}{|c|c|c|c|c|}
\hline & $\begin{array}{l}\text { Included } \\
\text { group } \\
(n=324)\end{array}$ & $\begin{array}{l}\text { Excluded } \\
\text { group } \\
(n=71)\end{array}$ & $\begin{array}{l}\text { Test } \\
\text { statistic } \\
\chi^{2} / T / U\end{array}$ & $\begin{array}{l}\rho- \\
\text { value }\end{array}$ \\
\hline \multicolumn{5}{|l|}{ Demographic factors } \\
\hline Male, \% & 64.8 & 64.8 & 0.00 & 1.00 \\
\hline Age, years, mean (SD) & $65.9(12.1)$ & $70.4(14.0)$ & 2.79 & $<0.01$ \\
\hline Marital status: in a relationship, \% & 71.3 & 56.3 & 6.05 & 0.01 \\
\hline Higher educational level, \% & $25.4^{a}$ & $32.8^{b}$ & 19.68 & $<0.01$ \\
\hline \multicolumn{5}{|l|}{ Stroke-related factors } \\
\hline Ischaemic, \% & 92.3 & 97.2 & 2.23 & 0.33 \\
\hline Left hemisphere, \% & $39.0^{a}$ & 45.1 & 8.05 & 0.09 \\
\hline Severity of stroke (NIHSS), mean (SD) & $2.7(3.2)$ & $3.3(3.3)$ & $9,975.00$ & 0.08 \\
\hline No stroke symptoms (NIHSS 0), \% & 24.4 & 21.1 & & \\
\hline Minor stroke symptoms (NIHSS 1-4), \% & 57.1 & 50.7 & & \\
\hline Moderate stroke symptoms (NIHSS 5-12), \% & 16.4 & 25.4 & & \\
\hline Moderate to severe stroke symptoms (NIHSS 13), \% & 2.1 & 2.8 & & \\
\hline ADL 4 days post-stroke (BI), mean (SD) & $17.0(4.8)$ & $16.1(4.9)$ & $9,575.50$ & 0.02 \\
\hline Cognitive functioning 2 months post-stroke (MoCA) & $23.8(3.7)^{c}$ & $21.9(5.4)^{d}$ & $5,072.50$ & $<0.05$ \\
\hline Cognitively impaired (MoCA $\leq 25$ ), \% & 66.3 & 75.6 & & \\
\hline Destination after discharge from hospital & & & 4.52 & 0.10 \\
\hline Home, \% & 72.2 & 62.0 & & \\
\hline (Geriatric) rehabilitation, \% & 27.8 & 38.0 & & \\
\hline
\end{tabular}

Notes. ${ }^{\mathrm{a}} n=323,{ }^{\mathrm{b}} n=61,{ }^{\mathrm{c}} n=306,{ }^{\mathrm{d}} n=41$. T: independent $t$-test; $U$ : Mann-Withney $U$ test; NIHSS: National Institutes of Health Stroke Scale; ADL: activities of daily living; BI: Barthel Index; MoCA: Montreal Cognitive Assessment; SD: standard deviation.

\section{Change of psychological factors over time}

Table 2 provides the results of the temporal stability analysis of psychological factors. All psychological factors except passive coping showed significant changes over time. At 2 years post-stroke, participants reported less proactive coping, lower self-efficacy, less extraversion, less optimism, more neuroticism and more pessimism in comparison with 2 months post-stroke. The largest effect sizes were found for optimism (Glass's $\Delta=-0.58$ ) and proactive coping (Glass's $\Delta=-0.42$ ). Furthermore, looking at changes over time ("worse", "equal", "better"), 28.6 $46.8 \%$ participants showed changes in a negative direction and $10.7-22.7 \%$ improved across all psychological factors. 


\section{Associations among psychological factors}

For all psychological factors moderate or strong correlations were found between scores at 2 months and 2 years post-stroke, ranging between 0.42 and 0.64 (Table 2). In Table 3 correlations among the various psychological factors within each timepoint are reported.

At 2 months post-stroke, all psychological factors correlated significantly with each other except for extraversion with neuroticism. The correlations ranged between very weak to strong. The highest correlation was found between proactive coping and self-efficacy $(r=0.62)$.

At 2 years post-stroke, all psychological factors correlated significantly with each other. The correlations ranged between weak and strong. The highest correlation was again found between proactive coping and self-efficacy $(r=0.71)$. Overall, correlations at 2 years were somewhat stronger compared with 2 months.

Table 2. Temporal stability of psychological factors

\begin{tabular}{|c|c|c|c|c|c|c|c|c|c|c|}
\hline \multirow[b]{2}{*}{$\begin{array}{l}\text { Psychological } \\
\text { factors }\end{array}$} & \multirow[b]{2}{*}{$\begin{array}{l}\text { Score } \\
\text { range }\end{array}$} & \multirow[b]{2}{*}{$\Pi$} & \multirow{2}{*}{$\begin{array}{l}2 \text { months } \\
\text { post- } \\
\text { stroke } \\
\text { Mean } \\
\text { (SD) }\end{array}$} & \multirow{2}{*}{$\begin{array}{l}2 \text { years } \\
\text { post- } \\
\text { stroke } \\
\text { Mean } \\
\text { (SD) }\end{array}$} & \multirow[b]{2}{*}{$t$} & \multirow[b]{2}{*}{$\begin{array}{l}\text { Effect } \\
\text { size }\end{array}$} & \multicolumn{4}{|c|}{ Changes over time 0.5 SD $^{a}$} \\
\hline & & & & & & & \%wors & \%equal & \%better & $r^{-}$Correlations \\
\hline $\begin{array}{l}\text { Proactive } \\
\text { coping }\end{array}$ & {$[1-4]$} & 301 & $3.1(0.5)$ & $2.9(0.7)$ & $6.83^{* *}$ & -0.42 & 46.8 & 33.6 & 19.6 & $0.55^{* *}$ \\
\hline Self-efficacy & [10-40] & 301 & $31.5(6.4)$ & $30.8(6.4)$ & $2.20^{* c}$ & -0.11 & 28.6 & 51.5 & 19.9 & $0.52^{* * c}$ \\
\hline Extraversion & [0-12] & 305 & $7.2(3.2)$ & $6.3(3.3)$ & $5.64^{* *}$ & -0.28 & 34.1 & 51.1 & 14.8 & $0.64^{* *}$ \\
\hline Optimism & [0-12] & 298 & $8.2(2.1)$ & $6.9(2.1)$ & $9.33^{* *}$ & -0.58 & 41.6 & 47.7 & 10.7 & $0.42^{* *}$ \\
\hline $\begin{array}{l}\text { Passive } \\
\text { coping }\end{array}$ & [7-28] & 304 & $10.5(2.8)$ & ) 10.9 (3.2) & $-0.87^{c}$ & 0.12 & 28.9 & 48.4 & 22.7 & $0.61^{* * c}$ \\
\hline Neuroticism & {$[0-12]$} & 305 & $3.6(3.1)$ & $4.4(3.5)$ & $-5.12^{* *}$ & 0.27 & 34.8 & 47.5 & 17.7 & $0.64^{* *}$ \\
\hline Pessimism & [0-12] & 294 & $4.4(2.8)$ & $4.9(2.3)$ & $-3.38^{* *}$ & * 0.19 & 35.0 & 43.2 & 21.8 & $0.49^{* *}$ \\
\hline
\end{tabular}

Notes. ${ }^{*} p<0.05,{ }^{* *} p<0.01 . \%$ worse, \% equal and \% better refer to categories of 0.5 SD change of the psychological variable score over time. ${ }^{b}$ Correlations between 2 months post-stroke and 2 years post-stroke. 'Based on transformed data. 
Table 3. Correlations of psychological measures at 2 months post-stroke (below the diagonal) and at 2 years post-stroke (above the diagonal)

\begin{tabular}{llllllll}
\hline Psychological factors & & $2^{2}$ & $3^{2}$ & 4 & 5 & 6 & 7 \\
\hline 1. Proactive coping & - & $0.71^{* *}$ & $0.50^{* *}$ & $0.47^{* *}$ & $-0.54^{* *}$ & $-0.46^{* *}$ & $-0.30^{* *}$ \\
2. Self-efficacy & $0.62^{* *}$ & - & $0.45^{* *}$ & $0.46^{* *}$ & $-0.56^{* *}$ & $-0.47^{* *}$ & $-0.34^{* *}$ \\
3. Extraversion & $0.27^{* *}$ & $0.27^{* *}$ & - & $0.43^{* *}$ & $-0.40^{* *}$ & $-0.28^{* *}$ & $-0.29^{* *}$ \\
4. Optimism & $0.41^{* *}$ & $0.44^{* *}$ & $0.21^{* *}$ & - & $-0.56^{* *}$ & $-0.53^{* *}$ & $-0.37^{* *}$ \\
5. Passive coping & $-0.46^{* *}$ & $-0.39^{* *}$ & $-0.19^{* *}$ & $-0.41^{* *}$ & - & $0.68^{* *}$ & $0.34^{* *}$ \\
6. Neuroticism & $-0.40^{* *}$ & $-0.31^{* *}$ & -0.09 & $-0.39^{* *}$ & $0.59^{* *}$ & - & $0.38^{* *}$ \\
7. Pessimism & $-0.15^{* *}$ & $-0.24^{* *}$ & $-0.14^{*}$ & $-0.28^{* *}$ & $0.26^{* *}$ & $0.26^{* *}$ & -
\end{tabular}

Notes. ${ }^{*} p<0.05,{ }^{* *} p<0.01$. Correlation coefficient is Pearson's correlation. ${ }^{\text {a At }} 2$ months poststroke based on transformed data due to non-normality.

\section{Dimensions among psychological factors}

The correlations among the psychological variables at both time-points were best described by the extraction of 2 factors using principal axis factoring as EFA extraction method (Table 4). After factor extraction and oblimin rotation, the factor correlation was 0.58 and -0.70 at 2 months post-stroke and 2 years poststroke respectively. The pattern matrices of both time points, consisting of the factor loadings after oblimin rotation, are shown in Table 5. For interpretation purposes, factor loadings on factor 1 at 2 months post-stroke were inverted.

At 2 months post-stroke, factors 1 and 2 are labelled as "maladaptive psychological factor" and "adaptive psychological factor", respectively. Passive coping and neuroticism had positive loadings on the maladaptive factor, whereas optimism had a negative loading on this factor. Proactive coping, self-efficacy, extraversion and optimism had positive loadings on the adaptive factor. Pessimism did not load on any factor. The explained variance of the 2 factors together was $43.6 \%$.

At 2 years post-stroke, factors 1 and 2 are labelled as "adaptive psychological factor" and "maladaptive psychological factor" respectively. Proactive coping, self-efficacy and extraversion had positive loadings on the adaptive factor. Passive coping, neuroticism and pessimism had positive loadings on the maladaptive factor. Furthermore, optimism had a negative loading on this factor. The explained variance of the 2 factors together was $54.8 \%$. 
Table 4. Exploration of factor structures at 2 months post-stroke and 2 years post-stroke

\begin{tabular}{|c|c|c|c|c|}
\hline Criterion for factor extraction & \multicolumn{2}{|c|}{2 months post-stroke } & \multicolumn{2}{|c|}{2 years post-stroke } \\
\hline $\mathrm{N}$ of extracted factors & 1 & 2 & 1 & 2 \\
\hline Eigenvalues & & & & \\
\hline $\begin{array}{l}\text { K1 criterion } \\
\text { (eigenvalues } \geq 1.0 \text { ) }\end{array}$ & 3.03 & 1.02 & 3.76 & 0.86 \\
\hline Scree plot & $\checkmark$ & & $\checkmark$ & \\
\hline $\begin{array}{l}\text { Residual correlations } \\
\text { Small }[-0.1 ; 0.1]\end{array}$ & {$[-0.06 ; 0.14]$} & {$[-0.07 ; 0.09]$} & {$[-0.07 ; 0.14]$} & {$[-0.04 ; 0.06]$} \\
\hline $\begin{array}{c}\rho \text { value, goodness-of-fit test } \\
\text { Non-significant }\end{array}$ & 0.00 & 0.08 & 0.00 & 0.10 \\
\hline
\end{tabular}

Notes. Bold indicates that the criterion is met.

Table 5. Factor loadings based on exploratory factor analysis after Oblimin rotation

\begin{tabular}{|c|c|c|c|c|}
\hline & \multicolumn{2}{|c|}{2 months post-stroke } & \multicolumn{2}{|c|}{2 years post-stroke } \\
\hline & $\begin{array}{l}\text { Factor } 1 \\
\text { "Maladaptive } \\
\text { PF"b }\end{array}$ & $\begin{array}{l}\text { Factor } 2 \\
\text { "Adaptive } \\
\text { PF" }\end{array}$ & $\begin{array}{l}\text { Factor } 1 \\
\text { "Adaptive } \\
\text { PF" }\end{array}$ & $\begin{array}{l}\text { Factor } 2 \\
\text { "Maladaptive } \\
\text { PF" }\end{array}$ \\
\hline Proactive coping & & 0.61 & 0.85 & \\
\hline Self-efficacyc & & 0.81 & 0.77 & \\
\hline Extraversion & & 0.37 & 0.58 & \\
\hline Optimism & -0.36 & 0.33 & & -0.51 \\
\hline Passive coping ${ }^{c}$ & 0.72 & & & 0.68 \\
\hline Neuroticism & 0.86 & & & 0.97 \\
\hline Pessimism & & & & 0.35 \\
\hline Eigenvalues & 3.03 & 1.02 & 3.76 & 0.86 \\
\hline Explained variance, \% & \multicolumn{2}{|c|}{43.55} & \multicolumn{2}{|c|}{54.84} \\
\hline Factor correlation & \multicolumn{2}{|c|}{-0.58} & \multicolumn{2}{|c|}{-0.70} \\
\hline
\end{tabular}

Notes. Factor loadings < 0.3 are suppressed. ${ }^{\circ}$ Forced 2 -factor analysis. ${ }^{b}$ Factor correlation and loadings are inverted for interpretation purposes. 'Based at 2 months post-stroke on transformed data due to non-normality. PF: psychological factor.

\section{Discussion}

This study found that scores on measures of psychological factors changed during the first 2 years post-stroke. The psychological factors were moderately to strongly correlated with each other and over time and clustered at both time points into 2 factors: an "adaptive psychological factor" (proactive coping, selfefficacy, extraversion) and a "maladaptive psychological factor" (passive coping and neuroticism). Scores on all adaptive psychological factors decreased over time, whereas scores on maladaptive psychological factors increased or remained stable (passive coping) over time. The added value of our study is that we evaluated the temporal stability of multiple psychological factors simultaneously in a large cohort of patients with stroke using a longitudinal design. 
To the best of our knowledge, the finding of a negative temporal impact across all psychological factors post-stroke has not been demonstrated previously. As mentioned in the introduction, previous research on temporal stability of psychological factors in stroke and other populations showed inconsistent results across and within psychological factors, possibly due to the use of different measures, time-points and designs.

Strikingly, even though the sample consisted mainly of patients with a mild stroke overall changes in a negative direction were found. In comparing our results with previous findings regarding temporal stability of psychological factors in healthy populations, we found different patterns of changes over time. Most studies assessing psychological factors in healthy adults showed temporal stability 9-14, whereas our data showed temporal changes in a negative direction across all psychological factors. This suggests that the occurrence of a stroke could be a possible cause of the observed negative changes over time.

The occurrence of stroke results in negative changes regarding emotional, cognitive and energy resources which could provide an explanation for the observed negative change of psychological factors over time. After a stroke, many patients suffer from depression ${ }^{30}$, cognitive complaints ${ }^{31}$, and disabling fatigue ${ }^{32}$ increasing their burden and calling on their reserves of resilience. The observed negative changes in psychological factors could be concomitant with these negative emotional, cognitive and energy changes. In fact, it was shown that neuroticism is concomitant with depressive symptoms ${ }^{33}$ and that cognitive complaints in patients with traumatic brain injury (TBI) are associated with the use of maladaptive coping styles ${ }^{7}$. In our sample, $66 \%$ were considered to be cognitively impaired (MoCa score $\leq 25$ ) at 2 months post-stroke. Furthermore, Wu et al. ${ }^{32}$ proposed a biopsychosocial model including psychological factors as an explanation for fatigue after stroke. Taken together, stroke is associated with negative changes in emotional, cognitive or energy resources. These consequences of stroke may form an explanation for the negative changes observed in psychological factors.

Although the occurrence of stroke provides a possible explanation for the significant differences over time on all measures except for passive coping, it remains unclear whether damage to the brain (i.e. the stroke) or the fact that a 
stroke is a negative life event (such as a cardiac event) or the chronic character (as in other diseases such as diabetes) or their combination may induce changes in psychological factors. From earlier studies we know that patients with acquired brain injury make more use of passive reactions and less use of problemsolving coping styles than the general population ${ }^{7}$, which may be related to the damage to the brain. From studies on survivors of a cardiac arrest we know that the impact of the event plays an important role in the quality of life in the long term ${ }^{34}$; therefore distress may also influence psychological functioning. A study on chronic diseases ${ }^{35}$ also found changes over time in extraversion and neuroticism after the onset of chronic diseases, such as heart disease, respiratory disease and stroke. Future studies are needed to relate the observed negative changes to stroke, brain damage, a negative life event, chronic character of the disease or their combination.

Furthermore, one could argue whether these changes comply with the minimal clinically relevant change of these measures and therefore represent clinically relevant changes and/or changes due to measurement error. Because this information is not available, we chose 0.5 SD as pragmatic indicator of change, as suggested by Norman et al. ${ }^{26}$. Future research should provide the minimal clinically relevant change per measure to investigate whether the changes observed in this study represent clinically relevant changes. Even if the observed changes do not reflect clinically relevant changes and thus suggest temporal stability, our findings imply, at the very least, that the psychological factors investigated do not improve naturally to a more beneficial level and, consequently, do not foster improved outcomes in terms of participation and quality of life.

To examine whether psychological factors can be modified by treatment programmes, systematic reviews and meta-analyses provide some evidence for the ability to change depression, anxiety, self-efficacy and coping by means of psychological therapy, to possibly improve the outcomes of patients with stroke in terms of quality of life and participation. ${ }^{36-40}$ Given these positive findings related to the modifiability of some psychological factors, treatment could be aimed at enhancing adaptive psychological factors and limiting maladaptive psychological factors in order to improve participation and quality of life of patients with stroke. 
However, to provide more insight for the development of such focused and personalized treatment, future research should reveal which patients are at risk of the negative changes over time regarding psychological factors.

Another implication is related to the occurrence of 2 clusters, namely an "adaptive psychological factor" (proactive coping, self-efficacy, extraversion) and a "maladaptive psychological factor" (passive coping and neuroticism). This could suggest the use of a single measure of adaptive psychological factors and a single measure of maladaptive psychological factors for subsequent studies. However, more research is needed to replicate these findings and provide direction for the selection or development of such measures. Also it should be noted that at 2 months post-stroke, pessimism did not load on the extracted factors, whereas optimism loaded on both factors. At 2 years post-stroke, pessimism did load on the adaptive psychological factor, but optimism, although inverted, also loaded on this maladaptive factor and not, as expected, on the adaptive factor.

While interpreting the results of our study, the following limitations should be taken into account. First, the homogeneous sample could limit the generalizability of our results to the entire stroke population or to other patient populations. Most patients in our study had a minor ischaemic stroke. An explanation for this homogeneity is that mild stroke comprises the largest group of stroke patients and patients with a severe ischaemic stroke or a haemorrhagic stroke are less often present, are less often referred to general hospitals, have greater difficulty understanding the questionnaires or study instructions and are less able to provide informed consent within the first week. ${ }^{4}$ Future research could investigate the temporal stability of psychological factors in patients with a more severe or haemorrhagic stroke. Furthermore, it would be interesting to examine whether, in other patient populations with mild brain injuries, such as mild TBI, or in other chronic diseases with a sudden onset, the same negative effect of time is seen to reveal whether these changes are specific for a mild brain injury (stroke or mild TBI) or related to a more general cause such as the onset of a disabling chronic disease or occurrence of other significant (health-related) life events. Secondly, psychological factors were measured at 2 time-points, 22 months apart. To provide evidence for the existence of linear or non-linear time effects and to reveal time-related changes within this time period psychological factors should 
ideally be assessed at more time points. Thirdly, time-dependent relationships with regard to depression, anxiety and other psychological factors such as locus of control, sense of coherence and resilience were not considered in this study. This limits any conclusion regarding these other psychological factors or the existence of a mediating role which might be played by a more general negative emotional state. ${ }^{33}$

Despite these limitations, we found, in a large prospective longitudinal multicentre cohort study across 7 different psychological factors in patients with stroke, changes toward less favourable scores which may be associated with worse outcome, such as participation and quality of life. Clinicians should attend to adaptive psychological factors (e.g. proactive coping, self-efficacy, extraversion) and maladaptive psychological factors (e.g. passive coping and neuroticism) during long-term care.

\section{Conflicts of interest and source of funding}

The authors have no conflict of interest to declare. The presented study is part of the Restore4Stroke Research Program, which is supported financially by VSBfund (grant no. 89000004) and coordinated by ZonMw (the Dutch Organization for Health Research and Development). 


\section{References}

1. Benjamin, E.J., Blaha, M.J., Chiuve, S.E., Cushman, M., Das, S.R., Deo, R., de Ferranti, S.D., Floyd, J., Fornage, M., Gillespie, C., Isasi, C.R., Jiménez, M.C., Jordan, L.C., Judd, S.E., Lackland, D., Lichtman, J.H., Lisabeth, L., Liu, S., Longenecker, C.T., Mackey, R.H., Matsushita, K., Mozaffarian, D., Mussolino, M.E., Nasir, K., Neumar, R.W., Palaniappan, L., Pandey, D.K., Thiagarajan, R.R., Reeves, M.J., Ritchey, M., Rodriguez, C.J., Roth, G.A., Rosamond, W.D., Sasson, C., Towfighi, A., Tsao, C.W., Turner, M.B., Virani, S.S., Voeks, J.H., Willey, J.Z., Wilkins, J.T., Wu, J.H.Y., Alger, H.M., Wong, S.S. and Muntner, P. (2017). Heart Disease and Stroke Statistics-2017 Update: A Report From the American Heart Association. Circulation. 135, e146-e603.

2. Geyh, S., Peter, C., Müller, R., Bickenbach, J.E., Kostanjsek, N., Üstün, B.T., Stucki, G. and Cieza, A. (2011). The Personal Factors of the International Classification of Functioning, Disability and Health in the literature - a systematic review and content analysis. Disabil Rehabil. 33, 1089-1102. 3. Darlington, A.-S.E., Dippel, D.W.J., Ribbers, G.M., van Balen, R., Passchier, J. and Busschbach, J.J.V. (2007). Coping Strategies as Determinants of Quality of Life in Stroke Patients: A Longitudinal Study. Cerebrovasc Dis. 23, 401-407.

4. van Mierlo, M.L., van Heugten, C.M., Post, M.W.M., Hoekstra, T. and Visser-Meily, J.M.A. (2017). Trajectories of health-related quality of life after stroke: results from a one-year prospective cohort study. Disabil Rehabil, 1-10.

5. van Mierlo, M.L., Schröder, C., van Heugten, C.M., Post, M.W.M., de Kort, P.L.M. and Visser-Meily, J.M.A. (2014). The Influence of Psychological Factors on Health-Related Quality of Life after Stroke: A Systematic Review. Int J Stroke. 9, 341-348.

6. Kim, S., Kim, J., Stewart, R., Kang, H., Kim, S., Shin, I., Park, M., Cho, K. and Yoon, J. (2013). Influences of Personality Traits on Quality of Life after Stroke. Eur Neurol. 69, 185-192.

7. Wolters Gregório, G., Ponds, R.W.H.M., Smeets, S.M.J., Jonker, F., Pouwels, C.G.J.G., Verhey, F.R. and van Heugten, C.M. (2015). Associations between executive functioning, coping, and psychosocial functioning after acquired brain injury. Br J Clin Psychol. 54, 291-306.

8. McCrae, R.R. and Costa, P.T. (2003). Personality in adulthood: A five-factor theory perspective. Guilford Press.

9. Carver, C.S., Scheier, M.F. and Segerstrom, S.C. (2010). Optimism. Clin Psychol Rev. 30, 879889.

10. Karsten, J., Penninx, B.W.J.H., Riese, H., Ormel, J., Nolen, W.A. and Hartman, C.A. (2012). The state effect of depressive and anxiety disorders on big five personality traits. J Psychiatr Res. 46, 644-650.

11. Kurtz, J.E., Putnam, S.H. and Stone, C. (1998). Stability of Normal Personality Traits after Traumatic Brain Injury. J Head Trauma Rehabil. 13, 1-14.

12. Leonhardt, A., Schmukle, S. and Exner, C. (2016). Evidence of Big-Five personality changes following acquired brain injury from a prospective longitudinal investigation. J Psychosom Res. 82, $17-23$. 
13. Nielsen, M.B. and Knardahl, S. (2014). Coping strategies: A prospective study of patterns, stability, and relationships with psychological distress. Scand J Psychol. 55, 142-150.

14. Chopik, W.J., Kim, E.S. and Smith, J. (2015). Changes in Optimism Are Associated With Changes in Health Over Time Among Older Adults. Soc Psychol Personal Sci. 6, 814-822.

15. Lannoo, E., De Deyne, C., Colardyn, F., De Soete, G. and Jannes, C. (1997). Personality change following head injury: Assessment with the neo five-factor inventory. J Psychosom Res. 43, 505511.

16. Sabariego, C., Barrera, A.E., Neubert, S., Stier-Jarmer, M., Bostan, C. and Cieza, A. (2013). Evaluation of an ICF-based patient education programme for stroke patients: A randomized, single-blinded, controlled, multicentre trial of the effects on self-efficacy, life satisfaction and functioning. Br J Health Psychol. 18, 707-728.

17. Scheenen, M.E., van der Horn, H.J., de Koning, M.E., van der Naalt, J. and Spikman, J.M. (2017). Stability of coping and the role of self-efficacy in the first year following mild traumatic brain injury. Soc Sci Med. 181, 184-190.

18. King, R.B., Shade-Zeldow, Y., Carlson, C.E., Feldman, J.L. and Philip, M. (2002). Adaptation to Stroke: A Longitudinal Study of Depressive Symptoms, Physical Health, and Coping Process. Top Stroke Rehabil. 9, 46-66.

19. Wolters Gregório, G., Brands, I., Stapert, S., Verhey, F.R. and van Heugten, C.M. (2014). Assessments of Coping After Acquired Brain Injury. J Head Trauma Rehabil. 29, E30-E42. 20. van Mierlo, M.L., van Heugten, C.M., Post, M.W.M., Lindeman, E., de Kort, P.L.M. and VisserMeily, J.M.A. (2014). A Longitudinal Cohort Study on Quality of Life in Stroke Patients and Their Partners: Restore4Stroke Cohort. Int J Stroke. 9, 148-154.

21. Bode, C., Thoolen, B. and de Ridder, D. (2008). Measuring proactive coping. Psychometric characteristics of the Utrecht Proactive Coping Competence scale (UPCC). Psychologie \& Gezondheid. 36, 81-91.

22. Leganger, A., Kraft, P. and Røysamb, E. (2000). Perceived self-efficacy in health behaviour research: Conceptualisation, measurement and correlates. Psychology \& Health. 15, 51-69.

23. Sanderman, R., Arrindell, W. and Ranchor, A. (2012). Het meten van

persoonlijkheidskenmerken met de Eysenck Personality Questionnaire (EPQ): Een handleiding. 2nd ed. ed. UMCG / Rijksuniversiteit Groningen, Research Institute SHARE.

24. Scheier, M.F., Carver, C.S. and Bridges, M.W. (1994). Distinguishing optimism from neuroticism (and trait anxiety, self-mastery, and self-esteem): A reevaluation of the Life Orientation Test. J Pers Soc Psychol. 67, 1063-1078.

25. Turner, H., Bryant-Waugh, R., Peveler, R. and Bucks, R.S. (2012). A Psychometric Evaluation of an English Version of the Utrecht Coping List. Eur Eat Disord Rev. 20, 339-342.

26. Norman, G.R., Sloan, J.A. and Wyrwich, K.W. (2003). Interpretation of Changes in Healthrelated Quality of Life. Med Care. 41, 582-592.

27. Glass, G.V. (1976). Primary, Secondary, and Meta-Analysis of Research. Educ Res. 5, 3.

28. Evans, J.D. (1996). Straightforward Statistics for the Behavioral Sciences. Brooks/Cole Publishing Company. 
29. Osborne, J.W. and Costello, A.B. (2009). Best practices in exploratory factor analysis: four recommendations for getting the most from your analysis. Pan-Pacific Management Review. 12 , 131-146.

30. Ayerbe, L., Ayis, S., Wolfe, C.D.A. and Rudd, A.G. (2013). Natural history, predictors and outcomes of depression after stroke: systematic review and meta-analysis. Br J Psychiatry. 202, 14-21.

31. Eskes, G.A., Lanctôt, K.L., Herrmann, N., Lindsay, P., Bayley, M., Bouvier, L., Dawson, D., Egi, S., Gilchrist, E., Green, T., Gubitz, G., Hill, M.D., Hopper, T., Khan, A., King, A., Kirton, A., Moorhouse, P., Smith, E.E., Green, J., Foley, N., Salter, K. and Swartz, R.H. (2015). Canadian Stroke Best Practice Recommendations: Mood, Cognition and Fatigue following Stroke Practice Guidelines, Update 2015. Int J Stroke. 10, 1130-1140.

32. Wu, S., Mead, G., Macleod, M. and Chalder, T. (2015). Model of Understanding Fatigue After Stroke. Stroke. 46, 893-898.

33. Sherry, S.B., Mackinnon, S.P., Macneil, M.A. and Fitzpatrick, S. (2013). Discrepancies confer vulnerability to depressive symptoms: A three-wave longitudinal study. J Couns Psychol. 60, 112126.

34. Moulaert, V., Wachelder, E.M., Verbunt, J.A., Wade, D.T. and van Heugten, C.M. (2010). Determinants of quality of life in survivors of cardiac arrest. J Rehabil Med. 42, 553-558.

35. Jokela, M., Hakulinen, C., Singh-Manoux, A. and Kivimäki, M. (2014). Personality change associated with chronic diseases: pooled analysis of four prospective cohort studies. Psychol Med. 44, 2629-2640.

36. Hildebrand, M.W. (2014). Effectiveness of Interventions for Adults With Psychological or Emotional Impairment After Stroke: An Evidence-Based Review. Am J Occup Ther. 69, 6901180050p6901180051.

37. Jones, F. and Riazi, A. (2010). Self-efficacy and self-management after stroke: a systematic review. Disabil and Rehabil. 33, 797-810.

38. Mehta, S., Pereira, S., Janzen, S., Mclntyre, A., McClure, A. and Teasell, R.W. (2012).

Effectiveness of Psychological Interventions in Chronic Stage of Stroke: A Systematic Review. Top Stroke Rehabil. 19, 536-544.

39. Stalder-Lüthy, F., Messerli-Bürgy, N., Hofer, H., Frischknecht, E., Znoj, H. and Barth, J. (2013). Effect of Psychological Interventions on Depressive Symptoms in Long-Term Rehabilitation After an Acquired Brain Injury: A Systematic Review and Meta-Analysis. Arch Phys Med Rehabil. 94 , 1386-1397.

40. Visser, M.M., Heijenbrok-Kal, M.H., van't Spijker, A., Lannoo, E., Busschbach, J.J.V. and Ribbers, G.M. (2016). Problem-Solving Therapy During Outpatient Stroke Rehabilitation Improves Coping and Health-Related Quality of Life. Stroke. 47, 135-142. 



\section{Chapter 4}

\section{Does the fear-avoidance model explain persistent symptoms after traumatic brain injury?}

Wijenberg, M. L. M., Stapert, S. Z., Verbunt, J. A., Ponsford, J. L., \& van Heugten, C. M. (2017). Brain injury, 31(12), 1597-1604. doi: $10.1080 / 02699052.2017 .1366551$.
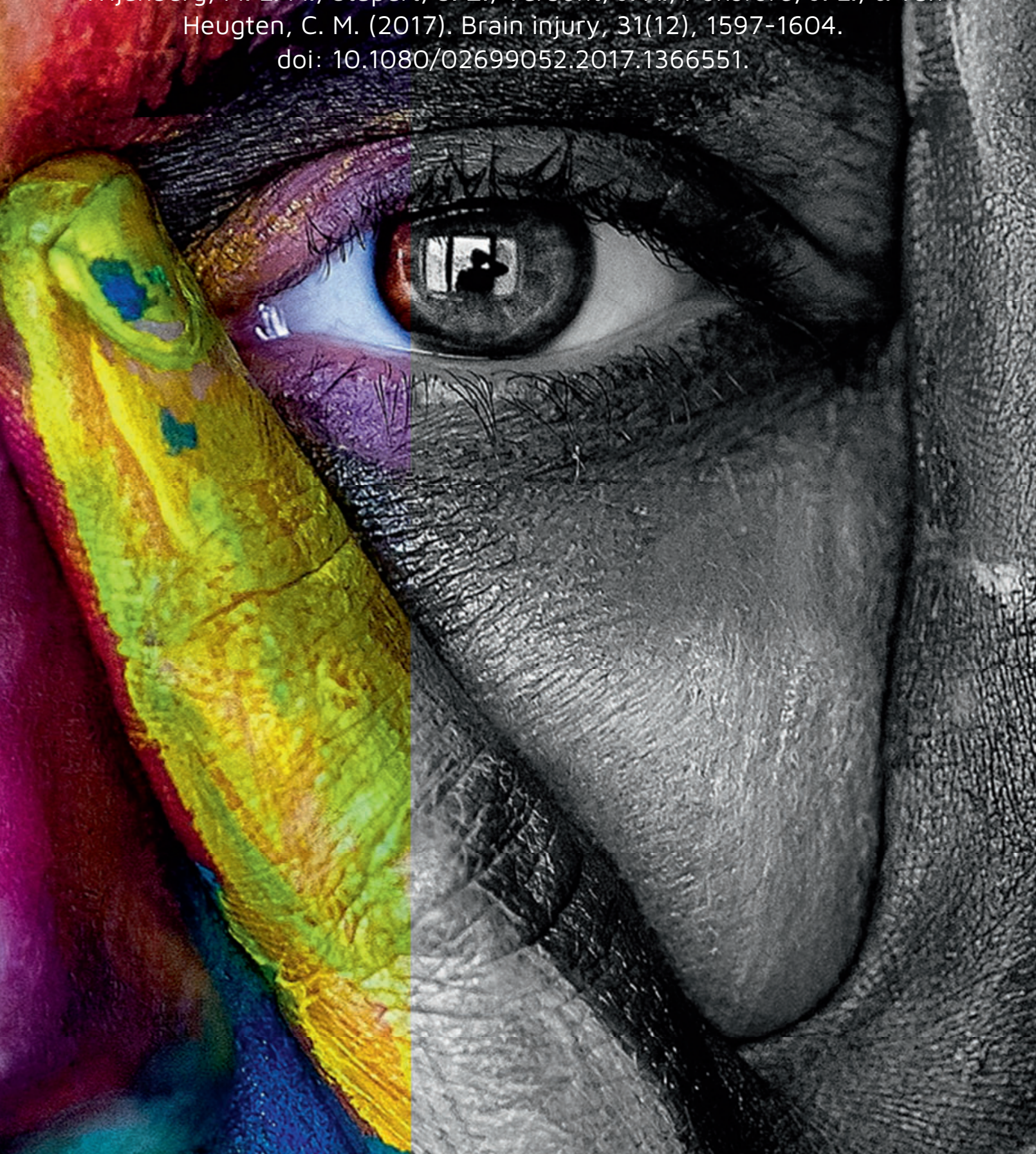


\begin{abstract}
Background. A minority of patients with mild traumatic brain injury (mTBI) experience a persistent symptom complex also known as post-concussion syndrome. Explanations for this syndrome are still lacking.

Objective. To investigate if the fear-avoidance model, including catastrophizing thoughts and fear-avoidance behaviour, poses a possible biopsychosocial explanation for lingering symptoms and delay in recovery after traumatic brain injury (TBI) with special focus on mTBI.
\end{abstract}

Design. Cross sectional study.

Participants. 48 patients with TBI, of which 31 patients with mTBI, had persistent symptoms (mean time since injury 48.2 months); $92 \%$ of the entire sample fulfilled the criteria for post-concussion syndrome.

Outcome variables. Catastrophizing, fear-avoidance, depression and postconcussion symptoms.

Results. High levels of catastrophizing were found in $10 \%$ and high levels of fearavoidance behaviour were found in 35\%. Catastrophizing, fear-avoidance behaviour, depressive symptoms and post-concussion symptoms correlated significantly with each other $(\rho<0.05)$.

Conclusion. The fear-avoidance model proposes a possible explanation for persistent symptoms. Validation and normative data are needed for suitable measures of catastrophizing and fear-avoidance of post-concussion symptoms after TBI. Longitudinal prospective cohort studies are needed to establish its causal and explanatory nature.

Keywords: catastrophizing, chronic phase, fear-avoidance behaviour, persistent symptoms, post concussional syndrome, traumatic brain injury 


\section{Introduction}

Traumatic brain injury (TBI) poses a major global health issue with its high prevalence and subsequently high costs in western society. ${ }^{1}$ The annual costs due to traumatic brain injury are estimated around $€ 33$ billion in Europe. ${ }^{2}$

Approximately $80-90 \%$ of TBls are considered to be mild. ${ }^{3}$ The vast majority of patients with mild traumatic brain injury (mTBI) across different populations (e.g. civilian, military or sports) show a rapid recovery within the first months and do not report any symptoms at three months post injury. ${ }^{4} \mathrm{~A}$ minority of the patient group reports persistent symptoms and experience long term interfering consequences of their mTBI, also known as post-concussion syndrome. The exact size of this minority remains debatable, with reported percentages ranging between 15 and $47 \%$ due to methodological variations across studies and inconsistencies regarding its definition. ${ }^{5-7}$ Finding a possible explanation for the persistence of symptoms has been of interest to many researchers in the last three decades, but no uniform explanation has been found. ${ }^{8,9}$

New and recent advances in brain imaging techniques reveal brain tissue damage in $\mathrm{mTBI}$, mostly vascular microstructural damage, that could not be visualized before. ${ }^{10}$ However, these parameters or other biological explanations do not predict the persistence of symptoms or occurrence of post-concussion syndrome. ${ }^{11}$ Although its name suggests that this symptom complex is specifically seen after concussion, post-concussion syndrome seems not specifically related to mTBI. 6, 12, 13 The nature and extent of this symptom complex is similar in other patient populations such as those with chronic pain syndromes ${ }^{14}$ or following traumas not involving the brain (e.g. after orthopaedic injuries) ${ }^{6,13}$. Moreover, healthy controls report post-concussion like symptoms such as cognitive problems, fatigue and headache. When removing the criterion of a history of $\mathrm{mTBl}$, a comparable prevalence of post-concussion syndrome can be found in healthy controls. ${ }^{15,16}$ These findings suggest that post-concussion syndrome is not brain injury specific; therefore psychological models should also be considered in explaining the development and nature of the post-concussion syndrome.

Regarding psychological causes, the most consistent finding has been that pre-injury mental health status predicts post-concussion syndrome. ${ }^{9}$ Furthermore, early post-injury stress and anxiety levels after mTBI are also indicated as 
predictors of post-concussion syndrome.9. 17 A multi modal explanation including both biological and psychosocial factors has also been suggested, but appears to explain not more than $40 \%$ variance of clinically relevant long term outcomes, such as post-concussion syndrome. ${ }^{9}$ Despite many efforts, an unequivocal explanation as to why this minority of patients experiences persistent symptoms indicative of post-concussion syndrome is still lacking. Silverberg et al. ${ }^{9}$ have suggested an integrated biopsychosocial approach for future studies on the basis of their systematic review of prognostic models.

A possible biopsychosocial explanation may be found in the fear-avoidance model. This model is well-validated in patients with several bodily distress syndromes including chronic pain ${ }^{18}$, tinnitus ${ }^{19,20}$, cancer survivors ${ }^{21}$, chronic fatigue ${ }^{22}$, fibromyalgia ${ }^{22}$ and fatigue in multiple sclerosis ${ }^{23,24}$. Furthermore, it provides the theoretical underpinnings of effective treatment options in these patient groups, such as graded exposure therapy ${ }^{25}$ or newer generations of cognitive behavioural therapy (CBT) such as mindfulness based $\mathrm{CBT}^{23}$.

Applying this model to post-concussion syndrome, patients with mTBI may (mis)interpret information regarding the damage to their brain and its immediate consequences in a catastrophic way, which results in increasing anxiety and avoidance behaviour over time. According to the fear-avoidance model, symptoms are wrongly interpreted as a sign of serious injury or disease over which one experiences little or no control. It is proposed that such misinterpretation of symptoms typically leads to a disproportional fear of symptoms and injury that develops over time into a disabling fear of experiencing symptoms such that people will avoid those activities that are presumed to worsen their problem. ${ }^{26}$ Although avoidance behaviour may be adaptive in the acute phase, it can contribute to disuse, disability and depression which paradoxically worsen the symptoms in later stages. ${ }^{27}$ In sum, this model suggests that it is not necessarily the severity of the injury, but rather a disease process of extended catastrophic thinking about the initial symptoms and fear-avoidance behaviour initiated by a biological injury that will explain in a time dependent manner the persistence of symptoms and the level of disability.

The fear-avoidance model has been postulated as a possible explanation for persistent symptoms in mTBI already over two decades ago by Kay et al. ${ }^{28}$. 
They proposed the combination of two fear-avoidance cycles - one regarding the pain (i.e. headache) experience as previously validated in patients with pain and one regarding the cognitive symptoms. According to the cognitive fear-avoidance cycle, the cognitive symptoms are erroneously interpreted as a sign of pathology over which one has little or no control. Such catastrophizing could extend to fear and avoidance of mental activities, also known as cogniphobia ${ }^{23,24}$, which subsequently decreases activity levels and may result in disuse, disability and depression. This could then increase the amount of cognitive failures, concluding its cyclic pattern, as suggested by Todd et al. ${ }^{29}$ and Martelli et al. ${ }^{30}$.

This combined pain/cognition-related fear-avoidance model has not been tested empirically, although it is consistent with the current literature in several ways. Dean et al. ${ }^{13}$ stated that headache and cognitive complaints are the most specific symptoms of the post-concussion symptoms following mTBI. The combined fear-avoidance model targets these symptoms specifically. In support of this, Khoury et al. ${ }^{31}$ and Broomhall et al. ${ }^{5}$ found respectively that catastrophizing about pain and fear-avoidance symptoms was significantly greater in patients with $\mathrm{TBI}$ in comparison to healthy or trauma controls. Moreover, multiple studies have shown that the fear-avoidance model explained the pain experience of patients with whiplash disorders. ${ }^{32,}{ }^{33}$ Furthermore, Schmidt ${ }^{34}$ showed higher levels of fear-avoidance regarding mental work in adults with chronic work-related stress compared to actively working employees. Despite these findings, to our knowledge the fear-avoidance model has never been empirically examined as a possible explanation for post-concussion syndrome in patients with mTBI.

Therefore this study examined the prevalence of catastrophizing thoughts and fear-avoidance behaviour in patients with persistent symptoms after TBI. In order to investigate whether the fear-avoidance model provides a possible explanation for post-concussion syndrome, the relationships between postconcussion symptoms, catastrophizing thoughts and fear-avoidance beliefs after TBI were examined. Separate analyses were performed on a subgroup of patients with mTBI because a biopsychosocial approach is proposed to be of special importance in explaining persistent symptoms after mTBI. ${ }^{9,12}$ 


\section{Methods}

\section{Participants}

Participants were recruited at the Zuyderland Medical Centre, Sittard-Geleen, the Netherlands. Inclusion criteria were incidence of TBI and fluent in Dutch. TBI was defined according to WHO criteria as an acute brain injury resulting from external mechanical force to the head. ${ }^{35}$ Patients with TBI who had received multidisciplinary treatment at the rehabilitation centre Zuyderland, Sittard-Geleen $(\mathrm{NL})$ in the period 2009 till 2012 were asked to participate. If they were willing to participate, they were sent an information letter, an informed consent form and questionnaires in 2013. In the period 2013 - 2016 patients with TBI who were receiving a multidisciplinary neuropsychological rehabilitation treatment for persistent symptoms were approached by their treating neuropsychologist for inclusion. These patients received the questionnaires as part of regular care and were asked for their permission to use this data for research purposes. Depending on the complaints, patients were referred by their rehabilitation physician to one or more of the following disciplines; physiotherapy, social work, medical psychology or occupational therapy. Recruitment into the study was carried out at least 3 months after the injury to ensure presence of persistent symptoms.

\section{Compliance with ethical standards}

All procedures were approved by and in accordance with the ethical standard of the medical ethics committee of Zuyderland Medical Centre, the Medical Review Ethics Committee of Maastricht University and the 1964 Helsinki declaration and its later amendments. Informed consent was obtained from all participants included in the study. Patients did not receive any financial compensation for their participation.

\section{Measures}

Basic demographic information. Personal characteristics including age, gender, level of education and current and premorbid employment status were retrieved from the hospital database. The level of education was based on the highest completed level of education and divided according to the 7 point Verhage classification. ${ }^{36}$ Medical data such as time since injury, cause of injury, severity of 
injury, presence of abnormal findings on available CT and/or MRI scans, total duration of multidisciplinary treatment received and presence of cognitive disorders when a neuropsychological assessment was available, were also retrieved from the hospital database. Causes of injury were categorized into 'traffic accidents', 'sport', 'violence' and 'falls'. Severity of TBI was classified as 'mild' or 'moderate to severe' and based on criteria developed by the WHO collaboration centre task force on mTBI. These stated that mTBI is identified by at least one of the following characteristics: a Glasgow Coma Scale (GCS) score of 13 to 15, a maximum duration of post-traumatic amnesia of 24 hours and a loss of consciousness up to 30 minutes. ${ }^{37}$ These variables were extracted from the hospital database. If none of these variables were available, the severity rating based on clinical judgement of the treating neurologist or rehabilitation physician was used.

Catastrophizing. Catastrophizing about post-concussion symptoms was assessed with the Post-Concussion Symptoms Catastrophizing Scale (PCS-CS), which is an adaptation of the Dutch translation of the Pain Catastrophizing Scale (PCS). ${ }^{38,} 39$ The PCS has adequate psychometric properties ${ }^{40}$ and is validated in acute and chronic whiplash disorders ${ }^{41-43}$ and used in patients with mTBI by Khoury et al. ${ }^{31}$. It consists of 13 items measuring the self-reported frequency of catastrophizing thoughts about the experienced pain with a 5 point Likert scale. The PCS was adapted by replacing the word 'pain' with common post-concussion symptoms in all items: 'headaches, dizziness, fatigue, memory and concentration problems'. The score ranges from 0 and 52, with higher scores indicating a higher intensity of catastrophizing. A score of 30 or higher can be used for identifying a high level of catastrophizing thoughts based on patients with pain and represents the $75^{\text {th }}$ percentile according to the manual. ${ }^{39}$ According to Severeijns et al. ${ }^{44}$ this score represents a Z-score of at least 1.5 in several pain populations within a community setting. A score of 23 or higher corresponds to the $50^{\text {th }}$ percentile and has also been used in the literature to indicate an above average level of catastrophizing. ${ }^{45}$ To our knowledge, no cut-off scores for patients with TBI specifically are available. Internal consistency of the PCS-CS was excellent in this sample (Cronbach's alpha $=0.94$ ). 
Fear-avoidance. Concussion-related fear-avoidance behaviour was assessed with an adapted version of the valid and reliable Dutch version of Tampa Scale for Kinesiophobia (TSK) ${ }^{46,47}$, called the Fear of Mental Activity scale (FMA). The TSK was adapted by replacing the word 'pain' with common post-concussion symptoms in all items: 'headaches, dizziness, fatigue, memory and concentration problems'. Additionally, items were adjusted to make them suitable for mTBI, e.g. 'My head tells me there is something dangerously wrong', instead of 'My body tells me there is something dangerously wrong'. It consists of 17 items and the score ranges from 17 to 68 with a score higher than 37 indicating an above average and according to the manual a high level of fear-avoidance behaviour in patients with pain. ${ }^{48,49}$ Using a more conservative cut-off equivalent to the $75^{\text {th }}$ percentile, a score higher than 48 indicates a high level of fear-avoidance behaviour. ${ }^{50}$ To our knowledge, no cut-off scores for patients with TBI specifically are available. Internal consistency of the FMA was good in this sample (Cronbach's alpha = 0.80).

Depressive symptoms. Depressive symptoms were assessed with the subscale depression of the Dutch version of the Hospital Anxiety and Depression Scale (HADS). ${ }^{51}$ It is a valid and reliable measure for screening depression in patients with TBI. ${ }^{52}$ The score ranges from 0 to 21 with a higher score indicating a higher intensity of depressive symptoms. Whelan-Goodinson et al. ${ }^{52}$ showed that a score of 8 or higher is an indication for depression in patients with TBI, which is in line with findings of a large review in the general population of Crawford et al. ${ }^{53}$.

Post-concussion symptoms. Post-concussion symptoms were assessed with the Dutch version of the Rivermead Post-Concussion Symptoms Questionnaire (RPQ) developed by King et al. ${ }^{54}$. The RPQ is commonly used to assess the severity of symptoms after mild or moderate TBI. ${ }^{55}$ It consists of 16 items assessing severity of symptoms in the last 24 hours in comparison to premorbid levels. It is a valid and reliable measure in TBI. ${ }^{55}$ The total score ranges from 0 to 64 . Report of three or more remaining symptoms, indicated by an item score of two or higher, was used as criterion for post-concussion syndrome. The same criterion has been used in previous research. ${ }^{56-60}$ 


\section{Statistical analyses}

Data analyses were performed using SPSS Statistics 22.0 for Windows (IBM Corp., Armonk, NY). If $\leq 25 \%$ of the items of the questionnaires were missing, the mean of the remaining non-missing items of the scale were imputed. If more than $25 \%$ of the items were missing, no imputation took place and the total score was included as missing value in subsequent analyses. Sample characteristics are described by descriptive statistics. No outcome variable was significantly skewed nor were there any significant outliers (the confidence interval of skewness and kurtosis included zero). Pearson's $\chi^{2}$ tests or independent sample $t$ tests were performed to analyse differences for all patient characteristics and within the RPQ between the two severity groups; 'mild' and 'moderate to severe'. Pearson correlation coefficients were calculated to show relationships between the variables constituting the fear-avoidance model; PCS-CS score, HADS score, FMA score and RPQ total score. These correlations were compared between the two severity groups: 'mild' and 'moderate to severe' after Fisher's Z transformation. For all statistical tests an alpha level of 0.05 was used.

\section{Results}

\section{Patient sample}

A total of 93 Dutch-speaking patients with TBI were approached and 48 patients were willing to participate (52\%). Our sample included 23 men and 25 women with a mean age of 45.5 years ( $S D=15.6$, range $16-78$ ). In most cases TBI was caused by traffic accidents (45.8\%). The sample consisted of $31 \mathrm{mTBI}$ cases and 17 moderate to severe TBI cases. The mean time since injury was 48.2 months ( $S D=$ 60.9 , range 2 - 373) and the patients received on average a total of 7.4 months multidisciplinary treatment for persistent symptoms. One patient with mTBI was assessed in the third month after his/her injury. All other patients were assessed after at least 3 months. Regarding work status, the percentage of participants working more than 24 hours/week before their TBI decreased from 59.4 to 24.3 at the moment of inclusion. See Table 1 for patient characteristics of the entire sample and the mTBI cases. Sample size deviations are the result of missing data in the hospital database. Except for gender, there were no significant differences found between the two severity groups on patient characteristics. The mTBI group 
had significantly more women than the more severe TBI group ( $\chi=5.42 ; \rho<$ 0.02).

Table 1. Patient characteristics

\begin{tabular}{|c|c|c|c|c|c|c|c|c|c|}
\hline \multirow[b]{2}{*}{ Variables } & \multicolumn{3}{|c|}{$\mathrm{TBI}(n=48)$} & \multicolumn{3}{|c|}{$\mathrm{mTBI}(n=31)$} & \multicolumn{3}{|c|}{$\begin{array}{l}\text { Moderate to severe } \\
\text { TBI }(n=17)\end{array}$} \\
\hline & $n$ & Value & $\begin{array}{l}\text { Data } \\
\text { range }\end{array}$ & $n$ & Value & $\begin{array}{l}\text { Data } \\
\text { range }\end{array}$ & $N$ & Value & $\begin{array}{l}\text { Data } \\
\text { range }\end{array}$ \\
\hline Gender, \% male & & 47.9 & & & 35.5 & & & $70.9^{*}$ & \\
\hline Age in years, mean (SD) & & $\begin{array}{l}45.5 \\
(15.6)\end{array}$ & {$[16-78]$} & & $\begin{array}{l}46.3 \\
(14.1)\end{array}$ & {$[16-78]$} & & 44.2 & {$[20-76]$} \\
\hline $\begin{array}{l}\text { Education level, mean } \\
\text { (SD) }\end{array}$ & 46 & $\begin{array}{l}5.4 \\
(1.0)\end{array}$ & {$[3-7]$} & 30 & $\begin{array}{l}5.5 \\
(0.9)\end{array}$ & {$[4-7]$} & 16 & $\begin{array}{l}5.1 \\
(1.0)\end{array}$ & {$[3-7]$} \\
\hline Premorbid work status & 37 & & & 28 & & & 9 & & \\
\hline$\%>24 h$ paid work & & 59.4 & & & 67.9 & & & 33.3 & \\
\hline$\% \leq 24 \mathrm{~h}$ paid work & & 10.8 & & & 10.7 & & & 11.1 & \\
\hline$\%$ no paid work & & 29.7 & & & 21.4 & & & 55.6 & \\
\hline Current work status & 37 & & & 28 & & & 9 & & \\
\hline$\%>24 h$ paid work & & 24.3 & & & 28.6 & & & 11.1 & \\
\hline$\% \leq 24$ paid work & & 32.4 & & & 32.2 & & & 33.3 & \\
\hline$\%$ no paid work & & 43.2 & & & 39.3 & & & 55.6 & \\
\hline $\begin{array}{l}\text { Time since injury in } \\
\text { months, median (IQR) }\end{array}$ & & $\begin{array}{l}34.0 \\
(53)\end{array}$ & {$[2-373]$} & & $\begin{array}{l}30.0 \\
(45)\end{array}$ & {$[2-126]$} & & $\begin{array}{l}52.0 \\
(56)\end{array}$ & [4-373] \\
\hline Cause of injury & & & & & & & & & \\
\hline Traffic accidents, \% & & 45.8 & & & 45.2 & & & 47.2 & \\
\hline Sport, \% & & 14.7 & & & 16.2 & & & 11.8 & \\
\hline Violence, \% & & 10.4 & & & 6.5 & & & 17.6 & \\
\hline Falls, \% & & 29.2 & & & 32.3 & & & 23.5 & \\
\hline Cognitive disorders $\%$ yes & 31 & 80.6 & & 17 & 76.5 & & 14 & 85.7 & \\
\hline $\begin{array}{l}\text { Duration multidisciplinary } \\
\text { treatment in months, } \\
\text { mean (SD) or median } \\
(I Q R) \text { in case of skewness }\end{array}$ & & $\begin{array}{l}5.0 \\
(10)\end{array}$ & {$[0-32]$} & & $\begin{array}{l}5.0 \\
\text { (9) }\end{array}$ & {$[0-32]$} & & $\begin{array}{l}8.5 \\
(8.2)\end{array}$ & {$[0-26]$} \\
\hline
\end{tabular}

Notes. IQR Interquartile Range. The mTBI group forms a subgroup of the TBI group. The TBI group consists of 48 patients, of which 31 are considered mild. If applicable, sample size deviations due to missing data are mentioned separately. Significant differences between 'mild' and 'moderate to severe' TBI group are marked. ${ }^{*} \rho<0.05$.

\section{Frequency of post-concussion syndrome, depression, catastrophizing and fear-avoidance behaviour}

Table 2 shows the prevalence of post-concussion symptoms in the entire sample and in mTBI cases specifically. Significant differences between the 'mild' and 'moderate to severe' group are also indicated. On the items where significant differences were found, the proportion of patients who were experiencing the symptom was higher in the mild group compared to the more severely injured group. Independent of severity, cognitive problems (memory/concentration/mental slowness) and fatigue were part of the most reported symptoms. Respectively $85.4 \%$ of the entire sample and $93.5 \%$ of the 
mTBI sample reported fatigue. Frequencies of cognitive problems varied for the entire and mTBI sample in the range of $81.3 \%-91.7 \%$ and $87.1 \%-93.5 \%$ respectively. Table 3 shows the scores on the PCS-CS, FMA, RPQ and HADS. The mean of the RPQ was 30.6. A total of $92 \%$ of the patients fulfilled the criterion of post-concussion syndrome (having three or more post-concussion symptoms).

The mean HADS score was 6.5. A total of $42 \%$ reported depressive symptoms at a clinical significant level. Furthermore, the mean PCS-CS score was 16.0. Using 23 as cut-off, $29 \%$ of the entire sample reported above average levels of catastrophizing. Using the more conservative cut-off of 30 as suggested by the scoring manual, $10 \%$ of the entire sample reported heightened levels of catastrophizing. The mean FMA score was 35.5. Using 37 as cut-off as suggested by the scoring manual, $35 \%$ of the entire sample reported above average levels of catastrophizing or fear-avoidance behaviour. Using the more conservative criterion of 48 as cut-off, $4 \%$ of the entire sample reported heightened levels of fear-avoidance behaviour. The frequencies of heightened levels of catastrophizing and fear-avoidance behaviour in the mTBI subsample, using the cut-off scores suggested by the scoring manuals, are shown in Table 3 (\%l).

Table 2. Prevalence of post-concussion symptoms (\%)

\begin{tabular}{llll}
\hline Post-concussion symptom (RPQ) & $\begin{array}{l}\mathrm{TBI} \\
(n=48)\end{array}$ & $\begin{array}{l}\mathrm{mTBI} \\
(n=31)\end{array}$ & $\begin{array}{l}\text { Moderate to severe TBI } \\
(n=17)\end{array}$ \\
\hline Headaches & 64.6 & 77.4 & $41.2^{*}$ \\
Dizziness & 58.3 & 61.3 & 52.9 \\
Nausea & 25.0 & 38.7 & $0.0^{* *}$ \\
Increased sensitivity to noise & 70.8 & $80.6^{5}$ & $52.9^{*}$ \\
Sleep disturbances & 54.2 & 54.8 & 52.9 \\
Fatigue & $85.4^{2}$ & $93.5^{1,2,3}$ & $70.6^{4,5^{*}}$ \\
Irritability & $77.1^{5}$ & 77.4 & $76.5^{2,3}$ \\
Feeling depressed/teary-eyed & 62.5 & 64.5 & 58.8 \\
Feeling impatient or frustrated & 75.0 & 74.2 & $76.5^{2,3}$ \\
Forgetfulness & $83.3^{3}$ & $93.5^{1,2,3}$ & $64.7^{*}$ \\
Reduced ability to concentrate & $91.7^{1}$ & $93.5^{1,2,3}$ & $88.2^{1}$ \\
Slowing of thought processes & $81.3^{4}$ & $87.1^{4}$ & $70.6^{4,5}$ \\
Blurred vision & 29.2 & 29.0 & 29.4 \\
Increased sensitivity to light & 39.6 & 51.6 & $17.6^{*}$ \\
Double vision & 18.8 & 19.4 & 17.6 \\
Feeling agitated/restless & 58.3 & 61.3 & 52.9 \\
\hline
\end{tabular}

Notes. RPQ Rivermead Post-Concussion Symptoms questionnaire. Top 5 ranking of most reported symptoms is provided in superscript. Significant differences in proportion between patients with 'mild' and 'moderate to severe' TBI are marked. ${ }^{*} \rho<0.05,{ }^{* *} \rho<0.01$. 


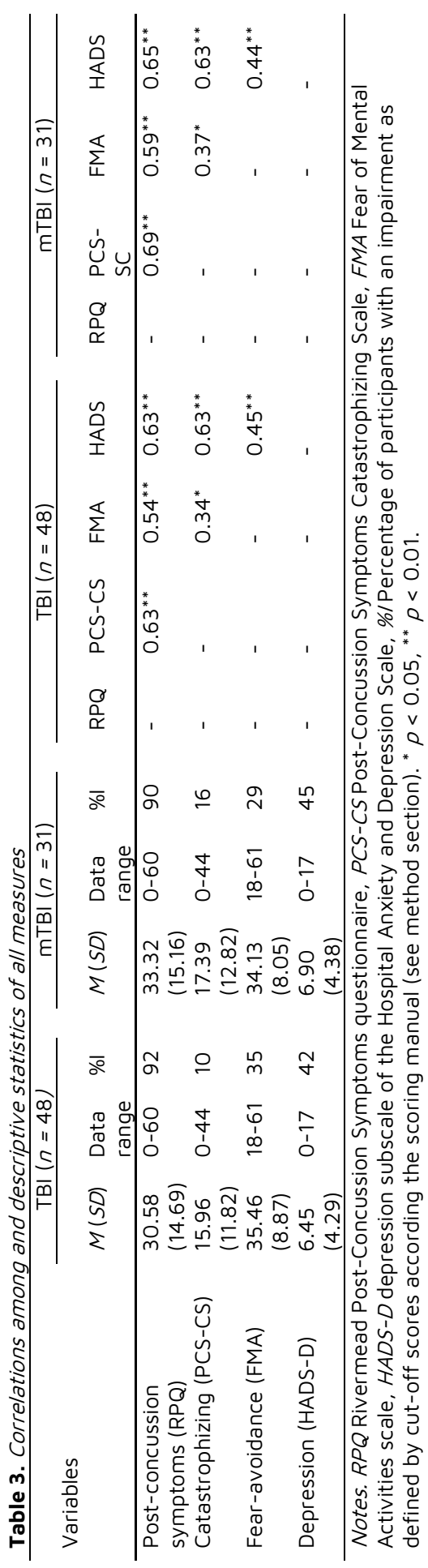




\section{Relationships between the variables in the FA model}

All measures were significantly correlated with each other $(\rho<0.05)$. The strongest association was seen between post-concussion symptoms and catastrophizing about these symptoms $(r=0.63$ in the entire sample and $r=0.69$ in the mTBI sample). See Figure 1 and 2 for a graphical presentation of the fearavoidance model in the entire sample and mTBI subsample respectively. As can been seen in Table 3, the correlations between post-concussion symptoms versus depression and catastrophizing are slightly higher in the mTBI subsample than in the entire sample. However, no significant differences were found between the 'mild' and 'moderate to severe' TBI group ( $\rho>0.05$ ).

Figure 1. Fear-avoidance model in patients with $T B I(n=48)$

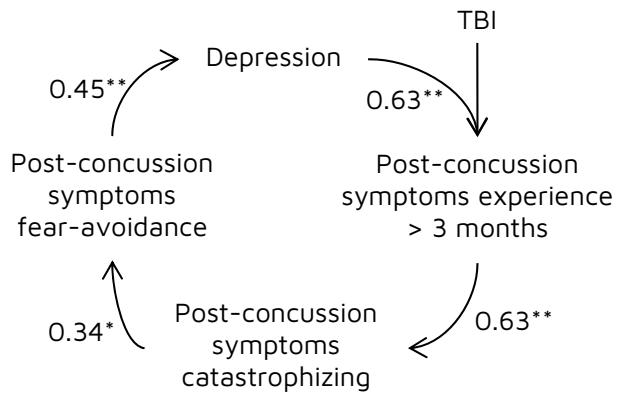

Notes. Values shown are Pearson correlations and based on cross-sectional data.

${ }^{*} \rho<0.05,{ }^{* *} \rho<0.01$.

Figure 2. Fear-avoidance model in patients with $m T B l$, a sub-group $(n=31)$

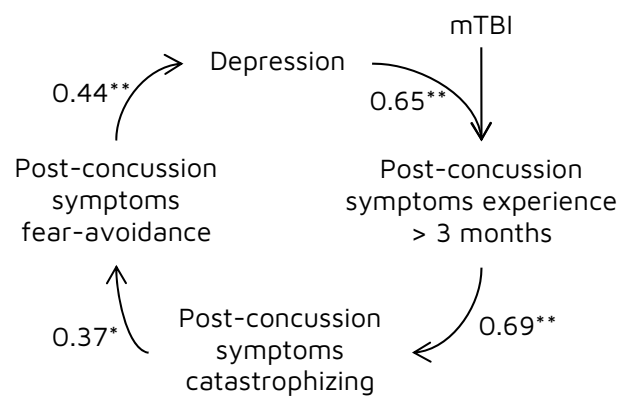

Notes. Values shown are Pearson correlations and based on cross-sectional data. ${ }^{* *} \rho<0.01$. 


\section{Discussion}

This study investigated in a group of TBI out-patients whether the fear-avoidance model is able to explain persistent symptoms in patients with TBI. It was hypothesized that this model would be of special importance for mTBI due to its integrative biopsychosocial nature whereas unimodal biological and/or psychological explanations lack the explanatory value needed for this 'miserable minority'61.

The results showed low levels of catastrophizing and fear-avoidance behaviour regarding post-concussion symptoms in comparison to pain experiences in several bodily distress syndromes, such as chronic pain and fibromyalgia. ${ }^{39,45,47,}$

50 Despite these low levels, all correlations suggested by the fear-avoidance model regarding post-concussion symptom experience were significant. The correlations between post-concussion symptoms versus catastrophizing and depression were slightly higher in the mTBI subgroup. These findings provide a preliminary indication that the fear-avoidance model has explanatory value in accounting for persistency of symptoms.

Despite the promising significant correlations within the fear-avoidance model, the levels of catastrophizing and fear-avoidance were relatively low. This discrepancy could suggest that the cut-off values used to classify patients with TBI as 'high catastrophizing' or 'highly fear-avoidant' in this study lacked sensitivity due to the scale adaptations made for this study. The PCS-CS was adapted by replacing the word 'pain' with 'headaches, dizziness, fatigue, memory and concentration problems'. Although unlikely given the high frequency of symptom reports, these post-concussion symptoms may not represent the symptom complex experienced by the patient resulting in lower levels reported. Another more plausible explanation could be that the question format, whereby multiple symptoms were included in a single item, makes it difficult to understand and interpret the question. The FMA was adapted in two different ways. We have changed the experienced symptom of pain into post-concussion symptoms. Furthermore, we asked about fear-avoidance behaviour regarding 'cogniphobia' in contrast to its original construct 'kinesiophobia'. These changes may have influenced levels of reporting and the use of the cut-off validated with the original measures in different populations may therefore have limited validity in our 
sample. Furthermore, our sample already received on average more than 7 months of neuropsychological rehabilitation treatment, which may have lowered their levels of catastrophizing or fear-avoidance. Moreover, lower frequency reports could also be the result of applicability of the fear-avoidance model to only a subgroup of clinically relevant size of the miserable minority and aiding individual tailored care.

To our knowledge, this is the first study of catastrophizing and fearavoidance behaviour with regard to post-concussion symptoms, which makes it impossible to compare levels of catastrophizing or fear-avoidance behaviour with other studies. Some studies, including other patient populations or non-patient populations, have found confirmatory results for the fear-avoidance model or its components with regard to pain and kinesiophobia or cogniphobia. 5, 31, 34, 62, 63 Other patient studies have looked at catastrophizing about pain in $\mathrm{mTB}^{31,62}$, the presence of a symptom of fear-avoidance in $\mathrm{mTBl}^{5}$ and the levels of catastrophizing and fear-avoidance with regard to pain and kinesiophobia in patients with whiplash disorders ${ }^{33,64}$. In non-patient populations the level of fearavoidance regarding chronic stress symptoms and cogniphobia ${ }^{34}$ and the level of catastrophizing and fear-avoidance regarding headache and cogniphobia have been studied ${ }^{63}$.

Another finding that may seem remarkable is that the prevalence of postconcussion symptoms is equal or higher in the mTBI group compared to the moderate to severe TBI group. Previous studies have reported mixed findings regarding the number of complaints and injury severity. Some studies found similar results demonstrating equal or higher levels of complaints in patients with mTBI compared to patients with moderate to severe TBI on the one hand. ${ }^{65,66}$ On the other hand, van der Horn et al. ${ }^{67}$ found increasing symptom reporting with increasing brain injury severity. Belanger et al. ${ }^{65}$ mentioned that their group differences disappeared when controlling for post-traumatic stress complaints. These inconsistent results show that a biological explanation on its own, such as injury severity, is not sufficiently able to explain persistence of symptoms ${ }^{11}$ and highlight the need for a biopsychosocial explanation ${ }^{9}$, such as the currently investigated fear-avoidance model. 
Our findings have to be interpreted with caution as this was a crosssectional exploratory study with a relatively small sample size and a heterogeneous cohort. We have included one patient who was assessed in the third month after the injury. However, on average participants were assessed 48.2 months after their injury. Because we were interested in whether the fearavoidance model would apply to patients with post-concussion syndrome specifically, the current sample, which consisted almost entirely of patients with post-concussion syndrome, was highly suitable for evaluating this specific research question. A selection bias and inclusion of a heterogeneous group of participants in different stages of their recovery or disease process should also be taken into account. A large longitudinal cohort study is needed to establish the evolution of catastrophizing thoughts and fear-avoidance behaviour and their time dependent role regarding post-concussion syndrome.

Despite these considerations and the exploratory nature of this study, the results do provide preliminary evidence that the fear-avoidance model may have added value in explaining persistency of symptoms, especially after mTBI. Prospective longitudinal studies are needed to confirm this preliminary evidence. Furthermore, to assess catastrophizing thoughts and fear-avoidance behaviour with the existing questionnaires in the mTBI patient population, we suggest a validation study for these measurements with a simplified administration which matches the capabilities of and symptoms experienced by the individual patient. Moreover, normative data is needed to establish correct cut-off scores for catastrophizing thoughts and fear-avoidance behaviour regarding post-concussion symptoms. These future directions will unravel the relevance of the biopsychosocial fear-avoidance model in patients with mTBI.

\section{Disclosure statement}

The authors report no conflicts of interest. The authors alone are responsible for the content and writing of the article. 


\section{References}

1. Corrigan, J.D., Selassie, A.W. and Orman, J.A.L. (2010). The epidemiology of traumatic brain injury. The Journal of head trauma rehabilitation. 25, 72-80.

2. Olesen, J., Gustavsson, A., Svensson, M., Wittchen, H.U. and Jönsson, B. (2012). The economic cost of brain disorders in Europe. European journal of neurology. 19, 155-162.

3. Faul, M., Xu, L., Wald, M., Coronado, V. and Dellinger, A.M. (2010). Traumatic brain injury in the United States: national estimates of prevalence and incidence, 2002-2006. Injury Prevention. 16, A268-A268.

4. Levin, H.S. and Diaz-Arrastia, R.R. (2015). Diagnosis, prognosis, and clinical management of mild traumatic brain injury. The Lancet Neurology. 14, 506-517.

5. Broomhall, L.G., Clark, C.R., McFarlane, A.C., O'Donnell, M., Bryant, R., Creamer, M. and Silove,

D. (2009). Early stage assessment and course of acute stress disorder after mild traumatic brain injury. J Nerv Ment Dis. 197, 178-181.

6. Meares, S., Shores, E.A., Taylor, A.J., Batchelor, J., Bryant, R.A., Baguley, I.J., Chapman, J., Gurka, J. and Marosszeky, J.E. (2011). The prospective course of postconcussion syndrome: the role of mild traumatic brain injury. Neuropsychology. 25, 454.

7. Wood, R.L. (2007). Post concussional syndrome: all in the minds eye! J Neurol Neurosurg Psychiatry. 78, 552.

8. Ruff, R.M. (2005). Two decades of advances in understanding of mild traumatic brain injury. The Journal of head trauma rehabilitation. 20, 5-18.

9. Silverberg, N.D., Gardner, A.J., Brubacher, J.R., Panenka, W.J., Li, J.J. and Iverson, G.L. (2015). Systematic review of multivariable prognostic models for mild traumatic brain injury. Journal of neurotrauma. 32, 517-526.

10. Yuh, E.L., Cooper, S.R., Mukherjee, P., Yue, J.K., Lingsma, H.F., Gordon, W.A., Valadka, A.B., Okonkwo, D.O., Schnyer, D.M. and Vassar, M.J. (2014). Diffusion tensor imaging for outcome prediction in mild traumatic brain injury: a TRACK-TBI study. Journal of neurotrauma. 31, 14571477.

11. Wäljas, M., Iverson, G.L., Lange, R.T., Hakulinen, U., Dastidar, P., Huhtala, H., Liimatainen, S., Hartikainen, K. and Öhman, J. (2015). A prospective biopsychosocial study of the persistent postconcussion symptoms following mild traumatic brain injury. Journal of neurotrauma. 32, 534-547. 12. Broshek, D.K., De Marco, A.P. and Freeman, J.R. (2015). A review of post-concussion syndrome and psychological factors associated with concussion. Brain injury. 29, 228-237.

13. Dean, P.J., O’Neill, D. and Sterr, A. (2012). Post-concussion syndrome: prevalence after mild traumatic brain injury in comparison with a sample without head injury. Brain injury. 26, 14-26. 14. Iverson, G.L. and McCracken, L.M. (1997). 'Postconcussive'symptoms in persons with chronic pain. Brain injury. 11, 783-790.

15. Clarke, L.A., Genat, R.C. and Anderson, J.F. (2012). Long-term cognitive complaint and postconcussive symptoms following mild traumatic brain injury: the role of cognitive and affective factors. Brain injury. 26, 298-307. 
16. Iverson, G.L. and Lange, R.T. (2003). Examination of" postconcussion-like" symptoms in a healthy sample. Applied Neuropsychology. 10, 137-144.

17. Ponsford, J., Cameron, P., Fitzgerald, M., Grant, M. and Mikocka-Walus, A. (2011). Long-term outcomes after uncomplicated mild traumatic brain injury: a comparison with trauma controls. Journal of neurotrauma. 28, 937-946.

18. Vlaeyen, J.W. and Linton, S.J. (2012). Fear-avoidance model of chronic musculoskeletal pain: 12 years on. Pain. 153, 1144-1147.

19. Cima, R.F., Crombez, G. and Vlaeyen, J.W. (2011). Catastrophizing and fear of tinnitus predict quality of life in patients with chronic tinnitus. Ear and hearing. 32, 634-641.

20. Kleinstäuber, M., Jasper, K., Schweda, I., Hiller, W., Andersson, G. and Weise, C. (2013). The role of fear-avoidance cognitions and behaviors in patients with chronic tinnitus. Cognitive behaviour therapy. 42, 84-99.

21. Velthuis, M.J., Peeters, P.H., Gijsen, B.C., van den Berg, J.-P., Koppejan-Rensenbrink, R.A., Vlaeyen, J.W. and May, A.M. (2012). Role of fear of movement in cancer survivors participating in a rehabilitation program: a longitudinal cohort study. Archives of physical medicine and rehabilitation. 93, 332-338.

22. Nijs, J., Roussel, N., Van Oosterwijck, J., De Kooning, M., Ickmans, K., Struyf, F., Meeus, M. and Lundberg, M. (2013). Fear of movement and avoidance behaviour toward physical activity in chronic-fatigue syndrome and fibromyalgia: state of the art and implications for clinical practice. Clinical Rheumatology. 32, 1121-1129.

23. Wijenberg, M.L.M., Stapert, S.Z., Köhler, S. and Bol, Y. (2016). Explaining fatigue in multiple sclerosis: cross-validation of a biopsychosocial model. Journal of behavioral medicine. 39, 815-822. 24. Bol, Y., Duits, A.A., Lousberg, R., Hupperts, R.M., Lacroix, M.H., Verhey, F.R. and Vlaeyen, J.W. (2010). Fatigue and physical disability in patients with multiple sclerosis: a structural equation modeling approach. Journal of behavioral medicine. 33, 355-363.

25. Volders, S., Boddez, Y., De Peuter, S., Meulders, A. and Vlaeyen, J.W. (2015). Avoidance behavior in chronic pain research: A cold case revisited. Behaviour research and therapy. 64, 3137.

26. Leeuw, M., Goossens, M.E., Linton, S.J., Crombez, G., Boersma, K. and Vlaeyen, J.W. (2007). The fear-avoidance model of musculoskeletal pain: current state of scientific evidence. Journal of behavioral medicine. 30, 77-94.

27. Crombez, G., Eccleston, C., Van Damme, S., Vlaeyen, J.W. and Karoly, P. (2012). Fearavoidance model of chronic pain: the next generation. The Clinical Journal of Pain. 28, 475-483.

28. Kay, T., Newman, B., Cavallo, M., Ezrachi, O. and Resnick, M. (1992). Toward a neuropsychological model of functional disability after mild traumatic brain injury. Neuropsychology. 6, 371.

29. Todd, D., Martelli, M. and Grayson, R. (1998). The Cogniphobia Scale (C-Scale): A measure of headache impact. Test in the public domain.

30. Martelli, M., MacMillan, P. and Grayson, R. (1999). Kinesiophobia and cogniphobia: Avoidanceconditioned pain-related disability (ACPRD). Archives of Clinical Neuropsychology. 14, 804-804. 
31. Khoury, S., Chouchou, F., Amzica, F., Giguère, J.-F., Denis, R., Rouleau, G.A. and Lavigne, G.J. (2013). Rapid EEG activity during sleep dominates in mild traumatic brain injury patients with acute pain. Journal of neurotrauma. 30, 633-641.

32. Kamper, S.J., Maher, C.G., Costa, L.d.C.M., McAuley, J.H., Hush, J.M. and Sterling, M. (2012). Does fear of movement mediate the relationship between pain intensity and disability in patients following whiplash injury? A prospective longitudinal study. Pain. 153, 113-119.

33. Nieto, R., Miró, J. and Huguet, A. (2009). The fear-avoidance model in whiplash injuries.

European Journal of Pain. 13, 518-523.

34. Schmidt, A.J. (2003). Does 'mental kinesiophobia'exist? Behaviour research and therapy. 41, 1243-1249.

35. Cassidy, J., Carroll, L., Peloso, P., Borg, J., von Holst, H., Holm, L., Kraus, J. and Coronado, V. (2004). WHO Collaborating Centre Task Force on Mild Traumatic Brain, Injury, Incidence, risk factors and prevention of mild traumatic brain injury: results of the WHO Collaborating Centre Task Force on Mild Traumatic Brain Injury. Journal of rehabilitation medicine. 43, 28-60.

36. Verhage, F. (1983). Het coderen van het opleidingsniveau voor researchdoeleinden. Groningen, The Netherlands: Academic Hospital Groningen, State University Groningen-internal publication.

37. Carroll, L., Cassidy, J., Holm, L., Kraus, J. and Coronado, V. (2004). Methodological issues and research recommendations for mild traumatic brain injury: the WHO Collaborating Centre Task Force on Mild Traumatic Brain Injury. Journal of rehabilitation medicine. 43, 113-125.

38. Crombez, G. and Vlaeyen, J.W.S. (1996). The Pain Catastrophizing Scale. Unpublished authorized Dutch/Flemish translation.

39. Sullivan, M.J., Bishop, S.R. and Pivik, J. (1995). The pain catastrophizing scale: development and validation. Psychological assessment. 7, 524.

40. Osman, A., Barrios, F.X., Gutierrez, P.M., Kopper, B.A., Merrifield, T. and Grittmann, L. (2000). The Pain Catastrophizing Scale: further psychometric evaluation with adult samples. Journal of behavioral medicine. 23, 351-365.

41. Miró, J., Nieto, R. and Huguet, A. (2008). The Catalan version of the Pain Catastrophizing Scale: a useful instrument to assess catastrophic thinking in whiplash patients. The Journal of Pain. 9, 397-406.

42. Sterling, M., Hodkinson, E., Pettiford, C., Souvlis, T. and Curatolo, M. (2008). Psychologic factors are related to some sensory pain thresholds but not nociceptive flexion reflex threshold in chronic whiplash. The Clinical Journal of Pain. 24, 124-130.

43. Rivest, K., Côté, J.N., Dumas, J.-P., Sterling, M. and De Serres, S.J. (2010). Relationships between pain thresholds, catastrophizing and gender in acute whiplash injury. Manual therapy. 15, 154-159.

44. Severeijns, R., van den Hout, M.A., Vlaeyen, J.W. and Picavet, H.S.J. (2002). Pain catastrophizing and general health status in a large Dutch community sample. Pain. 99, 367-376. 45. Van Damme, S., Crombez, G., Vlaeyen, J., Goubet, L., Van den Broeck, A. and Van Houdenhove, B. (2000). De pain catastrophizing scale: psychometrische karakteristieken en normering. Gedragstherapie. 33, 209-220. 
46. Goubert, L., Crombez, G., Vlaeyen, J.W., Van Damme, S., Van den Broeck, A. and Van Houdenhove, B. (2000). De Tampa schaal voor kinesiofobie: psychometrische karakteristieken en normering. Gedrag en gezondheid. 28, 54-62.

47. Miller, R., Kori, S. and Todd, D. (1991). The tampa scale. Unpublished report. Tampa, FL. 48. Houben, R.M., Leeuw, M., Vlaeyen, J.W., Goubert, L. and Picavet, H.S.J. (2005). Fear of movement/injury in the general population: factor structure and psychometric properties of an adapted version of the Tampa Scale for Kinesiophobia. Journal of behavioral medicine. 28, 415424.

49. Vlaeyen, J.W., Kole-Snijders, A.M., Rotteveel, A.M., Ruesink, R. and Heuts, P.H. (1995). The role of fear of movement/(re) injury in pain disability. Journal of occupational rehabilitation. 5, 235252.

50. Roelofs, J., van Breukelen, G., Sluiter, J., Frings-Dresen, M.H., Goossens, M., Thibault, P., Boersma, K. and Vlaeyen, J.W. (2011). Norming of the Tampa Scale for Kinesiophobia across pain diagnoses and various countries. Pain. 152, 1090-1095.

51. Zigmond, A.S. and Snaith, R.P. (1983). The hospital anxiety and depression scale. Acta psychiatrica scandinavica. 67, 361-370.

52. Whelan-Goodinson, R., Ponsford, J. and Schönberger, M. (2009). Validity of the Hospital Anxiety and Depression Scale to assess depression and anxiety following traumatic brain injury as compared with the Structured Clinical Interview for DSM-IV. Journal of affective disorders. 114, 94102.

53. Crawford, J., Henry, J., Crombie, C. and Taylor, E. (2001). Normative data for the HADS from a large non-clinical sample. British Journal of Clinical Psychology. 40, 429-434.

54. King, N., Crawford, S., Wenden, F., Moss, N. and Wade, D. (1995). The Rivermead Post Concussion Symptoms Questionnaire: a measure of symptoms commonly experienced after head injury and its reliability. Journal of neurology. 242, 587-592.

55. Eyres, S., Carey, A., Gilworth, G., Neumann, V. and Tennant, A. (2005). Construct validity and reliability of the Rivermead post-concussion symptoms questionnaire. Clinical Rehabilitation. 19, 878-887.

56. Oldenburg, C., Lundin, A., Edman, G., Nygren-de Boussard, C. and Bartfai, A. (2015). Cognitive reserve and persistent post-concussion symptoms-A prospective mild traumatic brain injury (mTBI) cohort study. Brain injury, 1-10.

57. McLean, S.A., Kirsch, N.L., Tan-Schriner, C.U., Sen, A., Frederiksen, S., Harris, R.E., Maixner, W. and Maio, R.F. (2009). Health status, not head injury, predicts concussion symptoms after minor injury. The American journal of emergency medicine. 27, 182-190.

58. Ingebrigtsen, T., Waterloo, K., Marup-Jensen, S., Attner, E. and Romner, B. (1998).

Quantification of post-concussion symptoms 3 months after minor head injury in 100 consecutive patients. Journal of neurology. 245, 609-612.

59. Sheedy, J., Harvey, E., Faux, S., Geffen, G. and Shores, E.A. (2009). Emergency Department Assessment of Mild Traumatic Brain Injury and the Prediction of Postconcussive Symptoms: A 3Month Prospective Study. The Journal of head trauma rehabilitation. 24, 333-343. 
60. Faux, S., Sheedy, J., Delaney, R. and Riopelle, R. (2011). Emergency department prediction of post-concussive syndrome following mild traumatic brain injury-an international cross-validation study. Brain injury. 25, 14-22.

61. Ruff, R.M., Camenzuli, L. and Mueller, J. (1996). Miserable minority: Emotional risk factors that influence the outcome of a mild traumatic brain injury. Brain injury. 10, 551-566.

62. Chaput, G., Lajoie, S.P., Naismith, L.M. and Lavigne, G. (2015). Pain catastrophizing correlates with early mild traumatic brain injury outcome. Pain research and management.

63. Suhr, J. and Spickard, B. (2012). Pain-related fear is associated with cognitive task avoidance: Exploration of the cogniphobia construct in a recurrent headache sample. The Clinical Neuropsychologist. 26, 1128-1141.

64. Nieto, R., Miró, J. and Huguet, A. (2013). Pain-related fear of movement and catastrophizing in whiplash-associated disorders. Rehabilitation psychology. 58, 361.

65. Belanger, H.G., Kretzmer, T., Vanderploeg, R.D. and French, L.M. (2010). Symptom complaints following combat-related traumatic brain injury: relationship to traumatic brain injury severity and posttraumatic stress disorder. Journal of the International Neuropsychological Society. 16, 194-199. 66. Dikmen, S., Machamer, J., Fann, J.R. and Temkin, N.R. (2010). Rates of symptom reporting following traumatic brain injury. Journal of the International Neuropsychological Society. 16, 401411.

67. van der Horn, H.J., Spikman, J.M., Jacobs, B. and van der Naalt, J. (2013). Postconcussive complaints, anxiety, and depression related to vocational outcome in minor to severe traumatic brain injury. Archives of Physical Medicine and Rehabilitation. 94, 867-874. 



\section{Psychometric properties of the Post-
Ussion Catastrophizing Scale (PCS-CS) and \\ Psychometric properties of the Post-
Concussion Catastrophizing Scale (PCS-CS) and the Fear of Mental Activity Scale (FMA). \\ Chapter 5}

Wijenberg, M. L. M., Stapert, S. Z, Rauwenhoff, J. C. C., Ve J., J. . Ponsford, J, L- \& van Heúgten, C.M. submitted.

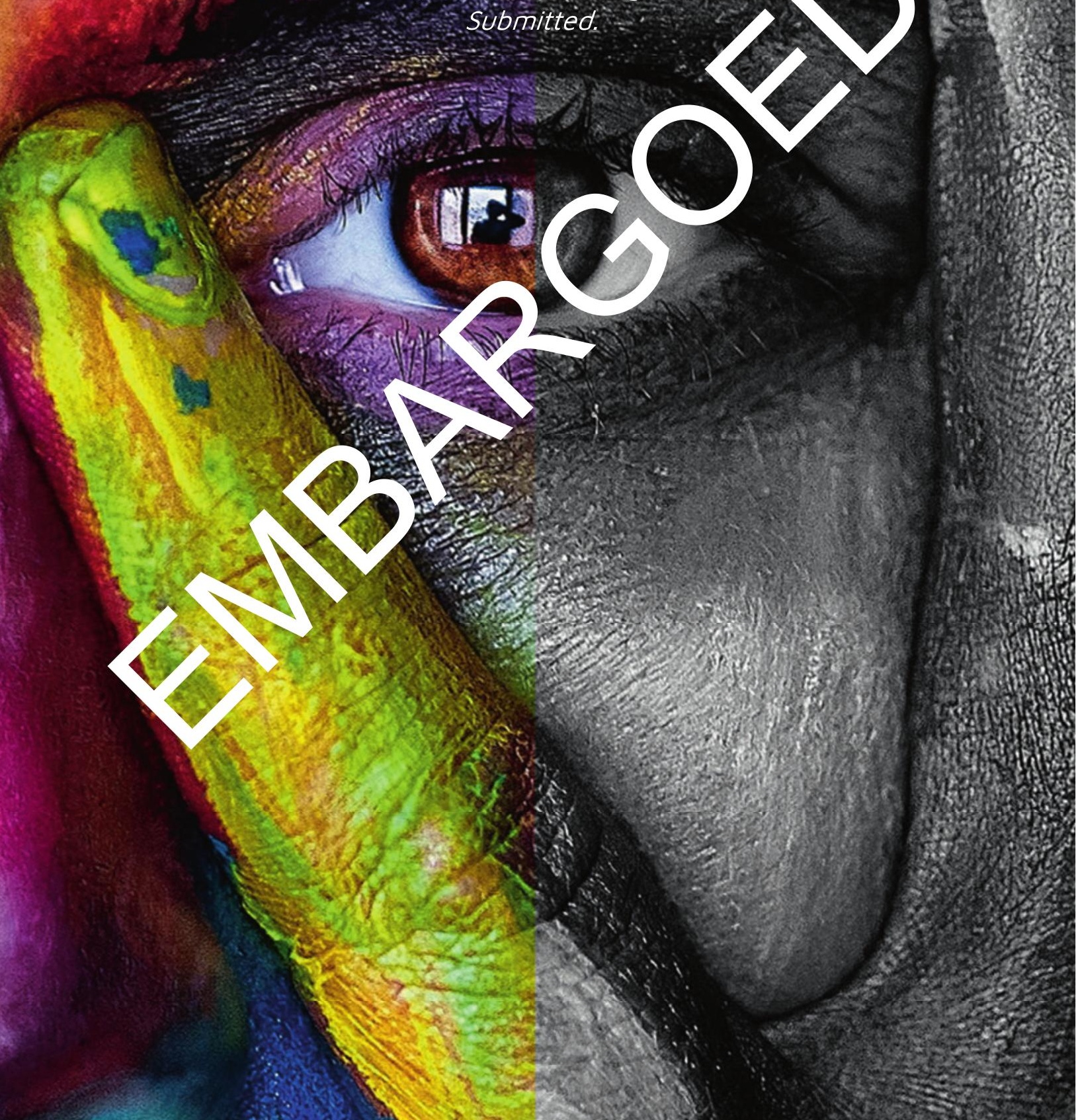




\section{Chapter 6}

Do fear and catastrophizing about mental activities relate to fear-avoidance behavior in a community sample? An experimental study.

Wijenberg, M. L. M.*, Rauwenhoff, J. C. C. ${ }^{*}$, Stapert, S. Z., Verbunt, J. A., \& van Heugten, C. M. (2021). Journal of Clinical and Experimental Neuropsychology, $43(1), 66-77$. doi: $10,1080 / 138033952021.1874881$.

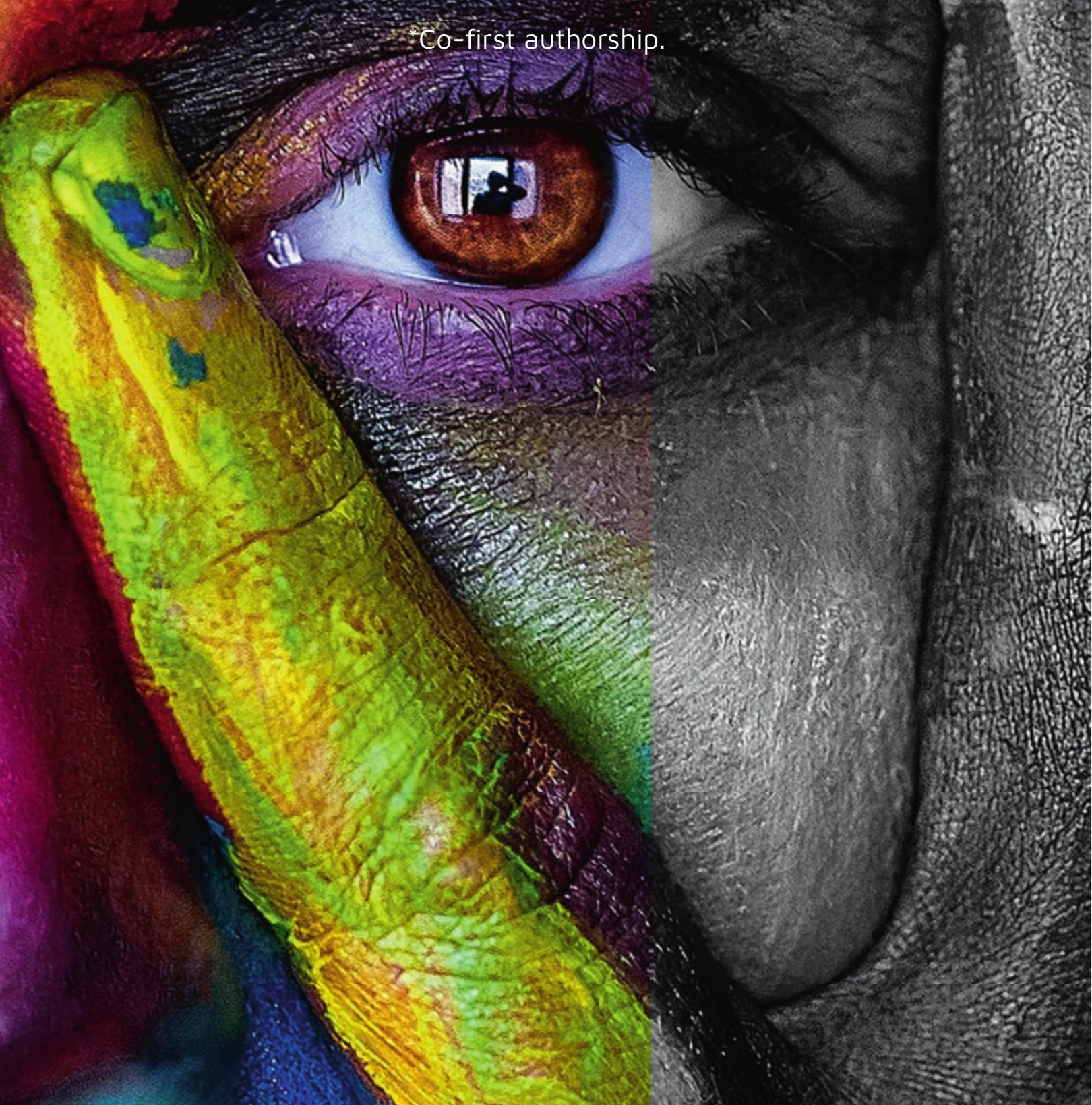


Introduction. Healthy people often experience headache, cognitive failures, or mental fatigue. Some people even experience these symptoms on a level comparable to patients with mild spectrum brain injuries. In these individuals, the fear-avoidance model explains symptoms as a consequence of catastrophizing and fear-avoidance towards mental activities. This experimental study investigated in healthy adults whether fear-avoidance and catastrophizing about mental activities are related to fear-avoidance behavior (i.e., behavioral avoidance of mental activities) according to the fear-avoidance model.

Method. A randomized crossover within-subject design was used with two measurements and 80 participants. Participants were exposed to three demanding cognitive tasks and their simplified counterparts. Post-concussion symptoms, catastrophizing, fear-avoidance, behavioral avoidance (time spent working on cognitive tasks), exposure to mental activity, depression, heart rate, and state-trait anxiety were assessed.

Results. Significant correlations between the variables of the fear-avoidance model were found. Furthermore, catastrophizers spent less time on difficult tasks compared to easy tasks. Both catastrophizing and female sex predicted time spent on difficult tasks, whereas only female sex predicted time spent on easy tasks.

Conclusions. This study found that, according to the fear-avoidance model, catastrophizing is related to behavioral avoidance of cognitively challenging tasks in a community sample.

Keywords: post-concussion like symptoms, fear-avoidance model, catastrophizing, brain injury, experiment. 


\section{Introduction}

Healthy adults often report cognitive, emotional, somatic, and behavioral complaints such as headaches, memory problems, depressed mood, apathy, and fatigue. ${ }^{1-3}$ They are not diagnosed with any physical or mental disease and therefore are considered "healthy". However, the symptoms they report can reach a degree comparable to patients recovering from mild traumatic brain injury (mTBI) or concussion. ${ }^{4,5}$ Dean et al. ${ }^{5}$ named this symptom complex in healthy adults "post-concussion like symptoms", which shows similarities with cogniform disorder (a subtype of somatoform disorders). ${ }^{6}$ Several studies have shown the incidence of post-concussion like symptoms in the general population. ${ }^{7,8}$ These symptoms are influenced by cultural and sex differences. ${ }^{9,} 10$

Looking at an explanation for post-concussion symptoms in mTBI, prior researchers have stated that biological (e.g. injury-related characteristics such as injury severity) or psychosocial causes (e.g. personal characteristics such as history of psychological treatment) seem to be important, but fail to explain this symptom persistence on their own, and thus have suggested an integrated biopsychosocial approach for future studies. ${ }^{11-15}$ Moreover, one of the most consistent findings has been that pre-injury mental health and early post-injury anxiety are important predictors of persistent post-concussion symptoms. ${ }^{15,16}$ Therefore, we wanted to investigate a theoretical biopsychosocial model, combining biological and psychosocial causes and centralizing the role of anxiety, known as the fear-avoidance model. This model was first developed to understand chronic pain. ${ }^{17}$ The model has been adapted and applied to various complaints in different patient populations ${ }^{17-20}$, including patients who experienced mild injury with cognitive deficits as a consequence, such as post-concussion symptoms following mTBI. ${ }^{20,}{ }^{21}$ Numerous studies confirmed the potential of this adapted model in explaining the disease process leading from early benign symptoms to persistent symptoms in patients with mTBI. ${ }^{20-24}$ Although this adapted model has not yet been tested in healthy adults, the original fearavoidance model (assessing pain) was tested and validated in healthy adults across several studies. ${ }^{25-27}$

The fear-avoidance model explains the mismatch between high severity levels of symptoms and low severity of physical injury. ${ }^{17}$ This mismatch is also 
present in healthy adults, explaining general symptom reactions within the normal range. Applying the model to post-concussion like symptoms specifically, the original model is adapted by changing chronic pain resulting in fear of physical activities (kinesiophobia) to post-concussion like symptoms resulting in fear of mental activities (cogniphobia). According to the adapted fear-avoidance model, post-concussion like symptoms are explained by a negative cycle of catastrophizing about symptoms, which leads to cogniphobia (i.e., fear of mental activities), which in turn leads to behavioral avoidance of cognitively demanding tasks (i.e., disuse) or depressive symptoms (see Figure 1). Previous research has shown that the adapted fear-avoidance model is relevant for explaining persistent post-concussion symptoms after TBI. ${ }^{20,21}$ Unfortunately, the potential and mechanism of the adapted fear-avoidance model in a non-clinical sample remain unknown.

Figure 1. The fear-avoidance model applied to post-concussion like symptoms.

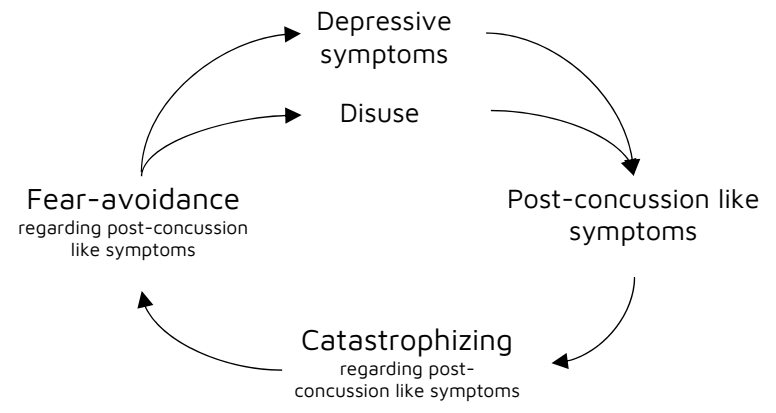

For this reason, an experimental study was conducted to investigate in healthy adults whether fear-avoidance and catastrophizing about mental activities are related to fear-avoidance behavior (i.e., behavioral avoidance of mental activities) according to the fear-avoidance model. The study aimed to relate fearavoidance behavior in healthy participants to their fear-avoidance and catastrophizing thoughts. This experiment was based on the experimental paradigm and results of Vlaeyen et al. ${ }^{28}$. In the current study, participants were presented with cognitively challenging tasks to evoke fear-avoidance behavior. Participants were able to choose the duration of time spent working on these 
tasks. Thus, a manipulating variable was introduced (cognitively challenging tasks) in order to evoke features of "psychopathology" (fear-avoidance behavior) in healthy subjects, as is done in experimental psychopathology. ${ }^{29,} 30$ This can contribute to the formation of theories explaining disease processes, in this instance the fear-avoidance model.

The following hypotheses were tested:

1) We predicted that catastrophizing would be positively associated with post-concussion like symptoms and fear-avoidance, whereas disuse and depression would be positively associated with fear-avoidance and postconcussion like symptoms. This hypothesis would be supported by significant correlations consistent with the fear-avoidance model (see Figure 1). This hypothesis was not tested with the experimental manipulation, but was tested as a necessary first step to verify the interrelationships between variables of the fear-avoidance model in this population.

2) It was hypothesized that participants with higher levels of fearavoidance and catastrophizing thoughts (2a) show fear-avoidance behavior (i.e. behavioral avoidance) when performing a cognitively challenging task (i.e., spend less time on the task), (2b) perform worse on this task, and would be more (2c) anxious and (2d) stressed during the task compared to participants with low levels of fear-avoidance and catastrophizing thoughts. Furthermore, it was predicted that these differences would not be seen on a task which was less cognitively challenging. This hypothesis was tested with the experimental manipulation.

3) It was expected that participant's level of catastrophizing and fearavoidance, measured before experimental manipulation, would predict (3a) the time they spend on a cognitively challenging task and (3b) the performance on this task while controlling for sex, education, and age. This hypothesis was tested with the experimental manipulation.

The results of this experiment will show whether fear-avoidance and catastrophizing thoughts about cognitive tasks are related to post-concussion like symptoms in healthy adults (first hypothesis). Furthermore, it will give insight into the relationship between fear-avoidance and catastrophizing thoughts about mental activities and behavioral avoidance (second and third hypotheses). 


\section{Materials and methods}

\section{Participants}

Participants were recruited between March 2017 and August 2018 by researchers of Maastricht University. Participants were recruited through personal invitation (if they provided permission to be approached for new studies of Maastricht University) or response to an advertisement. The study was advertised through (1) an online research database available for students, (2) a local community app, and (3) flyers spread across the university and public places such as the hospital and supermarkets. Individuals were eligible for the study if they (1) were between 18 and 64 years of age; (2) spoke Dutch fluently; and (3) finished pre-university education, higher vocational education or academic education. Exclusion criteria were (1) history of any neurological disorder (including traumatic brain injury), (2) history of or current psychological and psychopharmacological treatment for depression or anxiety, (3) use of recreational drugs in the week before and during the study, and (4) unwillingness to sign informed consent. Inclusion and exclusion criteria were checked before the first and second measurements by means of selfreport.

\section{Measures}

Behavioral measures. In this experiment, there were two conditions: a difficult and an easy condition, in each of which the participants had to complete three computerized tasks. As a measure of behavioral avoidance, participants could choose the time spent on each task. During all tasks, a red stop button was shown which the participants could click on to end the task.

The tasks used in the difficult condition were three validated cognitive tasks used to increase the mental load of the participants. The first task was the Paced Auditory Serial Addition Task-Computerized (PASAT). ${ }^{31}$ During this task, participants heard numbers, ranging from one to nine with two-second intervals. They were instructed to add the current number to the previous number. The participants received visual feedback on whether their answer was correct or not. The second task was the Distress Tolerance Test (DTT). ${ }^{32}$ For this task the 64 stimulus cards of the Wisconsin Card Sorting Test (WCST) were used (i.e., four key cards and one deck card). ${ }^{33}$ The standard instructions of the WCST were 
presented, indicating that the participants must match the deck card with the key cards. They were not told how the cards were supposed to match. Regardless of the participants' response, the feedback was "correct" for the first three cards and "incorrect" for the next seven. The feedback on the $11^{\text {th }}$ card was "correct", hereafter the remaining cards were rated 'incorrect'. During the third task, participants had to solve various anagrams, originally used by Vrijsen et al. ${ }^{34}$. Participants were allowed to make notes (if preferred) and received visual feedback. These anagrams were difficult or even unsolvable.

During the easy condition, simplified versions of the tasks in the difficult condition were used. An easier version of the PASAT was used by prolonging the interval between two consecutive numbers by 3.5 seconds. The regular version of the WCST was used instead of the DTT. During the anagram task, participants again had to solve anagrams; however, now the anagrams were easier and always solvable. These anagrams all consisted of five letters.

Psychophysiological measure. Heart rate was measured during the cognitive tasks using Brain Vision Software (Brain Vision Software, Munich, Germany). Heart rate was recorded using a standard 3-lead electrocardiogram. Electrodes were placed below the left and right collarbone and below the left lower rib. Heart rate levels were calculated by averaging interbeat intervals by detecting the R spikes. ${ }^{35}$ These values were converted to average beats per minute per condition. This was done using Matlab (The MathWorks, Natick, Massachusetts). Higher beats per minute indicate higher physiological arousal.

Self-report measures. The Rivermead Post-Concussion Symptoms Questionnaire (RPQ) measures the severity of somatic, cognitive, and emotional symptoms following traumatic brain injury. ${ }^{36}$ The questionnaire consists of 16 items rated on a five-point Likert scale. Total scores range from 0 to 64 with higher scores indicating a higher frequency and severity. Three or more symptoms, indicated by at least three items with an item score of 2 or higher, were used as a criterion for a disabling symptom complex. ${ }^{21}$ This questionnaire was adapted for use within the healthy population as suggested by Dean et al. ${ }^{5}$. The question format was changed from "Compared with before the accident, do you now (i.e., over the last 24 
hours) suffer from:" to "Compared with your peers, do you now (i.e., over the last 24 hours) suffer from:". In the present study, the internal consistency was 0.82 and the test-retest reliability 0.67 .

The Post-Concussion Catastrophizing Scale (PCS-CS) measures the level of catastrophizing thoughts regarding post-concussion like symptoms. ${ }^{21}$ The PCS-CS is adaptive to the RPQ; participants answer questions about the symptom complex they reported on the RPQ. If participants did not report any symptoms, the most common post-concussion symptoms "headache, cognitive problems and/or fatigue" were depicted. Participants were then asked what they think/feel when they experience a headache, cognitive problems, and/or fatigue. The questionnaire consists of 13 items rated on a five-point Likert scale. Higher scores indicate higher levels of catastrophizing and ranges between 0 and 51 . In a healthy population, the cutoff score for the PCS-CS is 8 or 14 , depending if the individual had "no history" or "history of psychological treatment" respectively (Wijenberg, Stapert, Rauwenhoff, Verbunt, \& Van Heugten, unpublished results). The PCS-CS is an adaptation of a validated and reliable measure from the pain literature, the Pain Catastrophizing Scale. ${ }^{37}$ In the present study, the internal consistency was 0.87 and the test-retest reliability 0.65 .

The Fear of Mental Activities Scale (FMA) measures the level of fearavoidance regarding post-concussion like symptoms and cogniphobia in mTBI patients. ${ }^{21}$ The FMA is an adaptation of a validated and reliable measure from the pain literature, the Tampa Scale of Kinesiophobia (TSK). ${ }^{38}$ The FMA, like the PCS$\mathrm{CS}$, is adaptive to the RPQ. The participants were required to rate each question on a four-point Likert scale. It is a 17-item questionnaire with higher scores indicating greater fear of mental activity. The scoring of four items (items 4, 8, 12, and 16 ) is reversed. The total score ranges between 17 and 68. According to its validation study, the four inversed items need to be removed post-hoc, resulting in a cutoff score of 15 for a heightened level of fear-avoidance in a healthy population (Wijenberg, Stapert, Rauwenhoff, Verbunt, \& Van Heugten, unpublished results). The removal of the four reversed items is in line with the original validation of the TSK in the pain literature, stating that the four reversed items have been criticized as unreliable and too difficult. ${ }^{25,39,40}$ In this study, after 
removing the four inversed items, internal consistency was 0.78 and test-retest reliability 0.71 .

The State-Trait Anxiety Inventory (STAI) ${ }^{41}$ consists of two self-report scales measuring state and trait anxiety. Both subscales consist of 20 items which must be scored on a four-point Likert scale. Both scales have a maximum possible range of 20 to 80 with higher scores indicating greater anxiety. The Dutch version of the STAI and the subscales have good validity and reliability. ${ }^{42}$ Similar to prior studies $^{43}$, the STAI state was filled in before and after the difficult or easy tasks. A differential score was calculated, with a higher score indicating increased anxiety compared to before the tasks.

The Beck Depression Inventory-II revised (BDI) 44,45 is a 21-item questionnaire, which measures the level of depressive symptoms. The items are rated on a four-point Likert scale, with higher scores representing more severe depressive symptoms. The maximum possible range of the BDI is 0 to 63 . The BDI has been demonstrated to have good psychometric properties in a variety of samples including healthy subjects. ${ }^{46}$

Regarding personal characteristics, participants were asked to fill in their age, sex, education (highest obtained educational degree), and number of hours spent on mental activity per day. Number of hours spent on mental activity per day was used as a measure for exposure to mental work, as healthy participants could not be asked to compare their current activity level to before injury. In this study, exposure to mental work represents the inverse of "disuse" indicated by number of hours spent on mental activity per day. In other words, the scores were reversed to represent disuse.

\section{Procedure and experimental setup}

For this research, a randomized cross-over within-subject design with two study arms (see Figure 2) was used. In the first study arm, participants received the difficult tasks on the first measurement, and the easy tasks on the second measurement. In the second study arm, the order of difficult tasks and easy tasks was switched across the two measurements. Participants were divided into the first or second study arm using a counterbalanced design. On the day of the experiment, no caffeine intake was allowed. Furthermore, the temperature and 
humidity in the lab were kept constant during the experiment, since these conditions can affect heart rate. After completing the informed consent process, participants filled in their demographic characteristics, the RPQ, PCS-CS, FMA, STAI Trait, BDI, and the STAI State. Depending on the study arm, they were then asked to complete three difficult or easy tasks after a short practice period of the PASAT and the anagrams. Participants could choose the order to maximize its resemblance with solving multiple cognitive challenging problems in everyday life and someone's own preference to solve these different problems in a particular order. Additionally, they could stop at any moment and continue with the next task. If participants did not terminate the task, each task stopped automatically after 20 minutes. At the end of the tasks, participants were asked to fill out the STAl state again. During the tasks, heart rate was continuously measured. For the second measurement, one week after the first measurement, this procedure was repeated with the other task condition (easy or difficult). However, the STAI trait and BDI were not included. When both measurements were completed participants received course credits (university students) or $€ 7.50$ per hour in vouchers.

The experimental setup was considered valid when the following assumptions were met: participants spent less time and performed less well on the difficult tasks compared to easy tasks; the difficult tasks induced a stress reaction; age, sex, and education influenced performance in the difficult task; and the internal consistency and test-reliability of two newly-developed questionnaires, assessing catastrophizing and fear-avoidance, were sufficient. 
Figure 2. Design of the study: randomized cross-over within subject design.

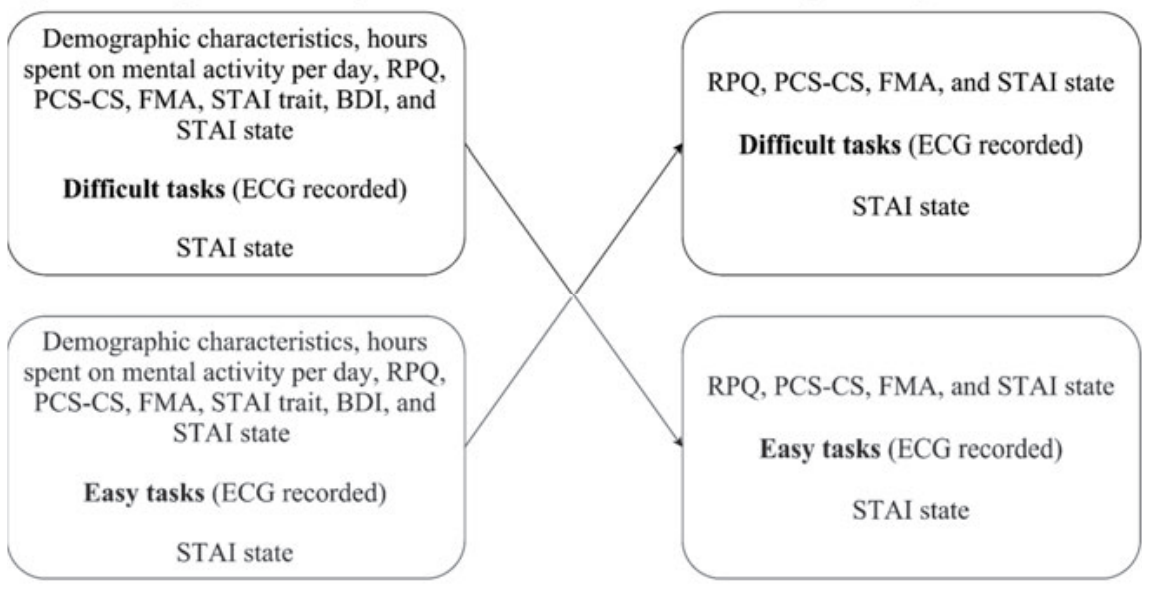

Notes. RPQ = Rivermead Post-Concussion Symptoms Questionnaire; PSC-CS = Post-Concussion Catastrophizing Scale; FMA = Fear of Mental Activities Scale; BDI = Beck Depression Inventory-II revised; STAI = State-Trait Anxiety Inventory; ECG = Electrocardiogram.

\section{Statistical Analyses}

All statistical analyses were performed using SPSS 24.0 for Windows (IBM Corp., Armonk, NY). Distributions of all variables were evaluated in terms of mean, SD, median, range, skewness, and kurtosis. No data imputation took place because there was no missing data (except for one participant who did not complete one questionnaire). Outliers and assumptions were checked. Outliers were identified according to the $3 I Q R$ rule and winsorized by the second-highest value. In case of non-normality (defined as skewness or kurtosis values outside the range of -1.0 to 1.0), multiple transformations were performed (log, square-root, or inverse). If normalization by transformation was not possible, nonparametric statistics were used. An alpha level of 0.05 was used unless otherwise stated.

To test if the condition manipulation (difficult versus easy tasks) was successful, differences in state anxiety (post-pre) and physiological arousal (average beats per minute) were compared between conditions using a paired sample t-test. A lower score (indicative for less induced anxiety or less arousal) was expected after the easy tasks compared to the difficult tasks.

To test hypothesis 1 (the interrelationships between variables of the fearavoidance model in healthy adults) correlations between "symptoms", "catastrophizing", "fear-avoidance", "depression", and "exposure to mental 
activity", assessed during the first measurement, were examined. Correlations of the fear-avoidance model were computed by Pearson correlations (in case of normality) or Spearman correlations (in case of non-normality).

To test hypothesis 2 (the effect of catastrophizing, fear-avoidance, and condition on behavioral avoidance, performance, induced anxiety, and stress) four three-way mixed ANOVAs were performed with time spent on tasks, performance, state-anxiety, and heart rate as the dependent variable, respectively. Time spent on the three cognitive tasks together per condition was calculated by the average of the standardized time spent per cognitive task. For all ANOVAs, high and low catastrophizers or fear-avoiders were derived from their respective median splits. Catastrophizing (low/high) and fear-avoidance (low/high) were considered between-subject factors, whereas condition (difficult/easy) was considered a within-subject factor. Besides normality and outliers, the assumptions of homogeneity of variance (assessed by Levene's test for equality of variance) and sphericity (assessed by Mauchly's test of sphericity) were checked.

To test hypothesis 3 (predicting performance and time spent on a cognitive task with catastrophizing and fear-avoidance, while controlling for sex, education, and age) two backward multiple regression analyses were performed (separately for time and performance in each condition). Dummy variables were created for categorical variables (catastrophizer, fear-avoider, sex and, education). The quantitative variable (age) was centered (subtracting the median due to nonnormality) and its quadratic term was added. The least significant variable with a threshold of $\alpha=0.1$ was removed stepwise. In this process, dummy variables were treated as a block. For both the full model as the final model, assumptions of independence of observations (assessed by Durbin-Watson statistics), linearity (assessed by visual inspection), homoscedasticity of residuals (assessed by visual inspection), multicollinearity (assessed by the variance inflation factor and correlations), outliers (assessed by studentized residuals, Cook's distance and centered leverage), and normality of residuals (assessed by visual inspection) were checked. 


\section{Results}

\section{Sample characteristics}

A total of 80 adults participated in the study. All participants completed both conditions. One participant ended the first session prematurely and did not complete the STAI State following the easy tasks. Participants had a mean age of 30.5 years $(S D=14.4)$ and $66.3 \%$ were female. Despite the exclusion criterion of a low level of education, three participants indicated a low education level as their highest obtained degree (3.8\%). Since their scores fell within the range of the rest of the sample, they were not excluded from the analyses. The average number of hours spent on mental activities per day was 7.1 hours $(S D=3.0)$. Participant characteristics are shown in Table 1.

Table 1. Personal characteristics $(N=80)$.

\begin{tabular}{lll}
\hline Characteristics & Values & Range \\
\hline Sex, \% female (n) & $66.3(53)$ & $18-64$ \\
Mean age in years (SD) & $30.5(14.4)$ & $3-7$ \\
Education level, \% ( $\mathrm{n})$ & & \\
$\quad$ Low (level 4 -5$)$ & $3.8(3)$ & $50.0(40)$ \\
$\quad$ Medium (level 6 - 7) & $46.3(37)$ & $1-13$ \\
$\quad$ High (level 8) & $7.1(3.0)$ & \\
\hline
\end{tabular}

\section{Experimental manipulation check}

To check if the manipulation of induced stress as a result of task difficulty was successful, differences in state anxiety (post-pre) and physiological arousal (average beats per minute) were compared between conditions. Results show that participants reported a significantly higher increase in state anxiety after the difficult tasks compared to the easy tasks ( $p<.01, D=0.69$ ). After removal of one outlier, the results show that participants did not differ in heart rate for the difficult tasks compared to the easy tasks $(p=.44)$.

\section{Hypothesis 1: The fear-avoidance model in healthy adults}

Table 2 shows the level of post-concussion like symptoms, catastrophizing, fearavoidance, exposure to mental activity, and depression. Next to the reliability indexes, the percentages of participants fulfilling the criterion of post-concussion 
syndrome or having a heightened level of catastrophizing, fear-avoidance, and depression are reported. The distributions of all variables were skewed; for normalization, winsorizing and/or different transformations across the variables were needed. Therefore, although Pearson correlation analyses revealed similar results, nonparametric statistics were chosen.

Table 2. Descriptive statistics of the fear-avoidance model in healthy adults $(N=80)$.

\begin{tabular}{llll}
\hline Variables & Mean (SD) & Range & $\% 1$ \\
\hline Post-concussion like symptoms (RPQ) & $6.21(6.10)$ & $0-28$ & 33.8 \\
Catastrophizing (PCS-CS) & $6.24(5.63)$ & $0-26$ & 27.5 \\
Fear-avoidance (FMA) & $15.90(3.81)$ & $13-36$ & 45.0 \\
Depression (BDI) & $5.24(4.56)$ & $0-21$ & 16.3 \\
Exposure to mental activity (inverse of 'disuse') & $7.11(3.04)$ & $1-13$ & NA \\
\hline
\end{tabular}

Notes. $S D=$ Standard Deviation; \%l = Percentage of participants with an impairment as defined by the cut-off scores (see Method section); RPQ = Rivermead Post-Concussion Symptoms Questionnaire; PCS-CS = Post-Concussion Symptom Catastrophizing Scale; FMA = Fear of Mental Activity Scale; $\mathrm{BDI}=$ Beck's Depression Inventory; NA = Not applicable.

The correlation analyses revealed that all correlations specific to the fearavoidance model were significant $(\rho<.05)$, except for the correlations involving exposure to mental activity (see Figure 3). Catastrophizing was positively associated with post-concussion like symptoms $(r=0.31)$ and fear-avoidance $(r=$ 0.46). In contrast to exposure to mental activity, depression was positively associated with fear-avoidance $(r=0.31)$ and post-concussion like symptoms $(r=$ 0.57). 
Figure 3. Spearman correlations of the fear-avoidance model.

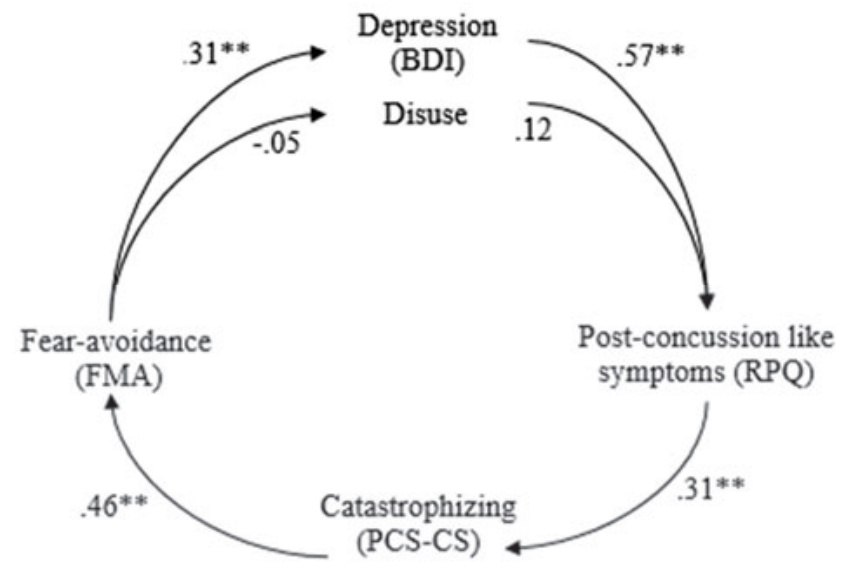

Notes. $\mathrm{BDI}=$ Beck Depression Inventory-II revised; RPQ $=$ Rivermead Post-Concussion Symptoms Questionnaire; PSC-CS = Post-Concussion Catastrophizing Scale; FMA = Fear of Mental Activities Scale.

\section{Hypothesis 2a: The effect of catastrophizing and fear-avoidance on behavioral avoidance}

A three-way mixed ANOVA was run to understand the effects of catastrophizing and fear-avoidance on behavioral avoidance (as measured by time spent on cognitive tasks). Time scores were not normally distributed per cell and required square-root transformations. There were no outliers and assumptions of homogeneity of variance and sphericity were met.

There were no significant three-way or two-way interactions ( $\rho>.05)$, but a significant within-subjects effect of condition $\left(F=7.68 ; \rho<.01\right.$; partial $\eta^{2}=.09$ ) and a significant between-subjects effect of catastrophizing $(F=4.90 ; \rho=.03$; partial $\eta^{2}=.06$ ) was found. Post-hoc analyses revealed that participants spent more time on easy tasks and that catastrophizers stopped sooner with the difficult tasks.

\section{Hypothesis 2b: The effect of catastrophizing and fear-avoidance on task performance}

A three-way mixed ANOVA was run to understand the effects of catastrophizing and fear-avoidance on task performance (measured as percentage correct on the 
PASAT). Performance scores were not normally distributed and a logarithmic transformation was needed in the easy condition. There was one outlier in the easy condition and therefore winsorized. Assumptions of homogeneity of variance and sphericity were met.

There were no significant three-way or two-way interactions ( $p>$.05), but a significant within-subjects effect of condition $(F=546.49 ; p<.01$; partial $\eta 2=$ .88) was found. Post-hoc analyses revealed that participants performed better on the easy tasks compared to the difficult tasks.

\section{Hypothesis 2c: The effect of catastrophizing and fear-avoidance on self- report anxiety}

A three-way mixed ANOVA was run to understand the effects of catastrophizing and fear-avoidance on state anxiety (difference score of anxiety before and after the tasks). Anxiety scores were not normally distributed; therefore, a log transformation was performed. There was one outlier in the easy condition and one in the difficult condition. These outliers were winsorized. The assumptions of homogeneity of variance and sphericity were met.

There were no significant three-way or two-way interactions ( $p$ >.05), but there was a significant within-subjects effect of condition $(F=31.33 ; p<.01$; partial $\eta 2=.30$ ). Post-hoc analyses revealed that participants had increased state anxiety following the difficult tasks compared to the easy tasks.

\section{Hypothesis 2d: The effect of catastrophizing and fear-avoidance on heart rate}

A three-way mixed ANOVA was run to understand the effects of catastrophizing and fear-avoidance on heart rate (measured as average beats per minute per condition). Heart rate was normally distributed in both conditions. There were no outliers and the assumptions of homogeneity of variance and sphericity were met.

There were no significant three-way interactions, two-way interactions, or main effects $(p>.05)$.

\section{Hypothesis 3a: The prediction of behavioral avoidance}

A backward multiple regression was run to understand whether personal 
characteristics (e.g., age, sex, education, or heightened level of catastrophizing or fear-avoidance) could predict behavioral avoidance (measured as time spent on cognitive tasks). Assumptions of multicollinearity were not met and led to the removal of the quadratic term of age. For all cases with a low education level (score 4 or $5, N=3$ ), leverage values surpassed the threshold of .2 and were removed.

In the difficult task, the final model revealed that female sex and a heightened level of catastrophizing significantly predicted behavioral avoidance $(F(2,74)=6.10, p<.01)$, accounting for $14.1 \%$ of the variation in behavioral avoidance. The prediction equation was "average standardized time spent on difficult tasks $=.07+-.17^{*}$ Catastrophizing $(-1=$ low catastrophizing; $1=$ high catastrophizing $)+-.23^{*} \operatorname{Sex}(-1=\text { male; } 1=\text { female })^{\prime \prime}$, meaning that if you are a catastrophizer or female, you spent less time on the difficult task.

In the easy task, time spent on the cognitive task was normalized after log transformation. The final model revealed that sex significantly predicted behavioral avoidance $(F(1,75)=4.018, \rho<.05)$, accounting for $5.1 \%$ of the variance in behavioral avoidance. The prediction equation was "natural logarithm of average standardized time spent on easy tasks = .08 + -.09*Sex $(-1=$ male; $1=$ female)", meaning that if you are a female, you spent less time on the easy task.

\section{Hypothesis 3b: The prediction of task performance}

A backward multiple regression was run to understand whether personal characteristics (e.g., age, sex, education, or having a heightened level of catastrophizing or fear-avoidance) could predict task performance on the PASAT. Assumptions of multicollinearity were not met and led to the removal of the quadratic term of age. For cases with a low education level (score 4 or $5, N=3$ ), leverage values surpassed the threshold of .2 and were removed.

In contrast to the easy task where no significant predictors were found, the final model of the difficult task revealed that age, sex, and education level significantly predicted task performance $(F 4,72)=5.497, \rho<.01)$, accounting for $19.1 \%$ of the variance in task performance. The prediction equation was "percentage correct on difficult PASAT $=56.33+-.52 *$ Age $($ Age-23 $)+-5.16 *$ Sex $(-$ 
$1=$ male; $1=$ female $)+15.83^{*}$ Education ( $1=$ higher vocational education; 0 =other)", meaning that if you are older or female or did not complete higher vocational education, you score lower on the difficult task.

\section{Discussion}

To investigate whether fear-avoidance and catastrophizing about mental activities are related to behavioral avoidance in a healthy population, an experimental study was conducted with 80 healthy adults engaging in cognitively challenging tasks. Participants were exposed to cognitive tasks and could choose the exposure time to these tasks as a proxy for behavioral avoidance.

Vlaeyen et al. ${ }^{28}$ experimentally tested the fear-avoidance model by letting people with lower back pain lift heavy bags. The current experiment was an adaptation to this experimental paradigm to fit the fear-avoidance model assessing post-concussion like symptoms and cogniphobia.

Although only tested post-hoc, the manipulation of the experiment was successful. That is, participants spent more time and performed better on the easy tasks; difficult tasks induced more anxiety compared to the easy tasks; age, sex, and education predicted performance in the difficult task; and internal consistencies and test-retest reliabilities ranged from sufficient to good.

In line with the fear-avoidance model and results of Vlaeyen (1995), the correlations specific to the fear-avoidance model were significant, meaning that the levels of post-concussion like symptoms, fear-avoidance, catastrophizing, and depression were significantly correlated. Furthermore, participants who reported higher levels of catastrophizing chose shorter exposure time to difficult tasks, suggestive of behavioral avoidance. Furthermore, we found that higher levels of catastrophizing predicted time spent on the difficult tasks. Additionally, female sex also predicted behavioral avoidance regardless of difficulty, in line with the established link between catastrophizing and female sex. ${ }^{47}$

Despite these promising results, several findings were not in line with our hypotheses. No significant correlations were found between "exposure to mental activity" and "fear-avoidance" or "post-concussion like symptoms". Furthermore, fear-avoidance was not related to time spent on the tasks, performance on a task, induced anxiety, and heart rate. Comparison with previous research is limited due 
to a lack of prior studies investigating the role of disuse concerning cogniphobia or post-concussion symptoms. However, multiple chronic pain studies found similar results, including significant correlations with depression and catastrophizing and not with disuse and fear-avoidance. The non-significant results could also be due to a lack of validity of the measures used for disuse and fear-avoidance. ${ }^{48-50}$ The inverse of disuse was measured by means of one non-validated question (i.e., "How many hours a day do you currently spend performing mental activities such as writing, working on the computer, reading, and participating in a meeting?"). The measure of fear-avoidance originated from the TSK questionnaire, which received some criticism, especially regarding its validity. ${ }^{51}$ Future studies are warranted to develop a more ecologically valid measure, such as the photograph series of daily activities (PHODA) scale assessing perceived harmfulness of daily activities. ${ }^{52}$ Furthermore, we did not find any effect on our psychophysiological measure (heart rate). This was also the case in the original experiment by Vlaeyen et al. (1995). Furthermore, factors affecting heart rate (e.g., participants' body weight, medication use, exercise prior to experiment, and the weather) were not considered.

Besides these unexpected findings, there are several limitations to consider. First, participants reported several other reasons than cogniphobia to terminate cognitive tasks (e.g., fatigue, boredom, lack of effort, frustration with difficult or non-solvable tasks). These reasons could have decreased the time spent on the cognitive tasks regardless of their level of catastrophizing or fear-avoidance. However, reasons for terminating the tasks were not retrieved systematically. Secondly, participants were rewarded, potentially influencing their time spent on the tasks, despite their level of catastrophizing or fear-avoidance. However, this seems unlikely as participants were informed beforehand that the experiment would take a fixed period (set at the maximum duration) and participants did not know that the experiment would terminate after their termination of the cognitive tasks. Thirdly, the absence of effects regarding fear-avoidance could also be related to the community sample in this study. Although symptom levels can be found on a comparable level in patient populations, it is stated that when hypothesized pathological processes are evoked in healthy participants a similar subclinical pathology originates, however to smaller extents. ${ }^{29}$ This effect might 
have been too small to become meaningful. It is therefore important to also administer this experimental study in patient populations with conditions associated with unexpected persistent cognitive symptoms such as mTBI to assess its generalizability. Furthermore, taking into account the limitations of stepwise selection, future research is needed to cross-validate the final models. Fourthly, the exclusion criterion related to absence of recreational drugs within one week before- and during testing was checked before the start of each measurement by the use of self-report. Self-report may potentially influence the results through the inclusion of unsuitable participants. However, since this study has a withinsubject design it is unlikely that this influenced the results. Fifth, no pilot testing occurred to check the experimental manipulation. However, post-hoc analyses were performed in order to test the manipulation, which appeared to be successful. Finally, one could argue that the common established interrelationships of the fear-avoidance model across various patient and healthy populations limit its specificity. One of the main elements of the fear-avoidance model is the prominent and evident role of psychological factors. Previous research has shown that psychological factors such as personality, coping, and psychological vulnerability are important to consider in various patient populations ${ }^{15,53,54}$ and healthy adults ${ }^{55-57}$. Future studies should also evaluate other potential explanations or models, such as an integrative model explaining medically unexplained symptoms $^{58}$, biopsychosocial model of overuse ${ }^{59}$, anxiety ${ }^{60}$, depression ${ }^{9,61}$, somatization ${ }^{62}$, alexithymia ${ }^{63}$, or low self-efficacy ${ }^{64}$, to understand if our findings regarding the fear-avoidance model are of additive value compared to these alternative explanations.

Despite some unexpected findings and lack of significant results concerning fear-avoidance, the results of this study extend our current knowledge on the fear-avoidance model applied to post-concussion (like) symptoms revealing its presence in healthy adults and highlighting the importance of catastrophizing due to its demonstrated relationship with behavioral avoidance. This biopsychosocial approach adds to our understanding why low levels of injury severity (i.e. benign injuries) can lead to high levels of symptom reporting which cannot be explained based on strictly biological models. Moreover, even in the absence of injury in a non-clinical sample, the normal ranges of daily complaints such as headaches are 
related to psychosocial variables. As post-concussion like symptoms occur within the healthy population and likely become more severe in combination with disease or injury (such as mTBI), the results support further (experimental) investigation into the fear-avoidance model and its associated treatment in patient populations.

\section{Acknowledgements}

We thank all participants for their participation. Furthermore, we would like to thank Myrthe Dingemanse, Noëlle Laros, and Veerle van Gils for helping collect the data. Lastly, we thank Charlotte Southcombe, Ashley K. Smith Watts, PhD, and the INS Global Engagement Committee Research Editing and Consulting Program for their English language editing service. No potential conflict of interest was reported by the author(s). 


\section{References}

1. Lee, A.R., Son, S.-M. and Kim, K.K. (2016). Information and communication technology overload and social networking service fatigue: A stress perspective. Computers in Human Behavior. 55, 5161.

2. Aaronson, L.S., Pallikkathayil, L. and Crighton, F. (2003). A qualitative investigation of fatigue among healthy working adults. Western journal of nursing research. 25, 419-433.

3. Wong, J.L., Regennitter, R.P. and Barrios, F. (1994). Base rate and simulated symptoms of mild head injury among normals. Archives of Clinical Neuropsychology. 9, 411-425.

4. Asken, B.M., Snyder, A.R., Clugston, J.R., Gaynor, L.S., Sullan, M.J. and Baver, R.M. (2017). Concussion-Like Symptom Reporting in Non-Concussed Collegiate Athletes. Archives of Clinical Neuropsychology. 32, 963-971.

5. Dean, P.J.A., O’Neill, D. and Sterr, A. (2012). Post-concussion syndrome: Prevalence after mild traumatic brain injury in comparison with a sample without head injury. Brain injury. 26, 14-26. 6. Delis, D.C. and Wetter, S.R. (2007). Cogniform disorder and cogniform condition: Proposed diagnoses for excessive cognitive symptoms. Archives of Clinical Neuropsychology. 22, 589-604. 7. Iverson, G.L. and Lange, R.T. (2003). Examination of" postconcussion-like" symptoms in a healthy sample. Applied Neuropsychology. 10, 137-144.

8. Voormolen, D.C., Cnossen, M.C., Polinder, S., Gravesteijn, B.Y., Von Steinbuechel, N., Real, R.G. and Haagsma, J.A. (2019). Prevalence of post-concussion-like symptoms in the general population in Italy, The Netherlands and the United Kingdom. Brain injury. 33, 1078-1086.

9. Wang, Y., Chan, R.C.K. and Deng, Y. (2006). Examination of postconcussion-like symptoms in healthy university students: relationships to subjective and objective neuropsychological function performance. Archives of Clinical Neuropsychology. 21, 339-347.

10. Zakzanis, K.K. and Yeung, E. (2011). Base rates of post-concussive symptoms in a nonconcussed multicultural sample. Archives of Clinical Neuropsychology. 26, 461-465.

11. Theadom, A., Parag, V., Dowell, T., McPherson, K., Starkey, N., Barker-Collo, S., Jones, K., Ameratunga, S. and Feigin, V.L. (2016). Persistent problems 1 year after mild traumatic brain injury: a longitudinal population study in New Zealand. Br J Gen Pract. 66, e16-23.

12. Scheenen, M.E., Spikman, J.M., de Koning, M.E., van der Horn, H.J., Roks, G., Hageman, G. and van der Naalt, J. (2016). Patients "at risk" of suffering from persistent complaints after mild traumatic brain injury: the role of coping, mood disorders and post-traumatic stress. Journal of neurotrauma.

13. Wäljas, M., Iverson, G.L., Lange, R.T., Hakulinen, U., Dastidar, P., Huhtala, H., Liimatainen, S., Hartikainen, K. and Öhman, J. (2015). A prospective biopsychosocial study of the persistent postconcussion symptoms following mild traumatic brain injury. Journal of neurotrauma. 32, 534-547. 14. Ponsford, J. (2017). Anxiety and depression following TBI. In: Neurobehavioural disability and social handicap following traumatic brain injury. McMillan, T.M., Wood, R.L. (eds). Routledge: Milton Park, Abingdon, Oxon; New York, NY, pps. 167-177. 
15. Silverberg, N.D., Gardner, A.J., Brubacher, J.R., Panenka, W.J., Li, J.J. and Iverson, G.L. (2015). Systematic review of multivariable prognostic models for mild traumatic brain injury. Journal of neurotrauma. 32, 517-526.

16. Cassidy, J.D., Cancelliere, C., Carroll, L.J., Côté, P., Hincapié, C.A., Holm, L.W., Hartvigsen, J., Donovan, J., Nygren-de Boussard, C. and Kristman, V.L. (2014). Systematic review of self-reported prognosis in adults after mild traumatic brain injury: results of the International Collaboration on Mild Traumatic Brain Injury Prognosis. Archives of Physical Medicine and Rehabilitation. 95, S132S151.

17. Vlaeyen, J.W., Crombez, G. and Linton, S.J. (2016). The fear-avoidance model of pain. Pain. $157,1588-1589$.

18. Cima, R.F., Maes, I.H., Joore, M.A., Scheyen, D.J., El Refaie, A., Baguley, D.M., Anteunis, L.J., van Breukelen, G.J. and Vlaeyen, J.W. (2012). Specialised treatment based on cognitive behaviour therapy versus usual care for tinnitus: a randomised controlled trial. The Lancet. 379, 1951-1959. 19. Wijenberg, M.L.M., Stapert, S.Z., Köhler, S. and Bol, Y. (2016). Explaining fatigue in multiple sclerosis: cross-validation of a biopsychosocial model. Journal of behavioral medicine. 39, 815-822. 20. Wijenberg, M.L.M., Hicks, A.J., Downing, M.G., van Heugten, C.M., Stapert, S.Z. and Ponsford, J.L. (2020). Relevance of the Fear-Avoidance Model for Chronic Disability after Traumatic Brain Injury. Journal of neurotrauma.

21. Wijenberg, M.L.M., Stapert, S.Z., Verbunt, J.A., Ponsford, J.L. and Van Heugten, C.M. (2017). Does the fear avoidance model explain persistent symptoms after traumatic brain injury? Brain injury. 31, 1597-1604.

22. Silverberg, N.D., Martin, P. and Panenka, W.J. (2019). Headache trigger sensitivity and avoidance after mild traumatic brain injury. Journal of neurotrauma.

23. Silverberg, N.D., Panenka, W.J. and Iverson, G.L. (2018). Fear avoidance and clinical outcomes from mild traumatic brain injury. Journal of neurotrauma. 35, 1864-1873.

24. Snell, D.L., Siegert, R.J., Debert, C., Cairncross, M. and Silverberg, N.D. (2020). Evaluation of the fear avoidance behavior after traumatic brain injury questionnaire. Journal of neurotrauma. 25. Houben, R.M., Leeuw, M., Vlaeyen, J.W., Goubert, L. and Picavet, H.S.J. (2005). Fear of movement/injury in the general population: factor structure and psychometric properties of an adapted version of the Tampa Scale for Kinesiophobia. Journal of behavioral medicine. 28, 415424.

26. Sullivan, M.J., Bishop, S.R. and Pivik, J. (1995). The pain catastrophizing scale: development and validation. Psychological assessment. 7, 524.

27. Trost, Z., France, C.R. and Thomas, J.S. (2011). Pain-related fear and avoidance of physical exertion following delayed-onset muscle soreness. Pain. 152, 1540-1547.

28. Vlaeyen, J.W., Kole-Snijders, A.M., Boeren, R.G. and Van Eek, H. (1995). Fear of movement/(re) injury in chronic low back pain and its relation to behavioral performance. Pain. 62, 363-372. 29. Jansen, A., Hout, M.v.d. and Merckelbach, H. (2010). Gek : experimentele psychopathologie : over angst, verslaving, depressie en andere ellende. Bohn Stafleu van Loghum: Houten. 
30. Forsyth, J.P. and Zvolensky, M.J. (2001). Experimental psychopathology, clinical science, and practice: An irrelevant or indispensable alliance? Applied and Preventive Psychology. 10, 243-264. 31. Lejuez, C., Kahler, C.W. and Brown, R.A. (2003). A modified computer version of the Paced Auditory Serial Addition Task (PASAT) as a laboratory-based stressor. The Behavior Therapist. 26 , 290-293.

32. Nock, M.K. and Mendes, W.B. (2008). Physiological arousal, distress tolerance, and social problem-solving deficits among adolescent self-injurers. Journal of Consulting and Clinical Psychology. 76, 28-38.

33. Berg, E.A. (1948). A simple objective technique for measuring flexibility in thinking. J Gen Psychol. 39, 15-22.

34. Vrijsen, J.N., Becker, E.S., Rinck, M., van Oostrom, I., Speckens, A., Whitmer, A. and Gotlib, I.H. (2014). Can memory bias be modified? The effects of an explicit cued-recall training in two independent samples. Cognitive Therapy and Research. 38, 217-225.

35. Crawford, J. and Doherty, L. (2011). Practical Aspects of ECG Recording. M \& K Update Ltd: Keswick.

36. King, N.S., Crawford, S., Wenden, F.J., Moss, N.E. and Wade, D.T. (1995). The Rivermead Post Concussion Symptoms Questionnaire: a measure of symptoms commonly experienced after head injury and its reliability. J Neurol. 242, 587-592.

37. Osman, A., Barrios, F.X., Gutierrez, P.M., Kopper, B.A., Merrifield, T. and Grittmann, L. (2000). The Pain Catastrophizing Scale: Further psychometric evaluation with adult samples. Journal of behavioral medicine. 23, 351-365.

38. Roelofs, J., Sluiter, J.K., Frings-Dresen, M.H.W., Goossens, M., Thibault, P., Boersma, K. and Vlaeyen, J.W.S. (2007). Fear of movement and (re)injury in chronic musculoskeletal pain: Evidence for an invariant two-factor model of the Tampa Scale for Kinesiophobia across pain diagnoses and Dutch, Swedish, and Canadian samples. Pain. 131, 181-190.

39. Goubert, L., Crombez, G., Van Damme, S., Vlaeyen, J.W.S., Bijttebier, P. and Roelofs, J. (2004). Confirmatory Factor Analysis of the Tampa Scale for Kinesiophobia: Invariant Two-Factor Model Across Low Back Pain Patients and Fibromyalgia Patients. The Clinical Journal of Pain. 20, 103-110. 40. Roelofs, J., Goubert, L., Peters, M.L., Vlaeyen, J.W. and Crombez, G. (2004). The Tampa Scale for Kinesiophobia: further examination of psychometric properties in patients with chronic low back pain and fibromyalgia. European Journal of Pain. 8, 495-502.

41. Spielberger, C.D. (1983). Manual for the State-Trait Anxiety Inventory STAI (form Y)(" selfevaluation questionnaire").

42. Van der Ploeg, H., Defares, P. and Spielberger, C. (1980). Handleiding bij de zelfbeoordelings vragenlijst (ZBV)[manual of the Dutch version of the State Trait Anxiety Inventory]. Lisse: Swets and Zeitinger.

43. Rossi, V. and Pourtois, G. (2012). Transient state-dependent fluctuations in anxiety measured using STAI, POMS, PANAS or VAS: a comparative review. Anxiety, Stress \& Coping. 25, 603-645. 44. Beck, A.T., Steer, R.A. and Brown, G.K. (1996). Beck depression inventory-II. San Antonio. 78, 490-498. 
45. Van der Does, A. (2002). De Nederlandse versie van de Beck depression inventory-Tweede Editie.[The Dutch version of the Beck depression inventory-]. Lisse, The Netherlands: Swets \& Zeitlinger.

46. Wang, Y.-P. and Gorenstein, C. (2013). Psychometric properties of the Beck Depression Inventory-II: a comprehensive review. Braz J Psychiatry. 35, 416-431.

47. Leung, L. (2012). Pain catastrophizing: an updated review. Indian journal of psychological medicine. 34, 204.

48. Cook, A.J., Brawer, P.A. and Vowles, K.E. (2006). The fear-avoidance model of chronic pain: validation and age analysis using structural equation modeling. Pain. 121, 195-206.

49. Verbunt, J.A., Smeets, R.J. and Wittink, H.M. (2010). Cause or effect? Deconditioning and chronic low back pain. Pain. 149, 428-430.

50. Wideman, T.H., Asmundson, G.G.J., Smeets, R.J.E.M., Zautra, A.J., Simmonds, M.J., Sullivan, M.J.L., Haythornthwaite, J.A. and Edwards, R.R. (2013). Rethinking the fear avoidance model: toward a multidimensional framework of pain-related disability. Pain. 154, 2262-2265.

51. Lundberg, M., Grimby-Ekman, A., Verbunt, J. and Simmonds, M. (2011). Pain-related fear: a critical review of the related measures. Pain research and treatment. 2011.

52. Leeuw, M., Goossens, M.E., van Breukelen, G.J., Boersma, K. and Vlaeyen, J.W. (2007). Measuring perceived harmfulness of physical activities in patients with chronic low back pain: the Photograph Series of Daily Activities-short electronic version. The Journal of Pain. 8, 840-849. 53. Pincus, T., Burton, A.K., Vogel, S. and Field, A.P. (2002). A systematic review of psychological factors as predictors of chronicity/disability in prospective cohorts of low back pain. Spine. 27, E109-E120.

54. van Mierlo, M.L., Schröder, C., van Heugten, C.M., Post, M.W., de Kort, P.L. and Visser-Meily, J.M. (2014). The influence of psychological factors on Health-Related Quality of Life after stroke: a systematic review. International journal of stroke. 9, 341-348.

55. Bernstein, E.E., Kleiman, E.M., van Bork, R., Moriarity, D.P., Mac Giollabhui, N., McNally, R.J., Abramson, L.Y. and Alloy, L.B. (2019). Unique and predictive relationships between components of cognitive vulnerability and symptoms of depression. Depression and Anxiety, 1-10.

56. Moroz, M. and Dunkley, D.M. (2019). Self-critical perfectionism, experiential avoidance, and depressive and anxious symptoms over two years: A three-wave longitudinal study. Behaviour research and therapy. 112, 18-27.

57. Riskind, J.H. and Alloy, L.B. (2006). Cognitive Vulnerability to Psychological Disorders: Overview of Theory, Design, And Methods. Journal of Social and Clinical Psychology. 25, 705-725. 58. Brown, R.J. (2004). Psychological mechanisms of medically unexplained symptoms: an integrative conceptual model. Psychological bulletin. 130, 793.

59. Hasenbring, M.I. and Verbunt, J.A. (2010). Fear-avoidance and endurance-related responses to pain: new models of behavior and their consequences for clinical practice. The Clinical Journal of Pain. 26, 747-753.

60. Fear, N., Jones, E., Groom, M., Greenberg, N., Hull, L., Hodgetts, T. and Wessely, S. (2009). Symptoms of post-concussional syndrome are non-specifically related to mild traumatic brain 
injury in UK Armed Forces personnel on return from deployment in Iraq: an analysis of selfreported data. Psychological medicine. 39, 1379.

61. Iverson, G.L. (2006). Misdiagnosis of the persistent postconcussion syndrome in patients with depression. Archives of Clinical Neuropsychology. 21, 303-310.

62. Harris, A.M., Orav, E.J., Bates, D.W. and Barsky, A.J. (2009). Somatization increases disability independent of comorbidity. Journal of general internal medicine. 24, 155.

63. Leising, D., Grande, T. and Faber, R. (2009). The Toronto Alexithymia Scale (TAS-20): A measure of general psychological distress. Journal of Research in Personality. 43, 707-710. 64. Zenger, M., Berth, H., Brähler, E. and Stöbel-Richter, Y. (2013). Health complaints and unemployment: The role of self-efficacy in a prospective cohort study. Journal of Social and Clinical Psychology. 32, 97-115. 



\section{Chapter 7}

\section{Relevance of the Fear-Avoidance Model for Chronic Disability after Traumatic Brain Injury.}

Wijenberg, M. L. M., Hicks, A. J., Dowñing, M. G., van Heugten, C. M., Stapert, S. Z., \& Ponsford, J, L. (2020). Journal of Neurotrauma,

$37(24), 2639-2646$.

doi: $10.1089 /$ nevi2020.7135. 


\begin{abstract}
Previous studies convincingly suggest that the biopsychosocial fearavoidance model (FAM) may be of added value in understanding chronic disability after traumatic brain injury (TBI). In this model, persistent symptoms occur as a result of catastrophizing and fear-avoidance regarding initial symptoms, leading to depression, reduced mental activity, and greater disability in daily functioning. This study examined the FAM in a large Englishspeaking TBI sample. A cross-sectional study was conducted in 117 individuals with complicated mild, moderate, or severe TBI at 1-5 years postinjury. Participants completed questionnaires assessing personal, injuryrelated, and psychological characteristics. Reliability, correlational, and regression analyses were performed. Main outcome measures of chronic disability were depression, disuse (e.g., fewer mental activities), and functional disability. The results revealed that all correlations suggested by the FAM were significant. Catastrophizing thoughts were positively associated with TBI-related symptoms and fear-avoidance thoughts. Main outcome measures were positively associated with fear-avoidance thoughts and TBI-related symptoms. Further, variables in the FAM were of additive value to personal, injury-related, and psychological variables in understanding chronic disability after TBI. The separate regression analyses for depression, fewer mental activities, and disability revealed "fearavoidance thoughts" as the only consistent variable. In conclusion, this study shows the association of the FAM with chronic disability after TBI, which has implications for assessment and future management of the FAM in TBI in English-speaking countries. Longitudinal studies are warranted to further investigate and refine the model.
\end{abstract}

Keywords: chronic disability; chronic phase; fear-avoidance model; traumatic brain injury 


\section{Introduction}

Traumatic brain injury (TBI) poses a major global health issue because of its high prevalence and significant societal costs. ${ }^{1}$ Severity of TBI is commonly categorized as mild, moderate, or severe depending on duration of post-traumatic amnesia (PTA), loss of consciousness, or Glasgow Coma Scale (GCS) score. ${ }^{2}$ TBI is associated with significant functional, emotional, cognitive, and behavioral symptoms that impact daily functioning and reduce quality of life. ${ }^{3}$ However, the extent and duration of these symptoms vary across individuals and their impact on chronic disability, such as impaired daily life functioning, is not fully explained by injury-related or personal variables only (e.g., injury severity parameters, time since injury, age, or education).4-11 Numerous studies have highlighted the potential contribution of psychosocial variables (e.g., personality, coping style, anxiety, and depression) to explain chronic disability. ${ }^{8-18}$ The contribution of all these variables suggests the need for a biopsychosocial approach to understand chronic disability after TBI.

One potential biopsychosocial approach that may explain persistent symptoms is the fear-avoidance model (FAM). This model has been validated in various other patient populations with bodily distress syndromes including those with chronic pain, tinnitus, chronic fatigue, whiplash syndrome, and fibromyalgia, as well as in cancer survivors. ${ }^{19-24}$ These syndromes have in common that they start with symptoms that evolve into chronic symptomatology in only a subset of patients. The FAM states that individual psychological reactions to changes as a consequence of an injury can influence the development and course of symptoms and eventually the emotional adaptation to these changes. ${ }^{25}$ Applying this model to symptoms after TBI, the persistent symptoms (i.e., somatic, cognitive and emotional changes) are interpreted as a sign of severe brain pathology over which one experiences little or no control. Such catastrophizing thoughts tend to result in fear and avoidance of mental activities, also labeled as cogniphobia ${ }^{26,27}$, and subsequently decrease activity levels, resulting in progressive symptoms of depression, reduction in mental activities (disuse), and enhanced functional disability (e.g., decreased ability to perform daily life activities such as work or social activities). This could, in turn, increase the number and magnitude of symptoms, concluding the cyclic pattern. ${ }^{26,27}$ This adapted FAM is depicted in Fig. 
1. Please note that the FAM poses "depression"/"disuse"/"disability" on the same level in the cycle, assuming that high levels of fear-avoidance would lead to high levels of depression, disuse, and disability, and that these outcomes of chronic disability would then fuel the symptoms concluding its cyclic pattern.

Fig. 1. The fear-avoidance model applied to TBI.

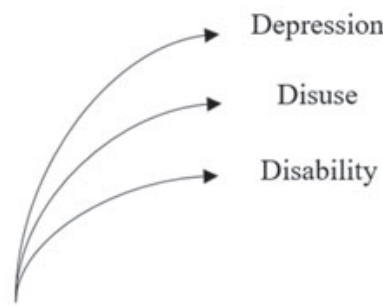

TBI-related fear-avoidance

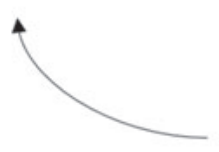

TBI-related

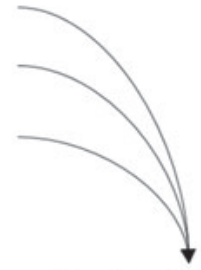

Persistent TBI-related symptoms catastrophizing

Notes. Schematic overview of fear-avoidance model applied to TBI, permitted by Wijenberg et al. ${ }^{28}$. TBI, Traumatic Brain Injury.

Preliminary studies have suggested that the FAM, or fear-avoidance on its own, is associated with chronic disability after TBI, ${ }^{28,29}$ especially in mild TBI where there can be a clear mismatch between the expected good recovery and the unexpected persistence of symptoms. A discrepancy that is still not understood, Wijenberg et al. ${ }^{28}$ conducted a small cross-sectional study in which they found the first evidence for the FAM in individuals with TBI of all severities ( $N=48$ ). Further, a prospective larger study by Silverberg et al. ${ }^{29}$ highlighted the importance of fear-avoidance in understanding chronic disability after mild TBI. Despite the promising results, these studies are limited by their use of self-report measurements that require validation in TBI samples, small sample size, or having examined only the influence of fear-avoidance rather than additional variables in the proposed biopsychosocial FAM (see Fig. 1).

Therefore, this large cross-sectional study has two aims: first, to examine the associations among the variables of the FAM (see Fig. 1) in a large cohort of individuals with complicated mild to severe TBI; and, second, to investigate 
whether elements of the FAM (TBI-related symptoms, catastrophizing thoughts, and fear-avoidance thoughts) would make an independent contribution to depression, disuse, and functional disability after TBI over and above the contribution of known personal, injury-related, and other psychological variables (e.g., pre-injury psychological treatment). Based on recent studies, it was hypothesized that the associations would be consistent with the FAM (see Fig. 1; e.g., catastrophizing thoughts will be positively associated with TBI-related symptoms and fear-avoidance thoughts, whereas depression, disuse, and functional disability will be positively associated with fear-avoidance thoughts and TBI-related symptoms). Further, we hypothesize that elements of the FAM (TBIrelated symptoms, catastrophizing thoughts, and fear-avoidance thoughts) would make an independent contribution to chronic disability after TBI in terms of mood, disuse, and functional disability.

\section{Methods}

\section{Participants and procedures.}

Participants were recruited at Monash Epworth Rehabilitation Research Centre (MERRC), Melbourne, Australia. Inclusion criteria were: (1) diagnosis of complicated mild to severe TBI, established by acute hospital evaluation; (2) date of injury between January 1, 2014 and January 1, 2018; and (3) being able to complete English online questionnaires (with assistance if needed). Individuals were invited to participate from December 2018 to March 2019, ensuring that data collection took place between 1 and 5 years post-injury.

Invitation letters were sent via e-mail or postal mail to eligible participants of an ongoing longitudinal cohort study ${ }^{30,31}$, who had provided consent to be approached for other studies. If willing to participate, they provided informed consent and completed the questionnaires online (after entering their unique study identifier) or over the phone with author M.L.M.W.. All procedures were approved by and in accordance with Epworth Healthcare and Monash University Human Research Ethics Committee (Project ID 16792). Participants did not receive any financial compensation for their participation. 


\section{Measures}

Basic demographic information. Personal characteristics including gender, age, education years, marital status, and employment status were retrieved from the MERRC research database following informed consent. Medical data including time since injury, cause of injury, multi-trauma (e.g., comorbid orthopedic injuries), and severity of TBI were also retrieved from the research database. Indices for severity of injury were the GCS score and PTA duration, measured prospectively using the Westmead PTA Scale ${ }^{32}$. Injury severity was based on PTA duration as follows: < 24 h, mild; 24 h to 1 week, moderate; > 1 week, severe. ${ }^{33}$ In cases of mild TBI, indications for complicated mild TBI (presence of abnormalities on computed tomography [CT]) were checked. Further, six yes/no-questions were asked at the beginning of the survey to assess pre-and post-injury neurological history, psychological treatment, and drug/alcohol abuse.

The fear-avoidance model.

TB/-related symptoms. Symptoms and symptom severity were assessed with the Rivermead Post-Concussion Symptom Questionnaire (RPQ), developed by King et al. ${ }^{34}$. This is a valid and reliable measure in individuals with mild to more severe TBI. ${ }^{35}$ It consists of 16 items, rated on a five-point Likert scale, measuring severity of symptoms in the past 24 hours in comparison with pre-injury levels. The total score ranges from 0 to 64 , with a higher score indicating a higher frequency and impact of symptoms. The presence of three or more remaining symptoms, indicated by at least three items with an item score of 2 or higher, was used as criterion for persistent disabling symptoms. ${ }^{28}$

Catastrophizing thoughts. Catastrophizing thoughts about TBI-related symptoms were assessed with the English version of the Post-Concussion Symptoms Catastrophizing Scale (PCS-CS). ${ }^{28}$ The PCS-CS has an excellent internal consistency and has been previously used in individuals with TBI. ${ }^{28}$ It consists of 13 items, rated on a five-point Likert scale, measuring the self-reported frequency of catastrophizing thoughts about an individual's self-reported symptoms on the RPQ. The score ranges from 0 and 52, with higher scores indicating a higher intensity of catastrophizing thoughts. The internal consistency of the PCS-CS in this study was excellent (Cronbach's $\alpha=0.97, n=116$ ). ${ }^{36,37}$ The questionnaire is 
available on request. Although online administration is preferred for the PCS-CS (e.g., enabling tailored instructions to a person's answer on the RPQ), see supplementary text for an overview of the questions.

Fear-avoidance thoughts. TBI-related fear-avoidance thoughts were assessed with the English version of the Fear of Mental Activity scale (FMA). ${ }^{28}$ The FMA has a good internal consistency and has been used in individuals with TBI before. ${ }^{28}$ It includes 17 items, rated on a 4-point Likert scale, measuring the selfreported frequency of fear-avoidance thoughts related to an individual's selfreported symptoms on the RPQ. In line with validation studies of the chronic pain fear-avoidance measure that the FMA is derived from ${ }^{38-40}$, the four reversed items were not used in the scoring, resulting in 13 items. The score ranges from 13 to 52. The internal consistency of the 13-item FMA in this study was excellent (Cronbach's $\alpha=0.93, n=113$ ). ${ }^{36,37}$ The questionnaire is available on request. Although online administration is preferred for the FMA (e.g., enabling tailored instructions to a person's answer on the RPQ), see supplementary text for an overview of the questions.

Depressive symptoms. Depressive symptoms were assessed with the depression subscale of the Hospital Anxiety and Depression Scale (HADS). ${ }^{41}$ It is a valid and reliable measure in individuals with TBI. ${ }^{42}$ It consists of seven items rated on a four-point Likert Scale with the total score ranging from 0 to 21 . A higher score indicates greater severity, with a score higher than 7 indicating clinically significant symptoms. ${ }^{42}$

Disuse. Validated questionnaires to assess "disuse of the brain" are lacking. We translated disuse in the TBI-related FAM to "amount of mental activity". Therefore, disuse was assessed with one question: "How many hours a day do you currently spend performing mental activities such as writing, working on the computer, reading, and participating in a meeting?". In this study, "amount of mental activity" represents the inverse of "disuse" indicated by number of hours spent on mental activity per day. In other words, the scores were reversed to represent "disuse".

Disability. Functional disability was assessed with the self-report version of the Glasgow Outcome Scale - Extended (GOS-E), developed by Wilson et al. ${ }^{43}$. The original GOS-E, administered as an interview and developed by Jennett et al. ${ }^{44}$, 
and the original GOS are the most widely used and accepted instruments in neurotrauma research for assessing outcomes after TBI. ${ }^{45}$ The postal version of the GOS-E is also found to be reliable to assess global outcome or disability. ${ }^{43}$ Based on a structured scoring system, the score ranges from 1 to 8 , with a higher score indicating a better global outcome. A score of $\leq 6$ was used as indication of functional disability. ${ }^{17}$

\section{Statistical analysis}

Data analyses were performed using SPSS Statistics 24.0 for windows (IBM Corp., Armonk, NY). Missing data were not imputed and were treated as missing in all analyses. Distributions of all variables were evaluated in terms of mean, standard deviation (SD), median, range, skewness, and kurtosis. Outliers and assumptions were checked. In case of non-normality (skewness or kurtosis values not between -1 and 1), non-parametric statistics were used. Sample characteristics are described by descriptive statistics. Participants were compared with nonresponders on basic demographic information using Mann-Whitney $U$ tests for non-normal distributed continuous variables, independent sample $t$ tests for normal distributed continuous variables and Pearson $\chi^{2}$ tests for categorical variables. For all statistical tests, unless stated otherwise, an $\alpha$ level of 0.05 was used.

To test the relationships within the FAM (see Fig. 1), the correlations of the FAM were calculated by Spearman correlations (in case of non-normality and/or ordinal variables).

To explore whether the FAM explains depression, disuse, and functional disability independently after controlling for known variables, the interrelationships of depression, disuse, and functional disability with personal, injury-related, psychological characteristics, and the additional FAM variables were examined. Personal characteristics included age, gender, education years, employment status, marital status, and assessment method (online/over the phone). Injury-related characteristics included GCS score, PTA duration, time since injury, cause of injury, multi-trauma, and neurological history (pre- and postinjury). Psychological characteristics included psychological treatment (pre- and post-injury) and drug/alcohol abuse (pre- and post-injury). The FAM variables 
included TBI-related symptoms, catastrophizing thoughts, and fear-avoidance thoughts.

For the interval variables, depression and disuse, backward multiple regression analyses were performed. Dummy variables were created for categorical variables (gender, employment status, marital status, assessment method, cause of injury, multi-trauma, pre- and post-injury neurological history, psychological treatment, and drugs/alcohol abuse). The continuous variables (age, education in years, GCS score, PTA duration, time since injury, TBI-related symptoms, catastrophizing thoughts, fear-avoidance thoughts) were centered (subtracting the median in case of non-normality or the mean in case of normality) and their quadratic terms were added. To prevent type 2-errors, the least significant variable was removed stepwise with a threshold of $\alpha=0.10$. In this process, dummy variables were treated as a block. Outliers (using box plots, studentized residuals and centered leverage values) and influential cases (using Cook's distance) were checked and if influential, removed as case. Collinearity and the homogeneity of residual variance were also checked for the full and final models.

For the ordinal variable, functional disability, the GOS-E was recoded into two groups: "Good Recovery" and "Poor Recovery", The outcomes "upper good" and "lower good" recovery were merged to create "Good Recovery", whereas the outcomes "upper moderate disability" - "vegetative state" denoted "Poor Recovery", resulting in a binary split used in other studies such as that of Ponsford et al. ${ }^{17}$. Because of the limited sample size and the skewed distribution of many independent variables, binomial hierarchical logistical regression analysis was performed with the variables significantly related to GOS-E in the bivariate analyses. Mann-Whitney $U$ tests (continuous variables) and Pearson $\chi 2$ analysis (categorical variables) were used to compare performances of those in the "Good Recovery" with those in the "Poor Recovery" group according to personal, injuryrelated, and psychological characteristics, and the additional FAM variables. Only measures that were significantly related to GOS-E in the bivariate analyses were entered into the binomial hierarchical logistical regression. This regression was conducted to establish (1) whether the included FAM variables would improve the fit compared with included personal, injury-related, and other psychological 
characteristics and (2) how well this model differentiated the "Good Recovery" from the "Poor Recovery" group. Bonferroni corrections for multiple comparisons were applied separately for each set of statistical tests. ${ }^{46}$ This strategy resulted in significance levels of $\rho=0.0125$ for the bivariate comparisons of continuous personal and injury-related variables with outcome; 0.0038 for the categorical personal and injury-related variables; 0.0167 for the bivariate comparisons of the addition FAM variables; and 0.0050 for the logistical regressions. Assumption of linearity of the continuous variables with respect to the logit of the dependent variable was assessed via the Box-Tidwell procedure. ${ }^{47}$ Further, the receiver operating characteristics (ROC) curve was inspected to reveal the discriminative value of the final model.

\section{Results}

\section{Participants}

Of the 191 individuals approached, 64 did not agree to participate and 10 were not reached, resulting in 117 participants (61.3\%). In total, 43 participants requested a phone interview to complete the questionnaires (36.8\%), and four stopped during the assessment (3.4\%). Two participants did not enter their unique study identifier when completing the questionnaires online, resulting in an anonymous response and preventing appropriate extraction of demographic information from the MERRC research database.

The final sample included 74 men and 41 women with a mean age of 51.63 years $(S D=18.75 ;$ [18-87]). In most cases, TBI was caused by traffic accidents (84.3\%). Based on PTA duration, injury severity was considered mild for $13.5 \%$ (PTA < 24 h), moderate for 17.3\% (PTA = 1-7 days), and severe for $69.2 \%$ (PTA > 7 days). The mild group consisted solely of individuals with complicated mild TBI (presence of abnormalities on CT). Regarding work status, 63.7\% were employed before the injury and $29.2 \%$ reported being able to work at the same level without problems after the injury. See Table 1 for an overview of all participants' characteristics. Sample size deviations are the results of missing data in the MERRC research database or items missed by participants during online administration. Participants were older $(\Delta M=17.02$ years; $U=2146.50$; standard error $[S E]=373.84 ; \rho<0.01)$ and more often married $\left(\chi^{2}[5]=25.28 ; \rho<0.01\right)$ 
than non-responders. No group differences were found for any other personal characteristics (gender, education years, and employment status) or medical data (time since injury, cause of injury, multi-trauma, GCS score, and PTA duration).

Table 1. Descriptives of participants.

\begin{tabular}{|c|c|c|c|}
\hline & $n$ & Value $^{a}$ & $\%$ \\
\hline \multicolumn{4}{|l|}{ Personal characteristics } \\
\hline Age (years) & 115 & $52(34)[18-87]$ & \\
\hline Gender & 115 & & $64.3 \%$ male \\
\hline Education years & 105 & $11.97(2.39)[8-18]$ & \\
\hline Employment status pre-injury & 115 & & $\begin{array}{l}\text { 49.6\% full-time employed } \\
4.3 \% \text { part-time employed }\end{array}$ \\
\hline Working status: pre-injury (GOS-E) & 113 & & $63.7 \%$ employed \\
\hline Working status: current (GOS-E) & 113 & & $\begin{array}{l}29.2 \% \text { same work without } \\
\text { problems } \\
23.0 \% \text { unable to work due to } \\
\text { TBI }\end{array}$ \\
\hline Marital status & 113 & & $50.4 \%$ married or de facto \\
\hline Assessment method & 115 & & $\begin{array}{l}62.6 \% \text { online } \\
37.4 \% \text { guided over the phone }\end{array}$ \\
\hline \multicolumn{4}{|l|}{ Injury-related characteristics } \\
\hline GCS score & 105 & $12(8)[3-15]$ & \\
\hline PTA duration (days) & 104 & 15 (19) [0-180] & \\
\hline Time since injury (years) & 115 & $2.65(1.16)[1-5]$ & \\
\hline Cause of injury & 115 & & $84.3 \%$ traffic accident \\
\hline Multi-trauma & 115 & & 80.0\% multi-trauma \\
\hline Neurological history pre-injury & 117 & & $3.4 \%$ yes \\
\hline Neurological history post-injury & 117 & & $30.2 \%$ yes \\
\hline \multicolumn{4}{|l|}{ Psychological characteristics } \\
\hline Psychological treatment pre-injury & 117 & & $26.5 \%$ yes \\
\hline Psychological treatment post-injury & 117 & & $53.8 \%$ yes \\
\hline Drugs/alcohol abuse pre-injury & 117 & & $9.4 \%$ yes \\
\hline Drugs/alcohol abuse post-injury & 117 & & $4.3 \%$ yes \\
\hline
\end{tabular}

Notes. ${ }^{a}$ Depending on normality, mean (standard deviation) [range] or median (interquartile range) [range] are reported. GOS-E, Glasgow Outcome Scale - Extended; GCS, Glasgow Coma Scale; PTA, post-traumatic amnesia.

\section{Relationships within the FAM}

See Table 2 for an overview of the scores on elements of the FAM and their percentage of participants with an impairment as defined by available cutoff scores (see Methods section). Spearman correlation analyses revealed that all correlations suggested by the FAM were significant $(\rho<0.05)$. See Fig. 2 for a graphical presentation of the correlations within the FAM. Catastrophizing thoughts were positively associated with TBI-related symptoms $(r=0.80)$ and fear-avoidance thoughts $(r=0.70)$. Although all outcome measures (depression, disuse, and disability) were positively associated with fear-avoidance thoughts 
and TBI-related symptoms, the strongest association was seen between depression and TBI-related symptoms $(r=0.80)$.

Table 2. Descriptives of the fear-avoidance model.

\begin{tabular}{llll}
\hline & $n$ & $V a l v e^{a}$ & $\% /$ \\
\hline TBI-related symptoms (RPQ) & 115 & $24(23)[0-54]$ & 80.0 \\
Catastrophizing thoughts (PCS-CS) & 116 & $12.27(13.07)[0-52]$ & - \\
Fear-avoidance thoughts (FMA) & 113 & $25.19(8.33)[13-44]$ & - \\
Depression (HADS D) & 113 & $6.12(4.68)[0-18]$ & 36.3 \\
Disuse (amount of mental activity) & 112 & $4.26(3.11)[0-15]$ & - \\
Disability (GOS-E) & 113 & $6.34(1.29)[3-8]$ & 55.8 \\
\hline
\end{tabular}

Notes. ${ }^{\circ}$ For continuous variables depending on normality, mean (standard deviation) [range] or median (interquartile range) [range] are reported. \%l, percentage of participants with an impairment as defined by the cutoff scores (see Methods section); RPQ, Rivermead PostConcussion Symptom Questionnaire; PCS-CS, Post-Concussion Symptoms Catastrophizing Scale; FMA, Fear of Mental Activity scale; HADS D, Depression subscale of the Hospital Anxiety and Depression Scale; GOS-E =, Glasgow Outcome Scale - Extended.

Figure 2. Spearman correlations of the fear-avoidance model in the current sample.

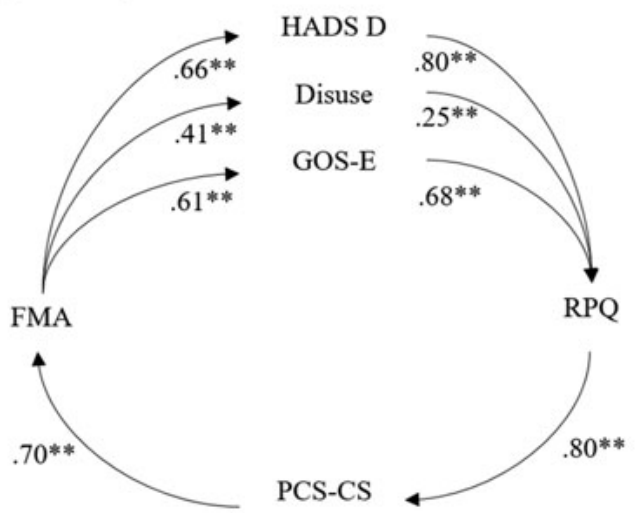

Notes. Values shown are based on cross-sectional data. ${ }^{*} p<0.05,{ }^{* *} p<0.01$. HADSD, Depression subscale of the Hospital Anxiety and Depression Scale; GOS-E, Glasgow Outcome Scale Extended; FMA, Fear of Mental Activity scale; RPQ, Rivermead Post-Concussion Symptom Questionnaire; PCS-CS, Post-Concussion Symptoms Catastrophizing Scale.

\section{Explanation of depression}

Eight outliers were identified according to centered leverage values, and were removed for the final model. The final model revealed that TBl-related symptoms, fear-avoidance thoughts, and post-injury neurological history were significantly associated with depression $(f 3,99]=59.79, \rho<0.01)$, accounting for $64.4 \%$ of the variation in depression (see Table 3 ). The results show that participants who reported more TBI-related symptoms, fear-avoidance thoughts, or no other neurological disease post-injury, reported more depressive symptoms. 
Table 3. Final regression model for the outcomes Depression and Disuse.

\begin{tabular}{|c|c|c|c|c|c|c|c|c|}
\hline & \multicolumn{4}{|c|}{ Depression $(n=103)^{a}$} & \multicolumn{4}{|c|}{ Disuse $(n=99)^{b}$} \\
\hline Predictor & $B$ & $\beta$ & $\begin{array}{l}S E \\
\text { of } B\end{array}$ & $\rho$ & $B$ & $\beta$ & $\begin{array}{l}\text { SE of } \\
B\end{array}$ & $\rho$ \\
\hline Constant & 5.69 & & 0.31 & $<0.01$ & 4.20 & & 0.27 & $<0.01$ \\
\hline Fear-avoidance thoughts & 0.11 & 0.21 & 0.05 & 0.02 & -0.10 & -0.28 & 0.03 & $<0.01$ \\
\hline TBI-related symptoms & 0.21 & 0.70 & 0.03 & $<0.01$ & & & & \\
\hline $\begin{array}{l}\text { Neurological history } \\
\text { post-injury }\end{array}$ & 0.83 & 0.16 & 0.35 & 0.02 & & & & \\
\hline Education years & & & & & 0.39 & 0.32 & 0.12 & $<0.01$ \\
\hline
\end{tabular}

Notes. ${ }^{\circ}$ Depression; scale range $=[0.00 ; 18.00], R^{2}=0.64, M S E=7.61$. The prediction equation was "depression $=5.69+0.21 \times \mathrm{TBI}$-related symptoms $(\mathrm{RPQ}-24)+0.11 \times$ fear-avoidance thoughts (FMA-25.19) $+0.83 \times$ post-injury neurological history $(-1=\text { yes; }+1=n 0)^{\prime \prime}$. 'Disuse; scale range $=[0.00 ; 12.00], R^{2}=0.22, M S E=7.12$. The prediction equation was "hours performing mental activities $=4.20+0.39 \times$ education years (education years -11.97$)+-0.10 \times$ fearavoidance thoughts (FMA-25.19)". TBI, traumatic brain injury; MSE, mean squared error; RPQ, score on Rivermead Post-Concussion Symptom Questionnaire; FMA, score on Fear of Mental Activity Scale.

\section{Explanation of disuse}

One outlier on disuse was identified and removed for the final model. The final model revealed that fear-avoidance thoughts and years of education were associated with disuse $(F[2,96]=13.73, \rho<0.01)$, accounting for $22.2 \%$ of the variation in disuse (see Table 3 ). The results show that participants, who reported more fear-avoidance thoughts or had completed fewer education years reported having spent less time on mental activities.

\section{Explanation of functional disability}

Bivariate analyses revealed that only age, post-injury neurological history, TBIrelated symptoms, catastrophizing thoughts, and fear-avoidance thoughts were significantly related to functional disability. Age was significantly higher in the "Good Recovery" group $\Delta$ Mean Rank = 15.47; $U=1942.50 ; S E=168.34 ; \rho=0.01$ ). $\left(\chi^{2}(5)=25.28 ; \rho<0.01\right)$, whereas pre-injury neurological history was significantly less prevalent in the "Good Recovery" group $\left(\chi^{2}(1)=12.43 ; \rho<0.01\right)$. Specifically for the FAM-related variables, the "Good Recovery" group was significantly associated with lower levels of TBI-related symptoms ( $\triangle$ Mean Rank = 36.45; $U=$ 541.00; $S E=170.78 ; \rho<0.01)$, catastrophizing thoughts ( $\triangle$ Mean Rank = 33.90; $U$ =630.00; SE = 172.17; $\rho<0.01$ ), and fear-avoidance thoughts ( $\Delta$ Mean Rank= 33.31; $U=646.50 ; S E=172.69 ; \rho<0.01)$. A binomial logistical hierarchical 
regression was performed to ascertain the association of age, post-injury neurological history, catastrophizing, fear-avoidance and TBI-related symptoms with the likelihood that participants reported good recovery. Based on this assessment, there were two outliers identified and all assumptions, including no multicollinearity, were met. At the first step (age + post-injury neurological history), the logistical regression model was statistically significant $\left(\chi^{2}[2]=14.68\right.$, $\rho<0.01)$. At the second step (+ FAM-related variables) the logistical regression model was statistically significant as well $\left(\chi^{2}[5]=50.53, \rho<0.01\right)$ and significantly improved compared with the previous step $\left(\chi^{2}[3]=35.85, \rho<0.01\right)$ (see Table 4). The final model explained $49.7 \%$ (Nagelkerke $R^{2}$ ) of the variance in functional disability and correctly classified $78.9 \%$ of cases. Sensitivity was $79.2 \%$ and specificity was $78.7 \%$. Of the five independent variables, none were statistically significant ( $\rho>0.05$ ). The area under the ROC curve was 0.87 (95\% confidence interval [Cl], 0.798-0.931), which is an excellent level of discrimination according to Hosmer et al. ${ }^{48}$.

Table 4. Logistical regression predicting likelihood of good recovery based on age, post-injury neurological injury, and FAM-related variables.

\begin{tabular}{|c|c|c|c|c|c|c|c|c|}
\hline \multirow{3}{*}{ Predictor } & \multicolumn{8}{|c|}{ Disability $(\mathrm{n}=109)$} \\
\hline & \multirow[t]{2}{*}{$B$} & \multirow[t]{2}{*}{$S E$} & \multirow[t]{2}{*}{ Wald } & \multirow[t]{2}{*}{$d f$} & \multirow[t]{2}{*}{$\rho$} & \multirow{2}{*}{$\begin{array}{l}\text { Odds } \\
\text { Ratio }\end{array}$} & \multicolumn{2}{|c|}{ 95\% Cl for Odds Ratio } \\
\hline & & & & & & & Lower & Upper \\
\hline Constant & 4.46 & 1.42 & 9.90 & 1 & $<0.01$ & 86.76 & & \\
\hline Age & -0.02 & 0.02 & 1.42 & 1 & 0.23 & 0.98 & 0.95 & 1.01 \\
\hline $\begin{array}{l}\text { Post-injury } \\
\text { neurological history }\end{array}$ & -1.31 & 0.73 & 3.19 & 1 & 0.07 & 0.27 & 0.07 & 1.14 \\
\hline $\begin{array}{l}\text { TBI-related } \\
\text { symptoms }\end{array}$ & -0.05 & 0.03 & 2.21 & 1 & 0.14 & 0.96 & 0.90 & 1.02 \\
\hline $\begin{array}{l}\text { Catastrophizing } \\
\text { thoughts }\end{array}$ & -0.05 & 0.04 & 1.74 & 1 & 0.19 & 0.95 & 0.88 & 1.03 \\
\hline $\begin{array}{l}\text { Fear-avoidance } \\
\text { thoughts }\end{array}$ & -0.08 & 0.05 & 3.18 & 1 & 0.07 & 0.92 & 0.84 & 1.01 \\
\hline $\begin{array}{l}\text { Notes. FAM, Fear-Av } \\
\text { defined as "1 = good } \\
\text { Outcome Scale - Ext } \\
\text { and "O = no history". }\end{array}$ & nded. & ost-in & euro & ic & $\begin{array}{l}\text { al, cor } \\
\text { sed o } \\
\text { ory is }\end{array}$ & ded & erval. [ & $\begin{array}{l}\text { bility is } \\
\text { Glasgow } \\
\text { gical history" }\end{array}$ \\
\hline
\end{tabular}

\section{Discussion}

The current study examined the FAM in a large English-speaking TBI sample. The first aim was to determine whether the relationships among the FAM variables were found in a large cohort of individuals with complicated mild to severe TBI. In line with the findings of Wijenberg et al. ${ }^{28}$, all correlations suggested by the FAM 
were significant. We found similar or even greater correlations in the current study, thereby replicating the previous findings in a large English-speaking Australian cohort. The results further support the presence of these relationships in individuals with moderate to severe TBI as well as in mild TBI, which has been the focus of most previous studies examining this construct.

The second aim was to investigate whether the FAM explains chronic disability after TBI over and above known personal, injury-related, and other psychological variables. In line with Silverberg et al. ${ }^{29}$, we found that the variables in the FAM are of additive value to personal, injury-related, and other psychological variables in understanding unfavorable chronic disability after TBI in terms of depression, disuse, and disability. The separate analyses for our three outcome measures (depression, disuse, and disability) revealed "fear-avoidance thoughts" to be the only consistent significant variable across the analyses. Higher levels of fear-avoidance thoughts were associated with higher levels of depression, less mental activity, and more functional disability over and above other known variables. This shows that how people think about their symptoms is related to chronic disability after TBI and may suggest further investigation of fear-avoidance as potential treatment target. Other significant contributors in the final models of depression, disuse, and functional disability included other FAM variables (TBI-related symptoms, catastrophizing thoughts), injury-related characteristics (post-injury neurological history), and personal characteristics (education years, age). Looking specifically at one of the most common measures for outcome after TBI, functional disability measured by the GOS-E, results reveal that the FAM-related variables were associated with functional disability over and above personal and injury-related variables, and that together with age and postinjury neurological history, these have a good level of discrimination. These results are also in line with multiple studies addressing the need for a biopsychosocial approach to understanding chronic disability after TBI. ${ }^{8-14}$

Nevertheless, several findings were not consistent with our expectations. Although the regression analyses of disability revealed that the final model significantly explained disability, explaining 49.7\% (Nagelkerke $\mathrm{R}^{2}$ ) of the variance and correctly classifying $78.9 \%$ of cases, none of the five independent variables in the model were significant. This could be a result of correlations among covariates 
in the model, lower power caused by fewer observations or selection bias introduced by missing values on other covariates. Although our analyses met the assumption of at least 15 cases per independent variable, cross validation should be performed to further validate our results. Further, we found that the occurrence of another neurological injury after TBI (e.g., another TBI or stroke) resulted in fewer depressive symptoms. A plausible explanation for this unexpected finding may be found in the phrasing of the question. Participants were asked by means of one "yes/no"-question if since the injury, they had been affected or currently felt affected by a new neurological disorder. Unfortunately, in retrospect, this phrasing could be misunderstood as meaning experiencing impact of their TBI, limiting the reliability of the answer given.

There are several limitations to consider in the current study, resulting in suggestions for future research. First, the results should be interpreted with caution because of the cross-sectional nature of the study. As the FAM describes a process over time, no conclusions can be drawn regarding mediation or causation. Therefore, a large longitudinal study assessing the FAM and its influence on chronic disability over time is warranted. Second, because of the lack of a validated questionnaire, disuse was measured by one non-validated question. Further, the Dutch version of the PCS-CS and FMA were validated, but future studies are needed for (further) validation and reference data of the English PCSCS, FMA and measure for disuse. Although less specific for mental activities, future studies could also use alternative measures for disuse that have been used and validated before in neurological patient populations, such as the Cognitive Reserve Index Questionnaire ${ }^{49}$ or a measure assessing limiting behavior ${ }^{50,51}$. Moreover, recently a new questionnaire to assess fear-avoidance behavior after traumatic brain injury (FAB-TBI) has been developed, which was derived through principal component analysis of existing fear-avoidance measures and was found to be a psychometrically sound measure by applying Rasch analysis. ${ }^{29,52}$ The FABTBI and FMA are both short self-report questionnaires derived from existing measures from the chronic pain literature. However, they differ in that the FABTBI is, in contrast to the FMA, limited by no tailored administration and signs of multi-dimensionality, but the validation process of the FAB-TBI is further advanced. Future studies should incorporate both the FAB-TBI and FMA to further 
validate these measures and compare strengths and weaknesses for implications regarding their use. Third, although many variables were taken into account, several variables, such as personal characteristics (e.g., coping, personality, disease expectancies, and impaired awareness) and environmental characteristics (such as content, and amount of, and satisfaction with, professional and personal support), known to impact chronic disability after $\mathrm{TBI}^{53}$, were not assessed. Future research should incorporate these variables as well to demonstrate the contribution of the FAM to chronic disability after TBI. Lastly, questionnaires were administered online or over the phone. Selection bias could have occurred as a consequence of online administration, which may be too difficult for some individuals with TBI. However, online administration was purposely selected because it enabled individuals with TBI to complete the questionnaires at their own pace and allowed for recruitment of rural and remote participants. Further, for those who required extra assistance, administration over the phone was also offered.

Despite some unexpected findings and limitations, this is the first large study examining the associations of the variables in the FAM with chronic disability after complicated mild to severe TBI. Although longitudinal studies are warranted, the findings favor the assessment of the FAM in English-speaking countries and may suggest further investigation of fear-avoidance as a potential treatment target. The FAM provides the theoretical underpinnings of a well-established treatment, namely exposure in vivo therapy. ${ }^{54}$

\section{Acknowledgements}

We thank all participants for their participation in this study. Further, we thank Lisa Johnston, David Lawson and Olivia McConchie for their help with the data collection. No funding was received. No competing financial interests exist. 


\section{SUPPLEMENTARY TEXT}

\section{Post-Concussion Symptoms Catastrophizing Scale (PCS-CS)}

PM. Administration is preferred online because the answers given on the RPQ are used in the administration of the PCS-CS and FMA.

You just indicated that you do not experience, as a problem, the symptoms you were asked about. Everyone experiences headache, cognitive symptoms and/or fatigue at some point in their lives. People are often exposed to situations that may cause these symptoms. We are interested in the types of thoughts and feelings that you have when you experience these symptoms. Listed below are thirteen statements describing different thoughts and feelings that may be associated with these symptoms. Using the following scale, please indicate the degree to which you have these thoughts and feelings when you are experiencing these symptoms.

\section{$\underline{O R}$}

You just indicated that you experience the following symptom(s):

*Symptoms inserted that have an item score on RPQ of 2 or higher *

Everyone experiences headache, cognitive symptoms and/or fatigue at some point in their lives. People are often exposed to situations that may cause these symptoms. We are interested in the types of thoughts and feelings that you have when you experience these symptoms. Listed below are thirteen statements describing different thoughts and feelings that may be associated with these symptoms. Using the following scale, please indicate the degree to which you have these thoughts and feelings when you are experiencing these symptoms. 
When I experience these symptoms...

1. I worry all the time about whether the symptoms will end.

2. I feel I can't go on.

3. It's terrible and I think it's never going to get any better.

4. It's awful and I feel that it overwhelms me.

5. I feel I can't stand it anymore.

6. I become afraid that the symptoms will get worse.

7. I keep thinking of other events during which I experience the symptoms.

8. I anxiously want the symptoms to go away.

9. I can't seem to keep it out of my mind.

10. I keep thinking about how difficult it is.

11. I keep thinking about how badly I want the symptoms to stop.

12. There's nothing I can do to reduce the intensity of the symptoms.

13. I wonder whether something serious may happen.
Not To a slight To a moderate To a great All the

at all degree degree degree time




\section{Fear of Mental Activity scale (FMA)}

PM. Administration is preferred online because the answers given on the RPQ are used in the administration of the PCS-CS and FMA.

You just indicated that you do not experience, as a problem, the symptoms you were asked about.

Everyone experiences headache, cognitive symptoms and/or fatigue at some point in their lives. We would like to examine how you feel about these symptoms and how you experience them. You are asked to indicate whether or not you agree with each of the statements listed. It is important that you only use your own opinion and thoughts; what others might think is not of interest here. We do not intend to assess your medical knowledge either. The questionnaire is just about the way you experience these symptoms.

$\underline{O R}$

You just indicated that you experience the following symptom(s):

*Symptoms inserted that have an item score on RPQ of 2 or higher*

Everyone experiences headache, cognitive symptoms and/or fatigue at some point in their lives. We would like to examine how you feel about these symptoms and how you experience them. You are asked to indicate whether or not you agree with each of the statements listed. It is important that you only use your own opinion and thoughts; what others might think is not of interest here. We do not intend to assess your medical knowledge either. The questionnaire is just about the way you experience these symptoms. 
Please indicate whether or not you

Strongly agree with statements listed below.

1. I'm afraid that I might injure my brain if I perform mental activities.

2. If I were to try to overcome it, these symptoms would increase.

3. My brain is telling me I have something dangerously wrong.

4. These symptoms would probably be relieved if I were to train my brain.

5. People aren't taking my medical condition seriously enough.

6. My accident has put my brain at risk for the rest of my life.

7. These symptoms always mean I have injured my brain.

8. Just because something aggravates these symptoms does not mean it is dangerous.

9. I am afraid that I might injure my brain accidentally

10. Simply being careful that I do not perform any unnecessary mental activities is the safest thing I can do to prevent these symptoms from worsening.

11. I wouldn't have this many symptoms if there wasn't something potentially dangerous going on in my brain.

12. Although I experience these symptoms, I would be better off if I were mentally active.

13. These symptoms let me know when to stop performing mental activities so that I don't injure my brain.

14. It's really not safe for a person with a condition like mine to perform a lot of mental activities.

15. I can't do all the things normal people do because it's too easy for my brain to get injured.

16. Even though something is causing me a lot of symptoms, I don't think it's actually dangerous.

17. No one should have to perform mental activities when he/she experiences these symptoms. 


\section{References}

1. Corrigan, J.D., Selassie, A.W. and Orman, J.A.L. (2010). The epidemiology of traumatic brain injury. Journal of Head Trauma Rehabilitation. 25, 72-80.

2. Levin, H.S. and Diaz-Arrastia, R.R. (2015). Diagnosis, prognosis, and clinical management of mild traumatic brain injury. Lancet Neurology. 14, 506-517.

3. Greenwald, B.D. and Rigg, J.L. (2009). Neurorehabilitation in traumatic brain injury: does it make a difference? Mt Sinai J Med. 76, 182-189.

4. Rassovsky, Y., Levi, Y., Agranov, E., Sela-Kaufman, M., Sverdlik, A. and Vakil, E. (2015).

Predicting long-term outcome following traumatic brain injury (TBI). J Clin Exp Neuropsychol. 37, 354-366.

5. Novack, T.A., Bush, B.A., Meythaler, J.M. and Canupp, K. (2001). Outcome after traumatic brain injury: pathway analysis of contributions from premorbid, injury severity, and recovery variables. Arch Phys Med Rehabil. 82, 300-305.

6. Cuthbert, J.P., Corrigan, J.D., Harrison-Felix, C., Coronado, V., Dijkers, M.P., Heinemann, A.W. and Whiteneck, G.G. (2011). Factors that predict acute hospitalization discharge disposition for adults with moderate to severe traumatic brain injury. Arch Phys Med Rehabil. 92, 721-730. e723. 7. Ruff, R. (2005). Two decades of advances in understanding of mild traumatic brain injury. J Head Trauma Rehabil. 20, 5-18.

8. Scheenen, M.E., Spikman, J.M., de Koning, M.E., van der Horn, H.J., Roks, G., Hageman, G. and van der Naalt, J. (2016). Patients "at risk" of suffering from persistent complaints after mild traumatic brain injury: the role of coping, mood disorders and post-traumatic stress. Journal of Neurotrauma. 34, 31-37.

9. Silverberg, N.D., Gardner, A.J., Brubacher, J.R., Panenka, W.J., Li, J.J. and Iverson, G.L. (2015). Systematic review of multivariable prognostic models for mild traumatic brain injury. Journal of Neurotrauma. 32, 517-526.

10. Theadom, A., Parag, V., Dowell, T., McPherson, K., Starkey, N., Barker-Collo, S., Jones, K., Ameratunga, S. and Feigin, V.L. (2016). Persistent problems 1 year after mild traumatic brain injury: a longitudinal population study in New Zealand. Br J Gen Pract. 66, e16-23.

11. Wäljas, M., Iverson, G.L., Lange, R.T., Hakulinen, U., Dastidar, P., Huhtala, H., Liimatainen, S., Hartikainen, K. and Öhman, J. (2015). A prospective biopsychosocial study of the persistent postconcussion symptoms following mild traumatic brain injury. Journal of Neurotrauma. 32, 534-547. 12. Ponsford, J. (2017). Anxiety and depression following TBI. In: Neurobehavioural disability and social handicap following traumatic brain injury. McMillan, T.M., Wood, R.L. (eds). Routledge: Milton Park, Abingdon, Oxon; New York, NY, pps. 167-177.

13. Ponsford, J., Wong, D., McKay, A., Alway, Y., Haines, K., Lee, N.K., Downing, M. and O'Donnell, M.L. (2016). Depression and anxiety following traumatic brain injury: Can these high prevalence disorders be effectively treated using adapted cognitive behavioural therapy? In: Innovations and Future Directions in the Behavioural and Cognitive Therapies. Menzies, R.G., Kyrios, M., Kazantzis, N. (eds). Australian Academic Press: Samford Valley, QLD, pps. 182-186. 
14. Wardlaw, C., Hicks, A.J., Sherer, M. and Ponsford, J.L. (2018). Psychological resilience is associated with participation outcomes following mild to severe traumatic brain injury. Front Neurol. 9, 563.

15. Belanger, H.G., Kretzmer, T., Vanderploeg, R.D. and French, L.M. (2010). Symptom complaints following combat-related traumatic brain injury: relationship to traumatic brain injury severity and posttraumatic stress disorder. Journal of the International Neuropsychological Society. 16, 194-199. 16. Dikmen, S., Machamer, J., Fann, J.R. and Temkin, N.R. (2010). Rates of symptom reporting following traumatic brain injury. Journal of the International Neuropsychological Society. 16, 401411.

17. Ponsford, J., Draper, K. and Schönberger, M. (2008). Functional outcome 10 years after traumatic brain injury: its relationship with demographic, injury severity, and cognitive and emotional status. Journal of the International Neuropsychological Society. 14, 233-242. 18. van der Horn, H.J., Spikman, J.M., Jacobs, B. and van der Naalt, J. (2013). Postconcussive complaints, anxiety, and depression related to vocational outcome in minor to severe traumatic brain injury. Archives of Physical Medicine and Rehabilitation. 94, 867-874.

19. Vlaeyen, J.W. and Linton, S.J. (2012). Fear-avoidance model of chronic musculoskeletal pain: 12 years on. Pain. 153, 1144-1147.

20. Cima, R.F., Crombez, G. and Vlaeyen, J.W. (2011). Catastrophizing and fear of tinnitus predict quality of life in patients with chronic tinnitus. Ear and Hearing. 32, 634-641.

21. Nijs, J., Roussel, N., Van Oosterwijck, J., De Kooning, M., Ickmans, K., Struyf, F., Meeus, M. and Lundberg, M. (2013). Fear of movement and avoidance behaviour toward physical activity in chronic-fatigue syndrome and fibromyalgia: state of the art and implications for clinical practice. Clinical Rheumatology. 32, 1121-1129.

22. Wijenberg, M.L.M., Stapert, S.Z., Köhler, S. and Bol, Y. (2016). Explaining fatigue in multiple sclerosis: cross-validation of a biopsychosocial model. Journal of behavioral medicine. 39, 815-822. 23. Nieto, R., Miró, J. and Huguet, A. (2009). The fear-avoidance model in whiplash injuries. European Journal of Pain. 13, 518-523.

24. Velthuis, M.J., Peeters, P.H., Gijsen, B.C., van den Berg, J.-P., Koppejan-Rensenbrink, R.A., Vlaeyen, J.W. and May, A.M. (2012). Role of fear of movement in cancer survivors participating in a rehabilitation program: a longitudinal cohort study. Archives of Physical Medicine and Rehabilitation. 93, 332-338.

25. Vlaeyen, J.W., Crombez, G. and Linton, S.J. (2016). The fear-avoidance model of pain. Pain. 157, 1588-1589.

26. Martelli, M., MacMillan, P. and Grayson, R. (1999). Kinesiophobia and cogniphobia: Avoidanceconditioned pain-related disability (ACPRD). Archives of Clinical Neuropsychology. 14, 804-804. 27. Todd, D., Martelli, M. and Grayson, R. (1998). The Cogniphobia Scale (C-Scale): A measure of headache impact. Test in the public domain.

28. Wijenberg, M.L.M., Stapert, S.Z., Verbunt, J.A., Ponsford, J.L. and Van Heugten, C.M. (2017). Does the fear avoidance model explain persistent symptoms after traumatic brain injury? Brain injury. 31, 1597-1604. 
29. Silverberg, N.D., Panenka, W. and Iverson, G.L. (2018). Fear avoidance and clinical outcomes from mild traumatic brain injury. Journal of Neurotrauma. 35, 1864-1873.

30. Ponsford, J.L., Downing, M.G., Olver, J., Ponsford, M., Acher, R., Carty, M. and Spitz, G. (2014). Longitudinal follow-up of patients with traumatic brain injury: outcome at two, five, and ten years post-injury. J Neurotrauma. 31, 64-77.

31. Ponsford, J.L., Olver, J. and Curran, C. (1995). A profile of outcome: 2 years after traumatic brain injury. Brain Inj. 9, 1-10.

32. Shores, E.A., Marosszeky, J.E., Sandanam, J. and Batchelor, J. (1986). Preliminary validation of a clinical scale for measuring the duration of post-traumatic amnesia. Med J Aust. 144, 569-572.

33. Draper, K., Ponsford, J. and Schönberger, M. (2007). Psychosocial and emotional outcomes 10 years following traumatic brain injury. J Head Trauma Rehabil. 22, 278-287.

34. King, N.S., Crawford, S., Wenden, F.J., Moss, N.E.G. and Wade, D.T. (1995). The Rivermead Post Concussion Symptoms Questionnaire: a measure of symptoms commonly experienced after head injury and its reliability. J Neurol. 242, 587-592.

35. Eyres, S., Carey, A., Gilworth, G., Neumann, V. and Tennant, A. (2005). Construct validity and reliability of the Rivermead post-concussion symptoms questionnaire. Clinical Rehabilitation. 19, 878-887.

36. Mallery, P. and George, D. (2003). SPSS for Windows step by step: a simple guide and reference: Allyn, Bacon, Boston.

37. Kline, P. (2013). Handbook of psychological testing. Routledge.

38. Goubert, L., Crombez, G., Van Damme, S., Vlaeyen, J.W., Bijttebier, P. and Roelofs, J. (2004). Confirmatory factor analysis of the Tampa Scale for Kinesiophobia: invariant two-factor model across low back pain patients and fibromyalgia patients. Clin J Pain. 20, 103-110.

39. Houben, R.M., Leeuw, M., Vlaeyen, J.W., Goubert, L. and Picavet, H.S. (2005). Fear of movement/injury in the general population: factor structure and psychometric properties of an adapted version of the Tampa Scale for Kinesiophobia. J Behav Med. 28, 415-424.

40. Roelofs, J., Goubert, L., Peters, M.L., Vlaeyen, J.W. and Crombez, G. (2004). The Tampa Scale for Kinesiophobia: further examination of psychometric properties in patients with chronic low back pain and fibromyalgia. European Journal of Pain. 8, 495-502.

41. Zigmond, A.S. and Snaith, R.P. (1983). The hospital anxiety and depression scale. Acta Psychiatrica Scandinavica. 67, 361-370.

42. Whelan-Goodinson, R., Ponsford, J. and Schönberger, M. (2009). Validity of the Hospital Anxiety and Depression Scale to assess depression and anxiety following traumatic brain injury as compared with the Structured Clinical Interview for DSM-IV. Journal of Affective Disorders. 114, 94102.

43. Wilson, J., Edwards, P., Fiddes, H., Stewart, E. and Teasdale, G. (2002). Reliability of postal questionnaires for the Glasgow Outcome Scale. J Neurotrauma. 19, 999-1005.

44. Jennett, B., Snoek, J., Bond, M. and Brooks, N. (1981). Disability after severe head injury: observations on the use of the Glasgow Outcome Scale. J Neurol Neurosurg Psychiatry. 44, 285293. 
45. Bullock, M.R., Merchant, R.E., Choi, S.C., Gilman, C.B., Kreutzer, J.S., Marmarou, A. and Teasdale, G.M. (2002). Outcome measures for clinical trials in neurotrauma. Neurosurg Focus. 13, 1-11.

46. Tabachnick, B.G., Fidell, L.S. and Ullman, J.B. (2007). Using multivariate statistics. Vol 5. Pearson Boston, MA.

47. Box, G.E. and Tidwell, P.W. (1962). Transformation of the independent variables.

Technometrics. 4, 531-550.

48. Hosmer, D.W., Lemeshow, S. and Sturdivant, R.X. (2013). Applied logistic regression. Vol 398. John Wiley \& Sons.

49. Nucci, M., Mapelli, D. and Mondini, S. (2012). Cognitive Reserve Index questionnaire (CRIq): a new instrument for measuring cognitive reserve. Aging Clin Exp Res. 24, 218-226.

50. Spence, M., Moss-Morris, R. and Chalder, T. (2005). The Behavioural Responses to Illness Questionnaire (BRIQ): a new predictive measure of medically unexplained symptoms following acute infection. Psychol Med. 35, 583-593.

51. Greenberg, J., Mace, R.A., Funes, C.J., Silverberg, N.D., Iverson, G.L., Caplan, D.N. and Vranceanu, A.-M. (2020). Pain catastrophizing and limiting behavior mediate the association between anxiety and postconcussion symptoms. Psychosomatics. 61, 49-55.

52. Snell, D.L., Siegert, R.J., Debert, C., Cairncross, M. and Silverberg, N.D. (2020). Evaluation of the fear avoidance behavior after traumatic brain injury questionnaire. Journal of neurotrauma.

37, 1566-1573.

53. Steiner, W.A., Ryser, L., Huber, E., Uebelhart, D., Aeschlimann, A. and Stucki, G. (2002). Use of the ICF model as a clinical problem-solving tool in physical therapy and rehabilitation medicine. Physical Therapy. 82, 1098-1107.

54. Woods, M.P. and Asmundson, G.J. (2008). Evaluating the efficacy of graded in vivo exposure for the treatment of fear in patients with chronic back pain: a randomized controlled clinical trial. Pain. 136, 271-280. 

Chapter 8

General discussion
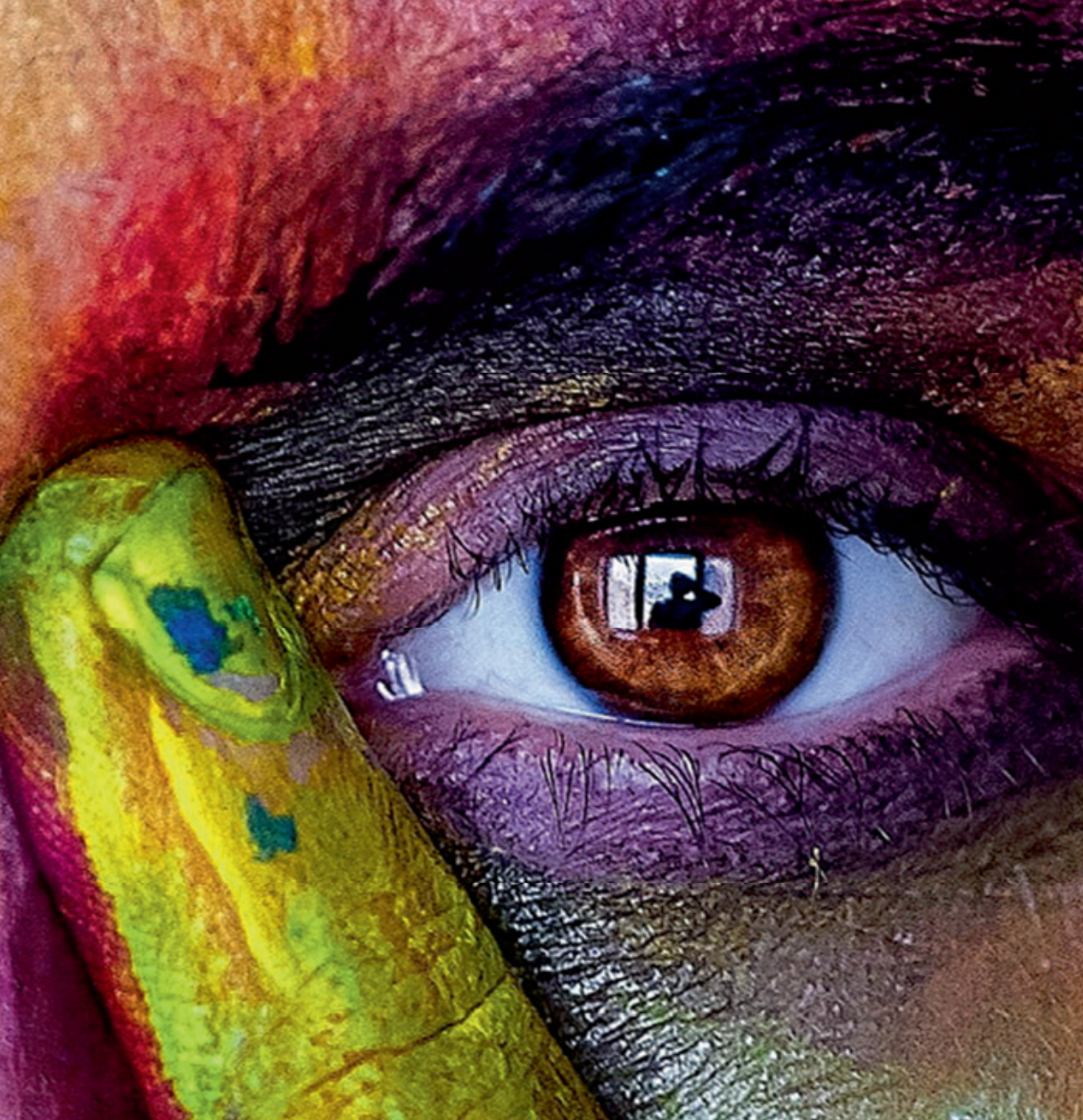

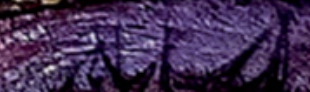

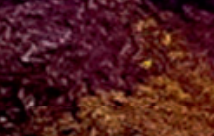


Although most patients with mild traumatic brain injury (mTBI) fully recover, some patients report persistent post-concussion symptoms (PCS) three months or longer post-injury. PCS encompasses physical (e.g., headache), cognitive (e.g., memory problems), emotional (e.g., depressive symptoms), and/or behavioral symptoms (e.g., irritability). To understand PCS, the importance of a biopsychosocial approach gained more attention and credit in the last decades from researchers and clinicians. ${ }^{1}$ Several studies emphasize the importance of anxiety, thoughts about symptoms, and a self-sustaining dysfunctional loop as potential key elements to understand $\mathrm{PCS}^{2-4} \mathrm{~A}$ biopsychosocial model incorporating these elements is the fear-avoidance (FA) model. The FA model is originally developed to explain pain-related disability in chronic musculoskeletal pain by a cyclic pattern including fear of movement, whereas adaptations were made by us to explain PCS by a cyclic pattern including fear of mental activities.

In this thesis, we explored the role of fear in chronic TBI-related disability in the context of the PCS-related FA model (see Figure 1, chapter 1). In the introduction, four research questions are proposed, which will be elaborated on sequentially in the following section.

\section{Main findings}

Aim 1: Exploring the FA model in patients with MS

We extended a first exploration of the FA model in another brain disease, namely Multiple Sclerosis (MS). In chapter 2, findings of a cross-sectional study of 218 patients with MS are presented to cross-validate the role of the FA model to understand fatigue after MS. The results reveal a successful cross-validation of the adapted FA model postulating fatigue as symptom instead of chronic pain. Catastrophizing, depression, physical disability, disease severity and fear-avoidance all contribute significantly to fatigue, either directly or indirectly, supporting the specific interrelationships as suggested by the FA model (see Figure 1, chapter 2). The results support the notion that catastrophizing about fatigue plays a central role: fueled by depression, catastrophizing thoughts mediate the relationship between fatigue and fatigue-related fear-avoidance behavior. 
Taking into consideration the cross-sectional nature of our study, we conclude that the results were in line with the FA model, highlighting the disabling role of anxiety and thoughts about symptoms.

Aim 2: Stability of psychological characteristics in the first two years post-stroke In chapter 3, a longitudinal study $(\mathrm{N}=324)$ is presented investigating if psychological characteristics remain stable in the first two years post-stroke. Results show that scores on all adaptive psychological characteristics (e.g., proactive coping, self-efficacy, optimism, extraversion) decrease over time, whereas scores on maladaptive psychological characteristics (e.g., neuroticism, pessimism) increase or remain stable (passive coping) over time. Clinicians should be aware of the impact of psychological characteristics on quality of life, consider their temporal (in)stability after stroke, and stimulate the use of more adaptive psychological characteristics, such as proactive coping and optimism. Future studies into effective treatment strategies (e.g., psychological therapy administered by a neuropsychologist such as problem-solving therapy ${ }^{5}$ ) are needed to help patients make use of more adaptive psychological characteristics in the long-term.

Aim 3: Psychometric properties of two newly developed questionnaires assessing catastrophizing and fear-avoidance thoughts

The studies investigating the psychometric properties of the Post-Concussion Symptoms Catastrophizing Scale (PCS-CS) and the Fear of Mental Activity scale (FMA) are presented in chapters $\mathbf{5}$ and $\mathbf{6}$.

The study presented in chapter $\mathbf{5}$ included 131 adults without history of brain injury and the results support the notion that the PCS-CS, FMA, and their provided cut-offs can be used to assess PCS-related catastrophizing and fearavoidance for research purposes and clinical practice in a reliable and valid manner. Furthermore, reference data of a cohort of working adults are now available and provide a cut-off for an increased level of catastrophizing and fearavoidance for research purposes and clinical practice (e.g., "Is the level of catastrophizing of patient $X$ higher or lower than expected compared to a reference group of working adults without history of brain injury?"). Despite these 
promising findings, the psychometric properties in patient populations still need further study and the study limitations, including convenience sampling, should be considered. We expect patients with mTBI, as a result of higher PCS levels, will report higher levels of PCS-related catastrophizing and fear-avoidance on a group level and therefore require different cut-offs.

To extend the exploration of the validity of the PCS-related fear-avoidance measures, we investigated whether fear-avoidance and catastrophizing about mental activities are related to behavioral avoidance in a healthy population. The results of this experimental study (chapter 6) reveal that catastrophizing, measured by the PCS-CS, relates to behavioral avoidance of mental activities in healthy adults. The results show that catastrophizers spend less time on the performance of difficult tasks as compared to easy cognitive tasks. This is in line with the assumed relationship between catastrophizing and fear-avoidance according to the FA model and demonstrates its link on a behavioral level. These findings also fit the current literature that highlights the importance of the way people interpret their symptoms as opposed to the symptom experience itself (i.e., irrational thoughts about health implications of someone's own symptoms can impact their behavior). ${ }^{4,6}$ Our study shows that healthy adults report PCS, have thoughts about these symptoms, and adjust their behavior in accordance with these thoughts. For instance, in daily life this could lead to avoidance of social events because one thinks that a headache will reoccur or increase as a result of overstimulation caused by music, chatter, and bright lights. We expect that the demonstrated link is also present or even stronger in patient populations. Therefore, future patient studies using the experimental design or more in-vivo mental activities (e.g., daily life activities) are needed to generalize and further interpret these findings.

Aim 4: Exploring the PCS-related FA model in patients with mild, moderate, and severe TBI

Our final research question is addressed in chapter 4 and chapter 7. Chapter 4 discusses the results of our pilot study exploring the PCS-related FA model and chapter $\mathbf{7}$ presents a large Australian cross-sectional study revealing the additive 
value of the PCS-related FA model over known predictors in understanding outcome after TBI of all severities.

The pilot study of 48 patients with mild and moderate to severe TBI in the chronic phase shows significant interrelationships within the FA model, similar to the study exploring the FA model in MS (chapter 2). Furthermore, the Australian cross-sectional study replicates this finding in a larger English sample of 117 patients with more severe TBI.

Looking into the additive value of the PCS-related FA model in understanding outcome after TBI for the first time, analyses reveal that elements of the FA model (e.g., catastrophizing and fear-avoidance) improve prediction of the main outcome (chronic disability) compared with known predictors alone (injury-related, such as severity indexes, or demographic, such as sex).

These findings indicate that further studies focusing on the FA model as a potential contribution to our understanding of persistent symptoms after TBI seem warranted. The model may be valuable as a theoretical model and stepping stone in both diagnostic and treatment stages.

\section{Conclusions and reflections}

Summarizing the findings of this thesis, multiple conclusions can be drawn. In the next paragraphs, these conclusions are discussed in conjunction with the methodologies of the presented studies and are linked to the existing knowledge of the FA model in chronic pain and TBI. Suggestions for future research studies are given.

All presented studies examining the specific interrelationships of the FA model (see Figure 1, chapter 1; chapter 2, 4, 6 and 7), confirm the interrelationships of the variables within the FA model. The confirmation of the role of fear in disease-related disability is found across study populations including healthy individuals, patients with TBI, and patients with MS. The strength of the associations within these populations seems comparable with those reported in the original FA model designed for chronic pain. ${ }^{7-9}$ However, the use of different measures and constructs complicates the comparison between populations. Comparing specifically the PCS-related FA model with the original pain-related FA model, theoretical differences are, but not limited to, explaining a symptom 
complex or syndrome (PCS) instead of a single symptom (pain) and the occurrences of a sudden eventful biomedical onset on a vital urgent organ (TBI) versus pain as a vital sign of bodily threat urging protective behaviors. Nonetheless, our studies extend the FA model now to MS (chapter 2), mild to severe TBI (chapter 4 and 7), and PCS-like symptoms in healthy adults (chapter 6). This advocates further research into the value of the PCS-related FA model to understand disability in relation to mental activities. For instance, it could also be of relevance in other neuropsychological conditions that are associated with successful timely recovery and have key symptoms similar to PCS (e.g., cognitive, emotional, and/or behavioral symptoms), such as minor stroke, transient ischemic attack, or headache disorders. ${ }^{10,11}$

Despite this consistent finding of the confirmation of the FA model in different populations, some limitations of our studies should be taken into account. Firstly, the studies presented in this thesis are cross-sectional and therefore, no conclusions can be drawn to the direction or development of relationships. No conclusion can be drawn regarding causality (e.g., PCS causes catastrophizing and catastrophizing causes fear-avoidance) or its cyclic pattern over time. Further longitudinal studies are needed to investigate the role of fearavoidance in disease-related disability over time. Such studies could disclose when the disease behavior initiates, how it develops over time by whom and what, and reveal the relative and potential time-dependent or personalized contribution of biomedical, psychological and social factors. Such studies could also reveal when PCS initiate and peak, and what the explanatory value of the FA model is next to other known factors over time. These findings would help customizing treatment by providing important information regarding who, what, when, and why. See Crombez et al. ${ }^{12}$ for an overview of the development of the FA model within chronic pain literature as a result of decades of research and lessons learned from clinical practice. They conclude that, although there is ample evidence to support the validity of the model in its original form, these studies helped developing the FA model, fine-tuned its research and clinical implications, and call for the next generation of studies.

Secondly, no study presented in this thesis compared different populations simultaneously. Future studies should also include a larger sample of patients with 
mild traumatic brain injury next to a control group such as patients with orthopedic injuries, in accordance with recommendations for future mTBI studies. ${ }^{13}$ This control group is necessary to reveal if the proposed PCS-related FA model is specific for mTBI or more generally applicable to persistent symptoms induced by a trauma, such as visiting the emergency room, influence of pain, and possible pre-existing neuropsychological differences in individuals who have a higher injury risk. ${ }^{14}$ For example, Broomhall et al. ${ }^{15}$ found that avoidance symptoms (e.g., avoidance of people or places), assessed during hospital stay because of a traumatic injury, are significantly higher in injury survivors with mTBI compared to injury survivors without mTBI.

Thirdly, the variables in the FA model were measured using mainly selfreport questionnaires. Future studies are recommended to use observations and behavioral measures. E.g., in chapter 6, our experimental study, we used 'time spent working on cognitive tasks' as behavioral measure. Future studies could also develop a more ecologically valid measure. E.g., the photograph series of daily activities (PHODA) scale is a more ecologically valid measure used in chronic pain to assess perceived harmfulness of daily activities by rating photographs depicting these daily activities. Adapting this to the PCS-related FA model, photographs showing challenging mental activities (e.g., working at a computer in a noisy environment) could be used.

Another conclusion can be drawn from the experimental study (chapter 6) and Australian cross-sectional study (chapter 7). Both analyses reveal that elements of the FA model (e.g., catastrophizing and fear-avoidance) predict the main outcome (respectively behavioral avoidance and chronic disability) over and above established biomedical (e.g., injury severity indexes), personal (e.g., sex, age), and/or psychological predictors (e.g., psychological treatment history). However, other personal and social (i.e., environmental) factors, not specific to the FA model, should also be included in future studies. Relevant personal factors for outcome after acquired brain injury are e.g., proactive coping, self-efficacy, optimism, and extraversion (chapter 3). ${ }^{16}$ Examples of important social factors are disease expectancies of caregivers, experienced support by patients' surroundings, and subjective appraisal of (lack of) received treatment by healthcare professionals. ${ }^{17,} 18$ 
Concerning methodological features, our results provide support for the use of the PCS-CS and FMA questionnaires for valid and reliable assessment of catastrophizing about PCS and fear-avoidance of mental activities respectively (chapter 3) and its link with fear-avoidance on a behavioral level (chapter 6). However, to further study the psychometric properties and obtain clinical reference data, future studies in patient populations and well-described subgroups are needed.

In sum, the results support the disabling role of anxiety as suggested by the FA model and its potential additive value in healthy adults (18-65 years old), in patients with MS, and patients with mild to severe TBI. These findings fit the current literature in the following ways: (1) they highlight the importance of the way people think about their experienced symptoms and not the symptom experience itself, similar to the research field of illness cognitions ${ }^{4,6}$; (2) they show a prominent role of fear-avoidance, similar to studies in e.9., $\mathrm{mTBl}^{19}$ or older adults $^{20}$; (3) they reveal disease expectations and anxiety as significant predictors of outcome (e.g., quality of life or disability), similar to previous studies in acquired brain injury ${ }^{16,21}$ or other medical conditions such as heart attack survivors ${ }^{22}$, chronic pain ${ }^{23}$, and tinnitus ${ }^{24}$. The studies in this thesis extend these findings by exploring the role of the full FA model including fear-avoidance thoughts (i.e., illness cognitions), disease expectations, and anxiety instead of stand-alone constructs.

Although future studies are needed to further study the potential of the PCS-related FA model in TBI, the promising and consistent results in the studies presented in this thesis highlight the potential of fear as treatment target. In chronic pain, research confirmed the effect of treatment to reduce fear of movement in order to decrease pain-related disability based on exposure in vivo. ${ }^{25,26}$ Exposure in vivo is a psychosocial treatment targeting disability and pain-related catastrophizing thoughts and fear-avoidance behavior. In this treatment, the individual is exposed to stimuli and situations that were previously avoided, eventually resulting in reduction of disability and fear-avoidance. Therefore, future studies aimed at reducing mTBI-related disability could include, but are not limited to, development of a treatment protocol designed for exposure to mental activities including behavioral experiments challenging beliefs and 
expectations of patients about their PCS and "injured" brain. Design of treatment protocols should start by first investigating the individual explanations and thoughts patients may have regarding their symptoms, taking into account the influence of their surrounding and healthcare professionals on these beliefs. This can be achieved using e.g., Socratic interviewing and focus groups. This information should be embedded within the established treatment protocol targeting chronic pain and incorporate the latest insights retrieved from systematic reviews regarding effective psychological treatments for PCS ${ }^{27-30}$. When this treatment protocol is developed, its effectiveness could be investigated using single-case experimental designs or randomized controlled trials, as suggested by the systematic reviews concluding the need for good quality and personalized intervention studies ${ }^{27-30}$.

\section{Implications for clinicians and researchers}

Some implications can be formulated for clinicians and researchers.

In the first place, comparing results of our studies to other studies on PCS and $\mathrm{mTBl}$, we observe that there are inconsistencies about the definition of PCS ${ }^{31}$ and $\mathrm{mTB}^{32}$ resulting in various problems such as high variation in estimates of suboptimal recovery trajectory of patients. We suggest using the definition of PCS reviewed by Polinder et al. ${ }^{13}$ (i.e., having PCS at least three months after TBI) and mTBI according to the $\mathrm{WHO}^{33}$ and EFNS ${ }^{34}$ (see chapter 1 for the criteria). We investigated three different groups (healthy adults with no biomedical pathology, mTBI with assumed temporary biomedical pathology, and moderate to severe TBI with clear chronic biomedical pathology). Based on the similarity of our findings across these groups, viewing TBI on a spectrum, gradually ranging from mild to severe, and using a biopsychosocial approach could also be helpful in better understanding outcome. ${ }^{35}$ In line with the need for good quality intervention studies $^{27-30}$, clinical practice would benefit most from evidence-based treatment options for patients seeking help to relieve their burden, empower their abilities, and improve their quality of life, despite the exact 'labelling' of their injury.

Above all, our study results highlight the importance of taking into account psychological factors to understand how people react to and recover from a (biomedical) injury, with special importance for TBI. Although Silverberg and 
Iverson ${ }^{3}$ show that these psychological factors are already important in the beginning of the recovery trajectory and not only at the chronic stage (e.g., three months after mild TBI), our patient studies were mainly performed at least three months after injury. Therefore, conclusions drawn from our studies apply to the chronic stage. Due to established additive value of psychological factors in the chronic stage, patients with PCS could potentially be helped with therapies applying a biopsychosocial perspective such as cognitive behavioral treatment. ${ }^{27-30}$ This is also in line with the notion that the FA model is a biopsychosocial model, which fits a cognitive behavioral therapy (e.g., exposure in vivo) focusing on regaining trust in recovery after a biomedical injury by altering disabling psychosocial influences.

Although "take into account psychological factors" to understand PCS seems straightforward, we expect several problems putting this in (clinical) practice. The problems were already postulated by Alexander ${ }^{36}$ specifically for neurologists and include; (1) neurologists often do not provide care anymore in the chronic phase; (2) most patients recover on their own; (3) neurologists can view patients with PCS as unpleasant clinical assignments including suspicion of exaggerating or malingering; (4) psychological issues can be vaguely specified and impede straight-forward treatment options; (5) in academia, the topic of PCS may be less intellectually compelling or rewarded as such. These problems may be applicable to more healthcare professionals and therefore still hinder successful implementation. We think solutions for these problems could be found in the opposite of some: (1) target the healthcare professional whom patients with PCS encounter (e.g., three months or later post-injury they encounter a general practitioner instead of a neurologist); (2) teach healthcare professionals how to use a biopsychosocial approach and view patients with PCS not as an unpleasant clinical assignments or PCS as less intellectually compelling research topic; (3) improve clinical skills to assess psychological issues and to prescribe the associated (neuro)psychological treatment. Alexander ${ }^{36}$ already stated that if the biopsychosocial approach is received with skepticism by patients and their surroundings, they do often acknowledge that the symptoms, regardless of their exact origin, are ruining their lives and that counselling could be helpful. It is important that the treating healthcare professional does not assume that the 
symptoms of their patient all represent real neurologic loss, but should focus on resolving disabling practical behavioral problems from a biopsychosocial perspective. As already stated by Ruff ${ }^{2}$, in the context of treatment, the controversy of brain-based versus psychologically-based disability seems academic at best and is of no use in clinical work, in line with an integrative or biopsychosocial approach ${ }^{37}$.

Furthermore, the first extensive exploration of the entire FA model for PCS in TBI, presented in this thesis, shows promising results and implicate that researchers and clinicians should consider the FA model as possible theoretical understanding of prolonged recovery of the patient. However, as stated before, future studies, especially longitudinal and treatment studies, are necessary to unravel the full potential of the FA model. At this stage, clinicians could be aware of the FA model during their intakes, administer questionnaires assessing factors related to the FA model (e.g., catastrophizing with the PCS-CS and fear-avoidance with the FMA), and compare the scores with our healthy adult cohort. Deviating scores should be reported back to the patient and openly discussed, followed by personalized psychoeducation about possible psychological processes such as the impact of someone's thoughts about their own symptoms on symptom severity (e.g., filling in a personal FA model using patients' symptoms and thoughts). This could normalize the disease process that has taken place for the patient, resulting in validation of suffering from symptoms, and if necessary with extra evidencebased psychological treatment, potentially breaking through the cyclic pattern. It is important to mention that although the FA model shows promising findings in our first exploration, and even if these are confirmed in follow-up studies, this explanation would not be applicable to all patients; the FA model only applies to patients with catastrophizing and fear-avoidance as disabling factors. It is a very heterogeneous patient group and many group-based studies, including ours, show a high variation across individuals (e.9., in chapter 4, 92\% of our sample reported having PCS whilst only 58\% reported a heightened level of catastrophizing according the cut-off presented in chapter 5). In chronic pain, besides exposure in vivo therapy, other therapies such as graded activity and acceptance and commitment therapy (ACT) are offered and investigated to do justice to the individual variation in treatment response. ${ }^{38}$ 
All in all, researchers and clinicians should not avoid the mental challenges PCS pose, but confront these challenges by thinking beyond diagnosis: ask the patient about his/her thoughts and feelings about PCS and take these into account in the efforts to help a person struggling with life's curveballs. 


\section{References}

1. Silverberg, N.D., Panenka, W. and Iverson, G.L. (2018). Fear avoidance and clinical outcomes from mild traumatic brain injury. Journal of neurotrauma. 35, 1864-1873.

2. Ruff, R.M. (2011). Mild traumatic brain injury and neural recovery: rethinking the debate. NeuroRehabilitation. 28, 167-180.

3. Silverberg, N.D. and Iverson, G.L. (2011). Etiology of the post-concussion syndrome: physiogenesis and psychogenesis revisited. NeuroRehabilitation. 29, 317-329.

4. Whittaker, R., Kemp, S. and House, A. (2007). Illness perceptions and outcome in mild head injury: a longitudinal study. Journal of Neurology, Neurosurgery \& Psychiatry. 78, 644-646.

5. Visser, M.M., Heijenbrok-Kal, M.H., van 't Spijker, A., Lannoo, E., Busschbach, J.J. and Ribbers, G.M. (2016). Problem-solving therapy during outpatient stroke rehabilitation improves coping and health-related quality of life: randomized controlled trial. Stroke. 47, 135-142.

6. Richardson, A.E. and Broadbent, E. (2017). Illness-Related Cognition. In: Oxford Research Encyclopedia of Psychology.

7. Cook, A.J., Brawer, P.A. and Vowles, K.E. (2006). The fear-avoidance model of chronic pain: validation and age analysis using structural equation modeling. Pain. 121, 195-206.

8. George, S.Z., Valencia, C. and Beneciuk, J.M. (2010). A psychometric investigation of fearavoidance model measures in patients with chronic low back pain. journal of orthopedic \& sports physical therapy. 40, 197-205.

9. Vlaeyen, J.W. and Linton, S.J. (2000). Fear-avoidance and its consequences in chronic musculoskeletal pain: a state of the art. Pain. 85, 317-332.

10. Brouwer-Goossensen, D., van Genugten, L., Lingsma, H., Dippel, D., Koudstaal, P. and den Hertog, H. (2016). Determinants of intention to change health-related behavior and actual change in patients with TIA or minor ischemic stroke. Patient education and counseling. 99, 644-650.

11. Rogers, D.G., Protti, T.A. and Smitherman, T.A. (2020). Fear, Avoidance, and Disability in Headache Disorders. Current pain and headache reports. 24, 1-8.

12. Crombez, G., Eccleston, C., Van Damme, S., Vlaeyen, J.W.S. and Karoly, P. (2012). FearAvoidance Model of Chronic Pain: The Next Generation. The Clinical Journal of Pain. 28, 475-483. 13. Polinder, S., Cnossen, M.C., Real, R.G., Covic, A., Gorbunova, A., Voormolen, D.C., Master, C.L., Haagsma, J.A., Diaz-Arrastia, R. and Von Steinbuechel, N. (2018). A multidimensional approach to post-concussion symptoms in mild traumatic brain injury. Frontiers in neurology. 9, 1113.

14. Rohling, M.L., Larrabee, G.J. and Millis, S.R. (2012). The "Miserable Minority" following mild traumatic brain injury: Who are they and do meta-analyses hide them? The Clinical Neuropsychologist. 26, 197-213.

15. Broomhall, L.G., Clark, C.R., McFarlane, A.C., O'Donnell, M., Bryant, R., Creamer, M. and Silove, D. (2009). Early stage assessment and course of acute stress disorder after mild traumatic brain injury. J Nerv Ment Dis. 197, 178-181. 
16. van Mierlo, M., van Heugten, C., Post, M.W., Hoekstra, T. and Visser-Meily, A. (2018).

Trajectories of health-related quality of life after stroke: results from a one-year prospective cohort study. Disability and rehabilitation. 40, 997-1006.

17. Renaud, M.I., van de Port, I.G., Catsman-Berrevoets, C.E., Jellema, K., Lambregts, S.A. and van Heugten, C.M. (2020). Activities and participation in the first 6 months after mild traumatic brain injury in children and adolescents. Journal of head trauma rehabilitation. 35, E501-E512.

18. Steiner, W.A., Ryser, L., Huber, E., Uebelhart, D., Aeschlimann, A. and Stucki, G. (2002). Use of the ICF model as a clinical problem-solving tool in physical therapy and rehabilitation medicine.

Physical therapy. 82, 1098-1107.

19. Snell, D.L., Siegert, R.J., Debert, C., Cairncross, M. and Silverberg, N.D. (2020). Evaluation of the fear avoidance behavior after traumatic brain injury questionnaire. Journal of neurotrauma. 20. Farina, F., Bennett, M., Griffith, J. and Lenaert, B. (2020). Fear of memory loss predicts increased memory failures and lower quality of life in older adults: preliminary findings from a fear-avoidance of memory loss (FAM) scale. Aging \& Mental Health, 1-7.

21. van der Naalt, J., Timmerman, M.E., de Koning, M.E., van der Horn, H.J., Scheenen, M.E., Jacobs, B., Hageman, G., Yilmaz, T., Roks, G. and Spikman, J.M. (2017). Early predictors of outcome after mild traumatic brain injury (UPFRONT): an observational cohort study. The Lancet Neurology. 16, 532-540.

22. Verberne, D., Moulaert, V., Verbunt, J. and van Heugten, C. (2018). Factors predicting quality of life and societal participation after survival of a cardiac arrest: A prognostic longitudinal cohort study. Resuscitation. 123, 51-57.

23. Linton, S.J., Flink, I.K. and Vlaeyen, J.W. (2018). Understanding the etiology of chronic pain from a psychological perspective. Physical therapy. 98, 315-324.

24. Cima, R. (2018). Bothersome tinnitus. Hno. 66, 369-374.

25. Woods, M.P. and Asmundson, G.J. (2008). Evaluating the efficacy of graded in vivo exposure for the treatment of fear in patients with chronic back pain: a randomized controlled clinical trial. Pain. 136, 271-280.

26. Vlaeyen, J.W., Crombez, G. and Linton, S.J. (2016). The fear-avoidance model of pain. Pain. 157, 1588-1589.

27. Teo, S.H., Fong, K.N., Chen, Z. and Chung, R.C. (2020). Cognitive and psychological interventions for the reduction of post-concussion symptoms in patients with mild traumatic brain injury: a systematic review. Brain injury. 34, 1305-1321.

28. Bergersen, K., Halvorsen, J.Ø., Tryti, E.A., Taylor, S.I. and Olsen, A. (2017). A systematic literature review of psychotherapeutic treatment of prolonged symptoms after mild traumatic brain injury. Brain injury. 31, 279-289.

29. Al Sayegh, A., Sandford, D. and Carson, A.J. (2010). Psychological approaches to treatment of postconcussion syndrome: a systematic review. Journal of Neurology, Neurosurgery \& Psychiatry. 81, 1128-1134.

30. Cooper, D.B., Bunner, A.E., Kennedy, J.E., Balldin, V., Tate, D.F., Eapen, B.C. and Jaramillo, C.A. (2015). Treatment of persistent post-concussive symptoms after mild traumatic brain injury: a 
systematic review of cognitive rehabilitation and behavioral health interventions in military service members and veterans. Brain imaging and behavior. 9, 403-420.

31. Rose, S.C., Fischer, A.N. and Heyer, G.L. (2015). How long is too long? The lack of consensus regarding the post-concussion syndrome diagnosis. Brain injury. 29, 798-803.

32. Kristman, V.L., Borg, J., Godbolt, A.K., Salmi, L.R., Cancelliere, C., Carroll, L.J., Holm, L.W., Nygren-de Boussard, C., Hartvigsen, J. and Abara, U. (2014). Methodological issues and research recommendations for prognosis after mild traumatic brain injury: results of the International Collaboration on Mild Traumatic Brain Injury Prognosis. Archives of Physical Medicine and Rehabilitation. 95, S265-S277.

33. Cassidy, J., Carroll, L., Peloso, P., Borg, J., von Holst, H., Holm, L., Kraus, J. and Coronado, V. (2004). WHO Collaborating Centre Task Force on Mild Traumatic Brain, Injury, Incidence, risk factors and prevention of mild traumatic brain injury: results of the WHO Collaborating Centre Task Force on Mild Traumatic Brain Injury. J Rehabil Med. 43, 28-60.

34. Vos, P., Alekseenko, Y., Battistin, L., Ehler, E., Gerstenbrand, F., Muresanu, D., Potapov, A., Stepan, C., Traubner, P. and Vecsei, L. (2012). Mild traumatic brain injury. European journal of neurology. 19, 191-198.

35. Mayer, A.R., Quinn, D.K. and Master, C.L. (2017). The spectrum of mild traumatic brain injury: a review. Neurology. 89, 623-632.

36. Alexander, M.P. (1995). Mild traumatic brain injury: pathophysiology, natural history, and clinical management. Neurology.

37. van der Horn, H.J., Out, M.L., de Koning, M.E., Mayer, A.R., Spikman, J.M., Sommer, I.E. and van der Naalt, J. (2019). An integrated perspective linking physiological and psychological consequences of mild traumatic brain injury. Journal of neurology, 1-10.

38. Bailey, K.M., Carleton, R.N., Vlaeyen, J.W. and Asmundson, G.J. (2010). Treatments addressing pain-related fear and anxiety in patients with chronic musculoskeletal pain: a preliminary review.

Cognitive behavior therapy. 39, 46-63. 

Chapter 9

\section{Scientific and Societal Impact}

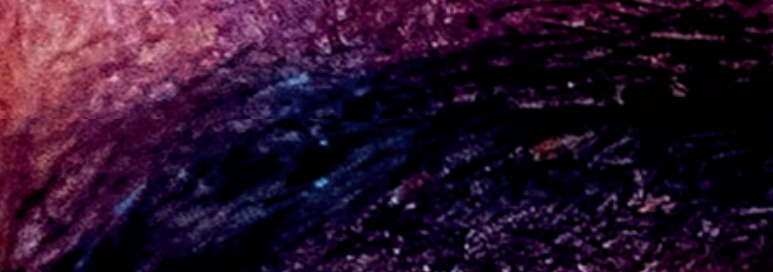

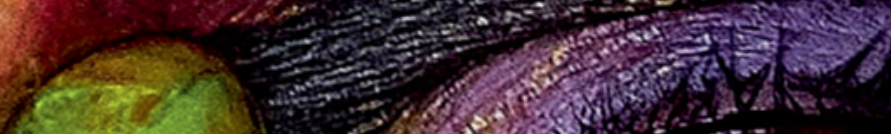
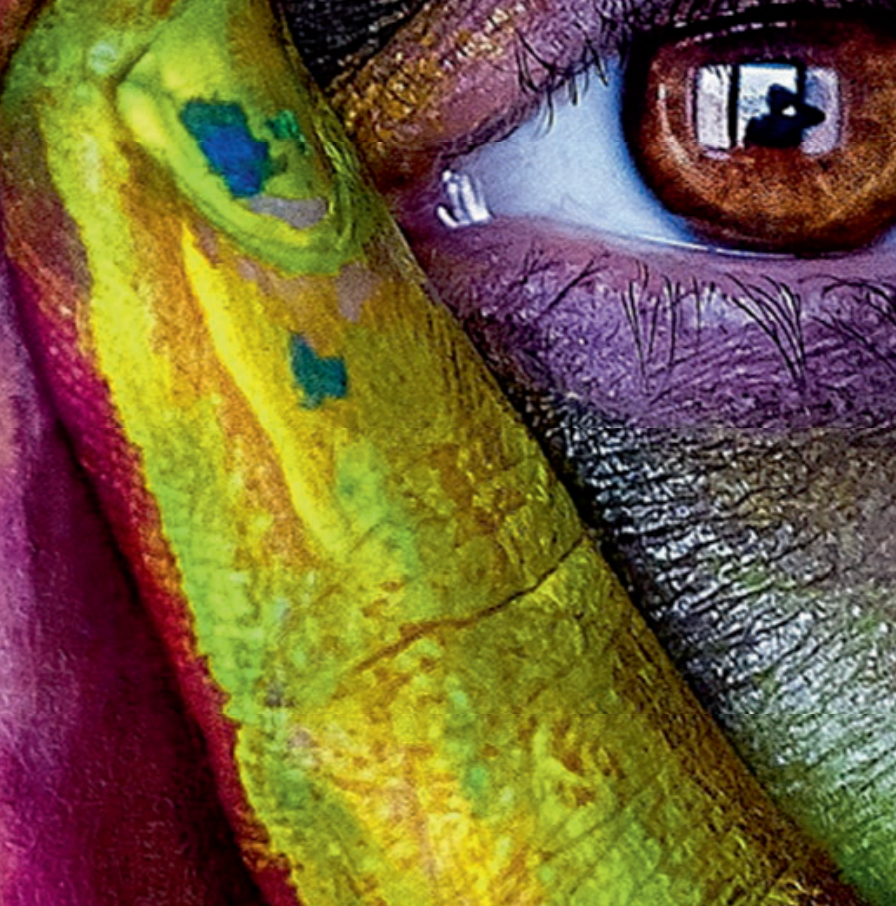


\section{Research presented in this thesis: main objective, results and conclusions}

In this thesis, six studies are described to explore if a new theoretical model could help understand why a subgroup of patients with mild traumatic brain injury (mTBl; also known as concussion) fails to recover timely. Group studies showed that full recovery could be expected within three months after the injury, but this subgroup fails to recover within this timeframe. These patients report persistent post-concussion symptoms (PCS). PCS encompasses physical (e.g., headache), cognitive (e.g., memory problems), emotional (e.g., depressive feelings), and/or behavioral symptoms (e.g., easily annoyed). The theoretical model studied was the fear-avoidance (FA) model, originally developed to explain disability in chronic lower back pain, and adapted by us to the PCS-related FA model. The PCS-related FA model uses a biopsychosocial approach, meaning that it combines biological (e.g., brain injury) and psychosocial factors (e.g., anxiety) to understand recovery patterns (e.g., chronic disability) after mTBI. This FA model states that the way people think about their symptoms influences their behavior and if they recover timely or not. For example, a patient could think that his/her headaches are a sign of permanent brain damage, therefore avoiding mental activities (e.g., reading and participating in meetings), and calling in sick for a longer period.

The results of the studies in this thesis support the idea that anxiety and thoughts about symptoms, as suggested by the PCS-related FA model, play an important role to understand PCS for various groups of people. Our studies extend the FA model now to patients with multiple sclerosis (MS), patients with mild to severe TBI, and healthy adults. Our studies also show that if "thoughts about symptoms" are taken into consideration, we can better predict who avoids cognitively challenging tasks or reports chronic disability. This is the case if we add "thoughts about symptoms" as a predictor to a set of more commonly used predictors such as injury severity, sex, age, and psychological vulnerability. Moreover, the results highlight that we can better understand recovery patterns after TBI if we use a biopsychosocial approach (i.e., combining biological and psychosocial factors). Above all, our study results support the importance of considering psychological factors if we want to understand how people react to and recover from a biological injury, with special importance for TBI. Therefore, patients with PCS could potentially be helped with therapies applying also a 
biopsychosocial approach, such as incorporating cognitive behavioral therapy, targeting thoughts about symptoms, into rehabilitation programs.

All in all, the presented studies show that researchers and clinicians should consider the PCS-related FA model as possible theoretical understanding of prolonged recovery of patients struggling with PCS. The full potential of the PCSrelated FA model still needs to be investigated, especially taking into account that the FA model will only be applicable to patients with catastrophizing thoughts and fear-avoidance behavior as disabling factors. Studies investigating the FA model as a disease process over time and its associated treatment are still needed as future steps.

\section{Relevance of study results for science and society: now and in the future.}

For the scientific community, the results are presented at conferences for scientific audiences and published in several international peer-reviewed publications. The findings (see previous section) are relevant for various research fields including (but not limited to): (1) clinical neuropsychology (e.g., recovery after $\mathrm{mTBI}$ or other relevant neuropsychological conditions such as minor stroke); (2) clinical psychology (e.g., a biopsychosocial model as theoretical basis for understanding a disease process linked to an evidence-based cognitive behavioral therapy); (3) rehabilitation medicine/neuropsychiatry (e.g., understanding suboptimal recovery after a (brain) injury of which one is expected to recover completely); (4) experimental psychopathology (e.g., understanding individual differences in behavior, emotion, and cognition, especially how people think about common symptoms and act upon these thoughts and beliefs). Furthermore, the results warrant continuation of the PCS-related FA model research line, especially studies investigating the FA model as disease process over time and the development and evaluation of individualized cognitive behavioral therapy, such as PCS-related exposure therapy. Depending on the complexity of the consequences a patient experiences, exposure therapy can be considered as a stand-alone psychological therapy or incorporated into a multidisciplinary rehabilitation treatment. Essential in this therapy is that patients are exposed to activities that they normally avoid due to catastrophizing thoughts and beliefs. With exposure therapy, these beliefs are corrected and patients feel able to 
resume their daily activities. In general, the emphasis on psychological factors and not merely on biological factors stimulates a biopsychosocial approach in future studies to further understand the individual impact of medical conditions. Our results suggest that better understanding, and therefore reducing chronic disability in patients with injuries of which one is expected to recover completely, is most likely achieved by further exploration of a biopsychosocial approach and adaptation of psychological processes. Finally, the results are presented in educational lectures and could be incorporated in the educational program of various healthcare providers, such as general practitioners, neurologists, rehabilitation physicians, and (neuro)psychologists.

For society, the results are relevant for healthcare professionals, policy makers, insurance companies, and patients themselves. Patients with PCS seek help to relieve their burden, empower their abilities, and improve their quality of life. However, an evidence-based treatment option for patients with PCS-related disability after mTBI is still lacking. This is associated with many costs on the individual level (e.g., chronic disability, suboptimal levels of participation, and loss of quality of life) and societal level (e.g., societal costs associated with inability to work and high long-lasting healthcare consumption). Society would benefit most from evidence-based, individualized, cost-effective treatment options targeting this patient group. Our results have helped to improve our current understanding of why some people do not recover timely after mTBI and highlight psychological factors as an essential element. Psychological factors should be treated using psychological therapies. Specifically, the FA model and its first treatment of choice (exposure therapy) is well studied in other patient groups experiencing longstanding symptoms such as chronic pain, tinnitus, and chronic fatigue. The next logical step would be studies investigating the PCS-related FA model over time and developing PCS-related exposure therapy.

At this stage, clinicians could be aware of the PCS-related FA model during their intakes, administer questionnaires assessing factors related to the FA model (e.g., catastrophizing with the Post-Concussion Symptoms Catastrophizing Scale (PCS-CS) and fear-avoidance with the Fear of Mental Activity scale (FMA)), and compare the scores with reference data of our healthy adult cohort. Deviating scores should be reported back to the patient and openly reflected upon, followed 
by information about possible psychological processes such as the impact of thoughts about symptoms on symptom experience. Filling in an individualized FA model together with the patient, including his/her own symptoms and thoughts, can be helpful during this reflective session. Understanding behavior in this way could normalize the disease process that has taken place for the patient, resulting in understanding of suffering from symptoms, and if necessary with extra treatment, potentially breaking through the cyclic pattern posed by the FA model. It is important to mention that although the FA model shows promising findings in our first exploration, this explanation would not be applicable to all patients. Even if our findings are confirmed in follow-up studies, the FA model only applies to patients with catastrophizing thoughts and fear-avoidance behavior as disabling factors.

All in all, researchers and clinicians should not avoid the mental challenges PCS pose, but confront these challenges by thinking beyond diagnosis: ask the patient about his/her thoughts and feelings about PCS and take these into account in the efforts to help a person struggling with life's curveballs. 



\section{Addendum}

summary

Samenvatting

Vragenlijsten PCS-CS en FMA

Curriculum vitae

Iist of publications

Bankwoord

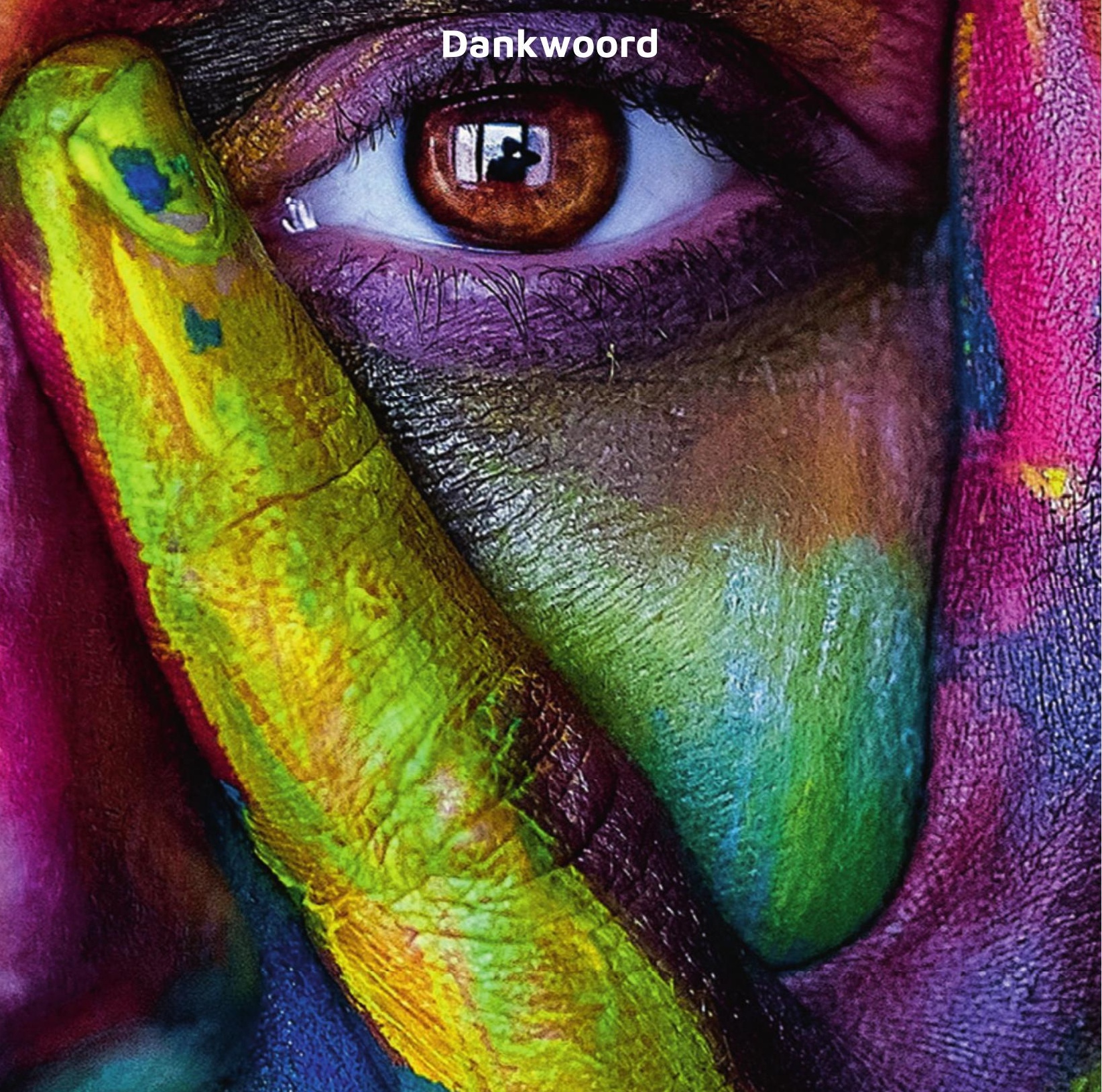





\section{Summary}

Although most patients with mild traumatic brain injury (mTBI) fully recover, approximately $20 \%$ of patients report persistent post-concussion symptoms (PCS) three months or longer post-injury. PCS encompasses physical (e.g., headache), cognitive (e.g., memory problems), emotional (e.g., depressive symptoms) and/or behavioral symptoms (e.g., irritability). Given the high impact for the individual and their surroundings, the high prevalence within chronic care settings and societal costs associated with suboptimal recovery, improving our understanding of PCS has been the focus of many researchers. Despite the large efforts and advancing techniques to date, a uniform explanation for PCS is still lacking. Previous studies showed that biomedical measures alone (e.g., injury severity indexes) fail to predict suboptimal recovery and introduced psychological factors (e.g., anxiety) as important additional predictors. Recent systematic literature reviews propose a biopsychosocial approach (i.e., combining biomedical and psychosocial factors) and emphasize the importance of anxiety, thoughts about symptoms, and a self-sustaining dysfunctional loop as potential key elements to understand PCS.

A biopsychosocial model centralizing the role of anxiety and explaining PCS as a self-sustaining dysfunctional loop is the fear-avoidance (FA) model. The FA model is originally developed in 1995 to explain chronic musculoskeletal pain and has been applied to various patient populations ever since. Applying this model to PCS in mTBI would indicate that patients erroneously interpret symptoms as a sign of brain pathology over which one has little or no control. Such catastrophizing thoughts could extend to fear of mental activities, introduced as 'cogniphobia' (similar to 'kinesiophobia' or fear of physical activity in chronic pain), and subsequently decrease activity levels and may result in progressive disuse, symptoms of depression, and disability. This could then increase the amount and magnitude of PCS concluding its cyclic pattern. The main aim of this thesis is to provide novel insights on persistent symptoms after brain injury by exploring the PCS-related FA model for the first time. Chapter 1 provides a more extensive background to the aims of this thesis.

In chapter 2, the first exploration of the FA model in another brain disease, namely Multiple Sclerosis (MS), is extended by means of a cross-validation study. 
The results reveal a successful cross-validation of the adapted FA model to understand fatigue after MS. Catastrophizing, depression, physical disability, disease severity and fear-avoidance all contribute significantly to fatigue, supporting the specific interrelationships as suggested by the FA model. The results support the notion that catastrophizing about fatigue plays a central role: fueled by depression, catastrophizing thoughts mediate the relationship between fatigue and fatigue-related fear-avoidance behavior. This study highlighted the disabling role of psychological characteristics, such as anxiety and thoughts about symptoms, in a neurological condition.

To improve our understanding of psychological characteristics in patients with acquired brain injury, chapter 3 presents a longitudinal study investigating if psychological characteristics remain stable in the first two years post-stroke. Results show that scores on all adaptive psychological characteristics (e.g., proactive coping, self-efficacy, optimism, extraversion) decrease over time, whereas scores on maladaptive psychological characteristics (e.g., neuroticism, pessimism) increase or remain stable (passive coping) over time. Clinicians should be aware of the impact of psychological characteristics on quality of life, consider their temporal (in)stability after stroke, and stimulate the use of more adaptive psychological characteristics, such as proactive coping and optimism.

Chapter 4 presents a first exploration of the PCS-related FA model. This pilot study examined patients in the chronic phase after mild or moderate to severe TBI. The results show significant interrelationships within the FA model and provide some useful suggestions regarding adaptations made by us to the questionnaires assessing PCS-related catastrophizing and fear-avoidance. These findings indicate that further studies focusing on the FA model as a potential contribution to our understanding of persistent symptoms after TBI seem warranted.

The suggestions regarding the questionnaires assessing PCS-related catastrophizing and fear-avoidance were processed and resulted in the first study investigating the psychometric properties of the Post-Concussion Symptoms Catastrophizing Scale (PCS-CS) and the Fear of Mental Activity scale (FMA). Although future studies assessing patient populations are warranted, a psychometric study in a non-brain injury population is presented as important first 
step in chapter 5. The results support the notion that the PCS-CS, FMA, and their provided cut-offs can be used to assess PCS-related catastrophizing and fearavoidance in a reliable and valid manner. Furthermore, reference data of a cohort of working adults are presented and provide a cut-off for an increased level of catastrophizing and fear-avoidance for research purposes and clinical practice.

To extend the exploration of the validity of the PCS-related fear-avoidance measures, we investigated in chapter $\mathbf{6}$ whether fear-avoidance and catastrophizing about mental activities are related to behavioral avoidance in a healthy population. The results of this experimental study reveal that catastrophizing relates to behavioral avoidance of mental activities in healthy adults. The results show that catastrophizers spend less time on the performance of difficult tasks as compared to easy cognitive tasks. This is in line with the assumed relationship between catastrophizing and fear-avoidance according to the FA model and demonstrates its link on a behavioral level. Furthermore, the additive value of the FA model over known predictors was supported by the finding that catastrophizing was a significant predictor of time spent on difficult cognitive tasks, next to female sex.

In chapter 7, we investigated the additive value of the PCS-related FA model in understanding outcome after TBI. Analyses reveal that elements of the FA model (e.g., catastrophizing and fear-avoidance) improve prediction of the main outcome (chronic disability after TBI) compared with known predictors alone (injury-related, such as severity indexes, or demographic, such as sex). This large Australian cross-sectional study revealed the additive value of the PCS-related FA model over known predictors in understanding outcome after TBI of all severities. These results suggest that the model may be valuable as a theoretical model and stepping stone in both diagnostic and treatment stages and enables its dissemination in English-speaking countries.

In chapter 8, we discuss and integrate all studies presented in this thesis, including the main findings, methodological considerations, suggestions for future research, and recommendations for clinical practice. Taking into account the main limitations (e.g., cross-sectional study design, lack of control group, mainly using self-report questionnaires), the studies in this thesis support the disabling role of anxiety as suggested by the FA model and its potential additive value across 
various study populations. Our studies extend the FA model now to MS, mild to severe TBI, and PCS-like symptoms in healthy adults. Furthermore, our studies reveal that elements of the FA model (e.g., catastrophizing and fear-avoidance) predict the main outcome (e.g., behavioral avoidance and chronic disability) over and above established biomedical (e.g., injury severity indexes), personal (e.g., sex, age) and/or psychological predictors (e.g., psychological treatment history). Taking into account that the FA model would not be applicable to all patients and longitudinal and treatment studies are warranted, the current findings implicate that researchers and clinicians should consider the PCS-related FA model as possible theoretical understanding of prolonged recovery of patients struggling with PCS. 



\section{Samenvatting}

Ondanks dat de meeste mensen na licht traumatisch hersenletsel (licht THL) volledig herstellen, ervaart ongeveer 20\% 3 maanden of langer postcommotionele symptomen (PCS). PCS omvatten fysieke (bijv. hoofdpijn), cognitieve (bijv. geheugenklachten), emotionele (bijv. depressieve klachten) en/of gedragsmatige (bijv. prikkelbaarheid) symptomen. Gezien de grote impact voor het individu en diens omgeving, het aantal mensen dat een beroep doet op zorg en ondersteuning en de hoge kosten van suboptimaal herstel voor de maatschappij (door bijv. geen of gedeeltelijke terugkeer naar werk), proberen veel onderzoekers inzicht te krijgen in de ontwikkeling van PCS. Ondanks vele pogingen en technische ontwikkelingen dusver, ontbreekt een eenduidige verklaring voor het ontstaan van PCS. Eerdere onderzoeken hebben aangetoond dat biomedische kenmerken (bijv. ernst van hersenletsel) op zichzelf niet in staat zijn suboptimaal herstel te voorspellen en introduceren psychologische kenmerken (bijv. angst) als belangrijke toevoeging. Recente systematische literatuuronderzoeken stellen een biopsychosociale benadering voor (oftewel het combineren van biomedische en psychosociale kenmerken) en benadrukken angst, gedachtes over symptomen en een negatieve cirkel die zichzelf in stand houdt als mogelijke kernelementen om PCS te begrijpen.

Een biopsychosociaal model, dat de rol van angst centraal stelt en PCS verklaart middels een negatieve cirkel die zichzelf in stand houdt, is het vreesvermijdingsmodel. Het vreesvermijdingsmodel is oorspronkelijk ontwikkeld in 1995 om chronische pijn aan het bewegingsapparaat (bijv. lage rugpijn) te verklaren en is sindsdien toegepast bij verschillende patiëntenpopulaties. Als dit model wordt toegepast op PCS na licht THL, zou dit betekenen dat patiënten hun symptomen foutief interpreteren als teken van breinschade waar ze weinig tot geen controle over hebben. Zulke catastroferende gedachten kunnen dan uitbreiden naar angst en het vermijden van mentale activiteiten, geïntroduceerd als "cognifobie" (zoals "kinesiofobie" of bewegingsangst bij chronische pijn). Dit leidt vervolgens tot lagere activiteitenniveaus wat uiteindelijk kan resulteren in minder het brein belasten, meer depressieve klachten en meer beperkingen. Dit kan dan weer de mate en ernst van PCS laten toenemen, waarmee de negatieve cirkel rond is en symptomen mogelijk verklaard zijn. Het hoofddoel van deze thesis 
is om nieuwe inzichten te geven over blijvende symptomen na hersenletsel door het PCS-gerelateerde vreesvermijdingsmodel voor het eerst te onderzoeken.

Hoofdstuk 1 geeft een meer vitgebreide achtergrond over de doelen van het onderzoek in deze thesis.

In hoofdstuk 2 wordt de eerste verkenning van het vreesvermijdingsmodel bij een andere relevante hersenziekte, namelijk Multiple Sclerosis (MS), voortgezet door een crossvalidatie onderzoek. De resultaten tonen een succesvolle crossvalidatie van het aangepaste vreesvermijdingsmodel om vermoeidheid na MS te begrijpen. Catastroferen, depressie, fysieke beperking, ernst van de ziekte en vreesvermijding dragen allemaal significant bij aan vermoeidheid, waarmee de specifieke onderlinge relaties conform het vreesvermijdingsmodel worden ondersteund. De resultaten ondersteunen het idee dat catastroferen over vermoeidheid een centrale rol speelt: gevoed door depressie, mediëren catastroferende gedachtes de relatie tussen vermoeidheid en vermoeidheidgerelateerd vreesvermijdingsgedrag. Dit onderzoek benadrukt het belang van de invaliderende rol van psychologische kenmerken, zoals angst en gedachtes over symptomen, bij mensen met een neurologische aandoening.

Om psychologische kenmerken bij patiënten met niet-aangeboren hersenletsel beter te begrijpen, staat in hoofdstuk $\mathbf{3}$ een longitudinale studie beschreven die onderzoekt of psychologische kenmerken stabiel blijven gedurende de eerste twee jaar na een beroerte. Resultaten laten zien dat de gerapporteerde niveaus op alle adaptieve psychologische kenmerken (bijv. proactieve coping, zelfeffectiviteit, optimisme, extraversie) afnemen, terwijl de gerapporteerde niveaus op de maladaptieve psychologische kenmerken (bijv. neuroticisme, pessimisme) toenemen of stabiel blijven (bijv. passieve coping) over tijd. Clinici zouden zich bewust moeten zijn van de impact van psychologische kenmerken op kwaliteit van leven, rekening houden met hun temporele (in)stabiliteit na een beroerte, en het gebruik van meer adaptieve psychologische kenmerken (zoals proactieve coping en optimisme) stimuleren.

In hoofdstuk 4 beschrijven we een eerste verkenning van het PCSgerelateerde vreesvermijdingsmodel. Deze pilotstudie onderzoekt patiënten in de chronische fase na licht of matig tot ernstig THL. De resultaten tonen significante onderlinge relaties binnen het vreesvermijdingsmodel aan. Bovendien worden 
aanpassingen van de vragenlijsten, die PCS-gerelateerd catastroferen en vreesvermijding meten, voorgesteld. De bevindingen laten zien dat toekomstige onderzoeken naar het vreesvermijdingsmodel om zo blijvende symptomen na THL beter te begrijpen gerechtvaardigd lijken.

De suggesties voor aanpassing van de vragenlijsten, die PCS-gerelateerd catastroferen en vreesvermijding meten, werden verwerkt en resulteerden in een eerste onderzoek naar de psychometrische eigenschappen van de "PostConcussion Symptoms Catastrophizing Scale" (PCS-CS) en de "Fear of Mental Activity scale" (FMA). Ondanks dat toekomstige onderzoeken in patiëntenpopulaties nodig zijn, wordt een psychometrisch onderzoek in een niethersenletsel populatie als belangrijke eerste stap gepresenteerd in hoofdstuk $\mathbf{5}$. De resultaten ondersteunen het idee dat de PCS-CS, FMA, en hun afkapwaardes betrouwbaar en valide gebruikt kunnen worden om PCS-gerelateerd catastroferen en vreesvermijding te meten. Bovendien worden normgegevens van een cohort werkende volwassenen gepresenteerd en worden grenswaardes gegeven voor een verhoogd niveau van catastroferen en vreesvermijding ten behoeve van onderzoeksdoeleinden en klinische gebruik.

Om de verkenning van de validiteit van de PCS-gerelateerde vreesvermijding meetinstrumenten uit te breiden, onderzochten wij in hoofdstuk 6 of vreesvermijding en catastroferen over mentale activiteiten gerelateerd was aan vermijdingsgedrag in een gezonde populatie. De resultaten van dit experimentele onderzoek laten zien dat catastroferen gerelateerd is aan gedragsmatig vermijden van mentale activiteiten in gezonde volwassenen. De resultaten tonen aan dat catastrofeerders minder tijd spenderen aan moeilijke cognitieve taken in vergelijking met makkelijke cognitieve taken. Dit komt overeen met de verwachte relatie tussen catastroferen en vreesvermijding volgens het vreesvermijdingsmodel en toont deze link op een gedragsmatig niveau aan. Bovendien wordt de meerwarde van het vreesvermijdingsmodel naast bekende voorspellers ondersteund door de bevinding dat niveau van catastroferen, naast vrouwelijk geslacht, een significante voorspeller is voor de tijd die gespendeerd wordt aan moeilijke cognitieve taken.

In hoofdstuk 7 onderzochten we de meerwarde van het PCS-gerelateerde vreesvermijdingsmodel om de vitkomst na THL beter te begrijpen. Analyses laten 
zien dat elementen van het vreesvermijdingsmodel (bijv. catastroferen en vreesvermijding) de voorspelling van de hoofduitkomstmaat (chronische beperkingen na THL) verbeteren in vergelijking met alleen bekende voorspellers (letsel gerelateerd zoals mate van ernst of demografisch zoals geslacht). Deze grootschalige Australische cross-sectionele studie bevestigt de meerwaarde van het PCS-gerelateerde vreesvermijdingsmodel naast bekende voorspellers om uitkomst na THL van alle mate van ernst te begrijpen. De resultaten impliceren dat het model mogelijk waardevol is als theoretisch model en als eerste opstap in zowel diagnostiek- als behandelfases. Tevens maken de resultaten het gebruik van de vragenlijsten in Engelstalige landen mogelijk.

In hoofdstuk 8 rapporteren en integreren we alle onderzoeken die zijn gepresenteerd in deze thesis, inclusief de hoofdbevindingen, methodologische overwegingen, suggesties voor toekomstig onderzoek en aanbevelingen voor de klinische praktijk. Rekening houdend met de voornaamste beperkingen (bijv. cross-sectioneel onderzoeksdesign, ontbreken van een controlegroep, voornamelijk gebruik van zelfrapportage vragenlijsten), ondersteunen de onderzoeken in deze thesis de invaliderende rol van angst conform het vreesvermijdingsmodel en diens mogelijke verklarende waarde bij verschillende onderzoeksgroepen. Onze onderzoeken breiden het vreesvermijdingsmodel nu uit naar MS, licht tot ernstig THL, en post-commotioneel-achtige symptomen in gezonde volwassenen. Bovendien tonen onze onderzoeken aan dat elementen van het vreesvermijdingsmodel (bijv. catastroferen en vreesvermijding) de hoofduitkomstmaat (bijv. vermijdingsgedrag of chronische beperkingen) voorspelt naast gevestigde biomedische (bijv. ernst van hersenletsel), persoonlijke (bijv. geslacht, leeftijd) en/of psychologische voorspellers (bijv. psychologisch behandelverleden). Rekening houdend met het idee dat het vreesvermijdingsmodel niet toegepast zal kunnen worden op alle patiënten en longitudinale en behandelstudies nog nodig zijn, impliceren de huidige resultaten dat onderzoekers en clinici het PCS-gerelateerde vreesvermijdingsmodel kunnen overwegen als mogelijke theoretische verklaring voor stagnerend herstel bij patiënten met PCS. 



\section{Vragenlijsten PCS-CS en FMA}

\section{Post-Concussion Symptoms Catastrophizing Scale (PCS-CS)}

N.B. Afname is bij voorkeur online omdat de antwoorden die worden gegeven op de RPQ (Rivermead Post-concussion symptoms Questionnaire) gebruikt worden in de afname van de PCS-CS en FMA.

$U$ heeft zojuist aangegeven geen van de gevraagde klachten als probleem te ervaren.

ledereen ervaart weleens hoofdpijn, cognitieve klachten en/of vermoeidheid. Mensen komen vaker in situaties die deze klachten veroorzaken. We zijn geïnteresseerd in de soort gedachten en gevoelens die u ervaart als u deze klachten heeft. In de onderstaande lijst staan dertien beweringen die verschillende gedachten en gevoelens beschrijven die mogelijk met deze klachten te maken hebben. Probeer aan te geven in welke mate deze gedachten en gevoelens ook voor $u$ van toepassing zijn.

OF

U heeft aangegeven deze klachten te ervaren:

"Symptomen worden ingevoegd met een item score op de RPQ van 2 of hoger"

ledereen ervart weleens deze klachten of hoofdpijn, cognitieve klachten en/of vermoeidheid. Mensen komen vaker in situaties die deze klachten veroorzaken. We zijn geïnteresseerd in de soort gedachten en gevoelens die $u$ ervaart als $u$ deze klachten heeft. In de onderstaande lijst staan dertien beweringen die verschillende gedachten en gevoelens beschrijven die mogelijk met deze klachten te maken hebben. Probeer aan te geven in welke mate deze gedachten en gevoelens ook voor $u$ van toepassing zijn. 


\begin{tabular}{|c|c|c|c|c|c|}
\hline Als ik deze klachten heb... & $\begin{array}{l}\text { Helemaal } \\
\text { niet }\end{array}$ & $\begin{array}{l}\text { In lichte } \\
\text { mate }\end{array}$ & $\begin{array}{l}\text { In zekere } \\
\text { mate }\end{array}$ & $\begin{array}{l}\text { In grote } \\
\text { mate }\end{array}$ & Altijd \\
\hline
\end{tabular}

1. vraag ik mij voortdurend af of de klachten zullen ophouden

2. voel ik dat ik zo niet verder kan

3. is dat verschrikkelijk en denk ik dat het nooit beter zal worden

4. is dat afschuwelijk en voel ik dat de klachten mij overweldigen

5. voel ik dat ik het niet meer vithoud

6. word ik bang dat de klachten erger worden

7. blijf ik denken aan andere situaties waarin deze klachten voorkomen

8. verlang ik hevig dat de klachten weggaan

9. kan ik de klachten niet uit mijn gedachten zetten

10. blijf ik eraan denken hoe moeilijk het allemaal is

11. blijf ik denken hoe graag ik zou willen dat de klachten ophouden

12. is er niets dat ik kan doen om de intensiteit van de klachten te verminderen

13. vraag ik mij af of er iets ernstigs kan gebeuren 


\section{Fear of Mental Activity scale (FMA)}

N.B. Afname is bij voorkeur online omdat de antwoorden die worden gegeven op de RPQ (Rivermead Post-concussion symptoms Questionnaire) gebruikt worden in de afname van de PCS-CS en FMA.

$U$ heeft zojuist aangegeven geen van de gevraagde klachten als probleem te ervaren.

ledereen ervaart weleens hoofdpijn, cognitieve klachten en/of vermoeidheid. Met deze vragenlijst willen wij onderzoeken op welke wijze u tegen deze klachten aankijkt en hoe $u$ deze klachten ervart. Het is de bedoeling dat $u$ aangeeft in welke mate $u$ het eens of oneens bent met elke bewering. Het is van essentieel belang dat u bij de beoordeling uitgaat van uw eigen gevoelens; wat anderen denken is hierbij niet relevant. Het is ook niet de bedoeling uw medische kennis te testen. Waar het om gaat is dat $u$ aangeeft hoe $u$ deze klachten ervaart.

\section{OF}

U heeft aangegeven deze klachten te ervaren:

"Symptomen worden ingevoegd met een item score op de RPQ van 2 of hoger"

ledereen ervaart weleens deze klachten of hoofdpijn, cognitieve klachten en/of vermoeidheid. Met deze vragenlijst willen wij onderzoeken op welke wijze u tegen deze klachten aankijkt en hoe $u$ deze klachten ervaart. Het is de bedoeling dat $u$ aangeeft in welke mate $u$ het eens of oneens bent met elke bewering. Het is van essentieel belang dat u bij de beoordeling uitgaat van uw eigen gevoelens; wat anderen denken is hierbij niet relevant. Het is ook niet de bedoeling uw medische kennis te testen. Waar het om gaat is dat $u$ aangeeft hoe $u$ deze klachten ervart. 
Geef van onderstaande beweringen aan in welke mate $u$ het eens of oneens bent met deze bewering.

1. Ik ben bang om bij denkwerk hersenletsel op te lopen.

2. Als ik deze klachten negeer, dan worden de klachten erger

3. Mijn hoofd zegt me dat er iets gevaarlijks mis is.

4. Mijn klachten zouden waarschijnlijk minder worden als ik hersentraining zou doen.

5. Mijn gezondheidstoestand wordt door anderen niet serieus genomen.

6. Door mijn klachten lopen mijn hersenen de rest van mijn leven gevaar.

7. Deze klachten betekenen dat er sprake is van hersenletsel.

8. Als mijn klachten erger worden door iets, betekent dat nog niet dat dat gevaarlijk is.

9. Ik ben bang om per ongeluk hersenletsel op te lopen.

10. De veiligste manier om te voorkomen dat mijn klachten erger worden, is gewoon oppassen dat ik geen onnodig denkwerk verricht.

11. Ik had wellicht minder klachten als er niet iets gevaarlijks aan de hand zou zijn met mijn hersenen.

12. Hoewel ik deze klachten heb, zou ik er beter aan toe zijn als ik denkwerk doe.

13. Mijn klachten zeggen me wanneer ik moet stoppen met denkwerk om geen hersenletsel op te lopen.

14. Voor iemand in mijn toestand is het echt af te raden om veel denkwerk te doe

15. Ik kan niet alles doen wat gewone mensen doen, omdat ik te gemakkelijk hersenletsel oploop.

16. Zelfs als ik ergens veel klachten door krijg, geloof ik niet dat dat gevaarlijk is

17. Ik zou geen denkwerk hoeven doen wanneer ik deze klachten heb.

$\begin{array}{cccc}\text { In hoge } & \text { Enigszins } & \text { Enigszins } & \text { In hoge } \\ \text { mate mee } & \text { mee } & \text { mee } & \text { mate mee } \\ \text { oneens } & \text { oneens } & \text { eens } & \text { eens }\end{array}$

(1)

O





\section{Curriculum Vitae}

Melloney Wijenberg was born on August 25, 1992 in Maastricht, The Netherlands. In 2004, she started her secondary education at the Sint Maartenscollege in Maastricht and received her diploma in 2010 at Lyceum Schöndeln in Roermond.

In the same year, she moved back to her hometown and started studying psychology at the Faculty of Psychology and Neuroscience at Maastricht University. During her bachelor study, she followed the honours program, completed multiple voluntary clinical internships, and followed clinical (neuro)psychology electives at the University of Amsterdam and Maastricht University. After completing her bachelor study in 2013 with distinction (cum laude), she was selected for the two-year research master program Cognitive and Clinical Neuroscience with a specialisation in Neuropsychology.

After obtaining her Research Master degree with distinction (cum laude) in 2015, she combined multiple research, education and clinical jobs. In May 2016, Melloney joined the Department of Psychology and Neuroscience at Maastricht University in May 2016 as a PhD candidate, under the supervision of prof. dr. Caroline van Heugten, prof. dr. Jeanine Verbunt and dr. Sven Stapert. Till September 2016 and from May 2019 onwards, Melloney combined her PhD with various clinical jobs at Zuyderland Medical Center, Novicare, and Adelante. In 2019, Melloney visited prof. dr. Jennie Ponsford and her research group at the Monash-Epworth Rehabilitation Research Center in Melbourne, Australia, to work on a project examining the fear-avoidance model in patients with more severe traumatic brain injury (TBI). Next to the studies described in this thesis, Melloney conducted a large longitudinal study in conjunction with all hospitals in Limburg $(\mathrm{NL})$ to examine the potential of the fear-avoidance model to explain postconcussion symptoms after mild TBI over time.

Currently, Melloney is working as a psychologist at the neurology department of Adelante, a rehabilitation center in Limburg (NL), which enables her to do what she loves: helping patients by combining clinical work with research, educational, and policy activities. 



\section{List of publications}

1. Wijenberg, M.L.M. (2015). A systematic review of the effect of early onset cognitive rehabilitation on acquired brain injury patients from a neural perspective. Maastricht Student Journal of Psychology and Neuroscience. 4.

2. Wijenberg, M.L.M., Stapert, S.Z., Köhler, S. and Bol, Y. (2016). Explaining fatigue in multiple sclerosis: cross-validation of a biopsychosocial model. J Behav Med. $39,815-822$.

3. Wijenberg, M.L.M., Stapert, S.Z., Verbunt, J.A., Ponsford, J.L. and Van Heugten, C.M. (2017). Does the fear avoidance model explain persistent symptoms after traumatic brain injury? Brain Inj. 31, 1597-1604.

4. Wijenberg, M.L.M., van Heugten, C.M., van Mierlo, M.L., Visser-Meily, J.M.A. and Post, M.W.M. (2019). Psychological factors after stroke: Are they stable over time? J Rehabil Med. 51, 18-25.

5. Wijenberg, M.L.M., Hicks, A.J., Downing, M.G., van Heugten, C.M., Stapert, S.Z. and Ponsford, J.L. (2020). Relevance of the Fear-Avoidance Model for Chronic Disability after Traumatic Brain Injury. J Neurotrauma. 37, 2639-2646.

6. Wijenberg, M.L.M., Rauwenhoff, J.C.C., Stapert, S.Z., Verbunt, J.A. and van Heugten, C.M. (2021). Do fear and catastrophizing about mental activities relate to fear-avoidance behavior in a community sample? An experimental study. J Clin Exp Neuropsychol. 43, 66-77.

7. Verberne, D.P.J., Ponds, R.W.H.M., Kroese, M.E.A.L., Wijenberg, M.L.M., Barten, D.G., Pasmans, R., Staals, J. and van Heugten, C.M. (2021). Long-term psychosocial outcome following mild traumatic brain injury and minor stroke: a direct longitudinal comparison. J Neurol. 



\section{Dankwoord}

Op diech höb iech lang gewach, hiel veul jaore vaan mien leeve - Beppie.

Daar is het moment aangebroken, mijn promotietraject komt tot een einde. Een promotietraject is heel veel teamwork. Ik wil dan ook graag alle mensen bedanken die dit mogelijk hebben gemaakt en hier een paar in het bijzonder noemen.

Ten eerste wil ik mijn promotieteam bedanken. Bedankt dat jullie je krachten hebben gebundeld om deze bijzondere en belangrijke onderzoekslijn mogelijk te maken en dat ik mij als promovendus hiervoor mocht inzetten. Caroline, ik heb altijd versteld gestaan van jouw passie voor gedegen onderzoek, oog voor detail, en hoe jij ondanks al jouw taken en verantwoordelijkheden zo betrokken was bij iedere stap. Ik wil je bedanken voor alle energie die je in mij hebt gestoken. Jeanine, ik heb veel van jouw expertise genoten warbij je me steeds kritisch liet nadenken over andere invalshoeken. Ik vind het heel bijzonder hoe jij je klinische blik steeds betrekt bij je onderzoek en vice versa. Ik heb hier veel van geleerd, bedankt! Sven, jij bent in veel opzichten voor mij een voorbeeld, van scientist-practioner pur sang tot je enorme relativeringsvermogen. Ik wil je bedanken voor je vertrouwen in mij, hoe je altijd tijd voor me maakte, voor je humor en je enorme passie om deze patiëntengroep verder te helpen met je vernieuwende kritische blik. Wat heb ik genoten van samen lesgeven en coördineren, ik hoop dat we dit nog vaak kunnen doen.

Dankzij jullie drie samen sta ik waar ik nu sta, bedankt hiervoor!

Graag wil ik alle leden van de beoordelingscommissie bedanken voor het lezen en beoordelen van mijn proefschrift: prof. dr. Madelon Peeters, prof. dr. Marleen Rijkeboer, prof. dr. Coen van Bennekom en prof. dr. Joke Spikman.

Tevens wil ik graag alle leden van de corona en de zeer betrokken pedel Fabiënne Dingena bedanken voor hun tijd om mijn verdediging mogelijk te maken.

Een speciaal woord van dank voor alle proefpersonen die aan de studies hebben deelgenomen. Zonder jullie bijdrage was dit alles niet mogelijk geweest en ben ik me er bewust van dat jullie dit belangeloos in jullie eigen tijd deden. Dank voor jullie bijdrage aan het vergroten van onze kennis over hoe we de mensen die het nodig hebben, het beste kunnen helpen. Jan, dank voor het maken van de persoonlijke chocoladerepen om zo onze proefpersonen te bedanken! 
Ik wil ook graag mijn dank vitspreken naar alle betrokken instellingen en hun bevlogen medewerkers voor het attenderen van proefpersonen op onze studies. Zonder hun medewerking hadden we nooit zoveel proefpersonen kunnen bereiken en wil ik hen bedanken om hier toch steeds mar weer, ondanks drukke werkagenda's, tijd voor te maken. In het bijzonder dank aan alle medewerkers van de ziekenhuizen in de regio Limburg (MUMC+, Zuyderland, Laurentius, SJG en VieCuri) die zich jarenlang belangeloos hebben ingezet voor de longitudinale studie om het PCS-gerelateerde vreesvermijdingsmodel te onderzoeken. Daarnaast wil ik de Gemeente Maastricht bedanken voor het benaderen van hun medewerkers. Zuyderland, VieCuri en Heliomare, dank voor jullie deelname aan de vervolgstudies van onze onderzoekslijn. Ook wil ik de landelijke werkgroep Commotio Cerebri bedanken dat ik mag deelnemen aan zo'n select gezelschap dat de behandeling voor mensen met licht traumatisch hersenletsel probeert te verbeteren.

Ik wil graag alle co-auteurs bedanken voor hun bijdrage aan de hoofdstukken van dit proefschrift. Ik heb mogen profiteren van jullie expertise, kritische blikken en suggesties, hetgeen heeft geresulteerd in verschillende mooie internationale publicaties. In het bijzonder dank aan de experts die hebben geholpen bij specifieke artikelen en vaak ook hun data beschikbaar stelden, namelijk Yvonne Bol, Seb Köhler, Marcel Post, Anne Visser-Meily, Marloes van Mierlo, Johanne Rauwenhoff, Jennie Ponsford, Marina Downing en Amelia Hicks. Dear Jennie, Marina, Amelia and your colleagues from MERRC, thank you for the opportunity you have given me to work together in Melbourne. It was a very special time for me, being able to talk to so many patients with traumatic brain injury, learning from your expertise and enjoying the sunny weather and your warm hospitality.

Collega's van het EHL, wat ben ik ontzettend dankbaar voor het leuke, bruisende team wat jullie zijn. Ik heb de uitbreiding van het EHL van dichtbij mogen meemaken; van enkele medewerkers naar nu een heel leger aan fantastische wetenschappers en ik ben ontzettend trots op het werk dat deze onderzoeksgroep in zo'n korte tijd klaar heeft kunnen spelen. Ik pluk in mijn klinische werk enorm de vruchten van de zorgproducten en scholingsmomenten die jullie gratis bieden. Ook een speciaal woord van dank voor Marianne, waarmee 
ik veel heb samengewerkt en gelachen in de opstart van de longitudinale studie. Naast het harde werken, was er ook altijd veel aandacht voor elkaar in het team en zal ik de organisatie van symposia met Fleur en de bijzondere uitjes, zoals Granada, Praag, zomerbarbecues en ambtenarencarnaval, koesteren.

De afdeling van Neuropsychology and Psychopharmacology is voor mij al sinds mijn studententijd een bijzondere plek geweest en ik ben heel blij dat ik hier ook als werknemer heb mogen rondlopen. Alle collega's van NPPP, bedankt voor de gezelligheid tijdens de jaarlijkse research days, teamuitjes en de lunches bij de koffie corner. Anke, bedankt voor je inspirerende manier van aanpakken en communiceren tijdens mijn tijd op NPPP als stagiaire, student-assistent en docent. Ik vond het geweldig om tutor, mentor en stagebegeleider te zijn. Dank aan de studenten, maar ook aan Sven en Pauline voor het samen coördineren van klinische vakken. Ook dank aan de afdeling revalidatiegeneeskunde, waar ik, dankzij de betrokkenheid van Jeanine, mocht aansluiten en veel van jullie kennis heb mogen profiteren. Marlies, dank voor jouw expertise over exposure behandelingen en betrokkenheid bij de opzet van de focusgroepen.

Daarnaast zijn er heel wat mensen die me op allerlei manieren hebben gesteund, van administratieve taken, ICT-ondersteuning en lab-ondersteuning tot fijne gesprekken en wijze woorden. Annemie, Margareth, Rosanne, Michiel, Erik, Achim, Irma, Hanneke en Jim, zonder jullie ondersteuning was het niet gelukt en wil jullie dan ook graag bedanken voor jullie cruciale hulp!

Ook wil ik mijn (ex-)collega's van Zuyderland, Novicare en Adelante bedanken voor hun steun, flexibiliteit en vertrouwen om mijn promotiewerkzaamheden te combineren met klinisch werk. Jullie wisten mij altijd te herinneren aan de reden warom ik wilde promoveren: mensen die het nodig hebben beter kunnen helpen!

Onderzoek opzetten en uitvoeren kost veel tijd en werk. Gelukkig hebben heel veel studenten zich ingezet als stagiair of onderzoeksassistent. Evi, Lisanne, Mark, Max, Maud, Milou, Iris, Johanne, Myrthe, Nick, Anemoon, Noelle, Veerle, Lieke en Chantal: ontzettend bedankt voor alle uren aan de telefoon, in de auto, bij mensen thuis en achter de laptops! Johanne, bedankt voor de fijne samenwerking, beginnend met de stage, snel daarna als collega's en op het einde zelfs als co-auteurs. 
Kantoor 2.753, een werkplek waar ik omringd was met lieve kamergenootjes. Eva, Christine, Robbie, Anneke, Pia, maar ook onze buren Eliza, Laura, Franziska en Johannes en de overburen Annemarie, Bert, Daan en Fleur, dank dat ik altijd bij jullie terecht kon voor serieuze gesprekken, wetenschappelijke zorgen en gezelligheid. In het speciaal, Christine, jij bent van begin tot einde mijn vaste kamergenoot geweest en ik heb het enorm gewaardeerd hoe jij altijd voor mij en mijn zorgen tijd had. Jij hebt mij ook kennis laten maken met het onderwerp duurzaamheid en dankzij jouw voorbeeld ben ik mij hier over de jaren heen steeds meer in gaan verdiepen.

Daan, wat heb ik genoten van onze ritjes in onze bolides naar alle deelnemende centra en gedeelde passie voor het feest van onze Limburgse roots met de mooiste muziek; ALAAF! Ik heb zo hard met jou gelachen en kon helemaal mezelf zijn bij jou. Bedaank!

Fleur, jij bent voor mij over de jaren heen meer geworden dan een collega. Mijn buurvrouw in het geliefde Heugem, hét sportmaatje dat begreep dat je sporten het beste kon belonen met wijn en boven alles een nieuwe vriendschap. Wat hebben we in jouw tuintje of in onze wijnbar "Vino \& Friends" veel gelachen, gehuild en vooral heel veel gepraat. Bedankt hiervoor, op nog vele avondjes!

Jess, wat was ik blij dat we deels samen in Australië waren. Het is eigenlijk best bijzonder om als collega's opeens een maand samen te wonen, maar wat heb ik er warme herinneringen aan. Van de hikes naar afgelegen stranden tot het communiceren met kangoeroes. Bedankt voor je fijne gezelschap, kooktips en plantenskills!

Laura, Brenda, Inge, Vivian, Iris en Marcella, bedankt voor onze vriendschap. Jullie staan al meer dan 10 jaar aan mijn zijde en Laura, jij zelfs al vanaf mijn kindertijd. Laura, wat zijn het speciale en vormende jaren voor ons geweest en wat voor hoogtepunten hebben we samen meegemaakt; onze bruiloften, maar natuurlijk ook de komst van Mathias. Bedankt dat als het moeilijk was op werk, we zoveel mooie ervaringen konden delen om ertegenover te zetten. Op naar alle volgende avonturen samen. Brenda en Inge, mijn paranimfen, wij hebben samen onze bachelor gedaan en zijn nu samen met onze promotietrajecten bezig. Brenda, ik ben onze vriendschap over de jaren steeds meer gaan waarderen, waarbij jij mij steeds energie geeft met jouw oprechte 
interesse, veerkracht en heerlijke lach. Vivian, Iris, en Inge, vanaf de bachelor al samen en ondanks onze reisafstanden hebben we nog steeds dezelfde onvoorwaardelijke sfeer met elkaar te pakken. Ik geniet zo van onze vriendinnendagjes en -weekenden waarbij we aan een stuk door praten. Marcella, ook al zien we elkaar minder door de afstand, ik waardeer onze diepere gesprekken over wat ons bezighoudt en jouw fijne adviezen enorm.

Lieve familie en schoonfamilie, wat bof ik met jullie. Pap en mam, bedankt dat jullie mij altijd zo steunen, zo betrokken zijn en me echt onvoorwaardelijk geliefd laten voelen. Anjo en Frans, mar ook de rest van de schoonfamilie, bedankt voor jullie heerlijk oase van rust in Berg waar ik graag kom. Anjo, bedankt voor al je heerlijke verwenthee, chocolaatjes en je luisterend oor. Frans, bedankt voor je overstijgende blik en nuttige adviezen. Eef en Max, bedankt dat ik altijd bij jullie terecht kon en helemaal werd verwend; logeerpartijtjes bij jullie voelden als ware hotelervaringen. Eef, ik ben zo trots op zo'n zus als jij, bedankt voor alle schaterlachen en dat wij zo heerlijk onszelf kunnen zijn bij elkaar. Helaas heb ik in deze jaren ook afscheid moeten nemen van mijn zo geliefde oma Jack. Ik voelde me altijd zo vertrouwd bij u en wat had ik dit moment graag met u beleefd. Oma Gien, ook aan u heb ik de afgelopen jaren veel steun gehad, waarbij uw doorzettingsvermogen en uiting van liefde aan uw naasten mij inspireren. Nielsje, of ondertussen eigenlijk gewoon Niels, in de afgelopen jaren heb ik mij altijd verheugd op de oppasweekenden. Een weekend waar ik al mijn zorgen vergat en heerlijk samen met Jeroen kon genieten van alle tijd met jou. Niels, je bent zo nieuwsgierig en lief, weet dat je altijd welkom bent bij ons!

Last but not least, Jeroen, in de afgelopen jaren zijn wij getrouwd en hebben we genoten van het samenwonen in onze geliefde stad. Jij staat al ruim 13 jaar aan mijn zijde en ik ben zo trots dat jij mijn man bent. Hoe onvoorwaardelijk jij mij hebt gesteund, maar ook altijd eerlijk was en mij soms ook een spiegel voorhield. Dit alles heeft ervoor gezorgd dat ik nu sta waar ik sta en ik kan je hier niet genoeg voor bedanken. Bedankt dat je mijn rots bent, ik op je kan leunen als ik het zwaar heb, mar ook vooral degene bent die altijd een lach op mijn gezicht kan toveren. We sluiten dit hoofdstuk nu af en op naar een hele mooie toekomst samen. 